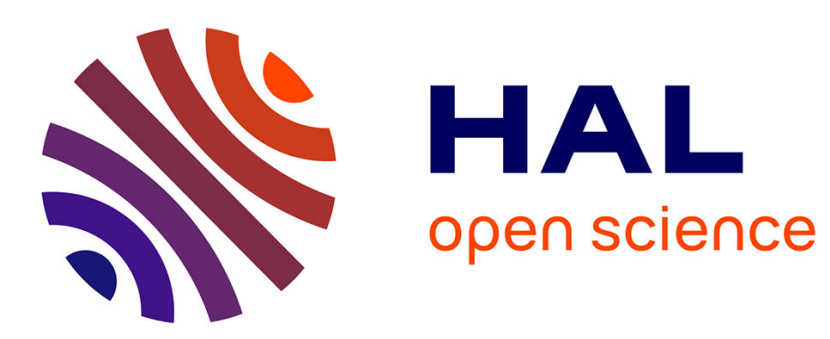

\title{
The origin(s) of modern amphibians: a commentary
}

D. Marjanovic, Michel Laurin

\section{To cite this version:}

D. Marjanovic, Michel Laurin. The origin(s) of modern amphibians: a commentary. Journal of Evolutionary Biology, 2009, 36, pp.336-338. 10.1007/s11692-009-9065-8 . hal-00549002

\section{HAL Id: hal-00549002 https://hal.science/hal-00549002}

Submitted on 7 May 2020

HAL is a multi-disciplinary open access archive for the deposit and dissemination of scientific research documents, whether they are published or not. The documents may come from teaching and research institutions in France or abroad, or from public or private research centers.
L'archive ouverte pluridisciplinaire HAL, est destinée au dépôt et à la diffusion de documents scientifiques de niveau recherche, publiés ou non, émanant des établissements d'enseignement et de recherche français ou étrangers, des laboratoires publics ou privés. 
The origin(s) of modern amphibians: a commentary

\author{
By \\ David Marjanović ${ }^{1}$ \\ and \\ Michel Laurin ${ }^{1 *}$
}

\begin{abstract}
${ }^{1}$ Address: UMR CNRS 7207 “Centre de Recherches sur la Paléobiodiversité et les Paléoenvironnements”, Muséum National d’Histoire Naturelle, Département Histoire de la Terre, Bâtiment de Géologie, case postale 48, 57 rue Cuvier, F-75231 Paris cedex 05, France *Corresponding author tel/fax. (+33 1) 44273692 E-mail: michel.laurin@upmc.fr
\end{abstract}

Number of words: 1884

Number of words in text section only: 1378 
Anderson (2008) recently reviewed the controversial topic of extant amphibian origins, on which three (groups of) hypotheses exist at the moment. Anderson favors the "polyphyly hypothesis” (PH), which considers the extant amphibians to be polyphyletic with respect to many Paleozoic limbed vertebrates and was most recently supported by the analysis of Anderson et al. (2008). Another is the "temnospondyl hypothesis" (TH - lissamphibians nested within temnospondyls), most recently supported by Ruta and Coates (2007). We prefer the "lepospondyl hypothesis” (LH - lissamphibians nested within "lepospondyls"; most recently supported by Vallin and Laurin, 2004 and Marjanović and Laurin, 2008a). We would like to clarify important points that were not discussed in Anderson's review, or for which crucial arguments were left out.

Anderson (2008) argues that most molecular dates favor the PH because they suggest a Devonian or Early Carboniferous diversification of Lissamphibia. This is inaccurate, since the confidence intervals of the dates obtained by Hugall et al. (2007) range from Early Carboniferous to Middle Permian, and our own molecular dating suggests a Permian origin. Indeed, three methods (molecular dating, a paleontological supertree and a confidence interval on the stratigraphic range of Lissamphibia) all hint at a Permian or (less likely) a Late Carboniferous origin of Lissamphibia (Marjanović and Laurin, 2007, 2008b).

Citing Schoch and Milner (2004), Anderson (2008: 234) argues that the LH is mainly supported by loss characters, and that this is problematic "given the relative ease that these losses can arise via paedomorphosis, which appears to evolve repeatedly.” This is especially surprising because we count (Supplementary Table 1) about fifty loss characters in the matrix by Anderson et al. (2008) - more than one out of five characters -, including several that describe the loss of bones that ossified late in the ontogeny of branchiosaurids (Schoch, 1992) and/or the aïstopod Phlegethontia (Anderson, 2002) and are absent in lissamphibians. 
Furthermore, Anderson's remark amounts to criticizing the use of loss characters simply because they could be homoplastic. Yet, Anderson (2008) emphasizes development characters such as digit development and skull ossification order, which are known to be homoplastic. For instance, under Anderson's version of the $\mathrm{PH}$, the similarity between the digit development orders of the branchiosaurid temnospondyl Apateon and the urodeles is either convergent, or homologous between these two taxa but reversed in anurans; indeed, Johanson et al. (2007) suggest that the digits of tetrapods are homologous to the "radials" of other sarcopterygians and find the "radials" of the Australian lungfish to develop independently of the rest of the forelimb (pectoral fin), like in urodeles and Apateon (and unlike in anurans and amniotes, where the limb chondrifies in a strict proximal-to-distal sequence), strongly suggesting that the urodele-Apateon pattern is plesiomorphic - regardless of whether the $\mathrm{PH}$, the TH, or the LH is (closest to) correct. Anderson (2008: 242) furthermore mentions that "the pattern of cranial ossification [...] has compared very closely with the sequence of cranial ossification seen in salamanders” (making explicit on the next page that these similarities are plesiomorphic); more recently, however, Germain and Laurin (2009) have shown that the ancestral urodele sequence, even though poorly constrained, differed in several respects from that of Apateon.

Nonetheless, the suggestion that loss characters are likely to be strongly correlated to each other and homoplastic is serious; and indeed the matrix by Vallin and Laurin (2004) contains a greater proportion of loss characters (Supplementary Table 2) than that by Anderson et al. (2008). Unfortunately, no rigorous test of this possibility exists. The closest workable approximation we are aware of is the skewness test proposed by Huelsenbeck (1991), which measures how well a set of characters is compatible with different numbers of phylogenetic hypotheses: the smaller the $g_{1}$ statistic, the fewer trees are compatible with the character set, and the stronger is therefore the coherent phylogenetic signal in that character 
set. The $g_{1}$ of the loss characters is much lower (and thus their phylogenetic signal higher) than that of the others in the matrix of Vallin and Laurin (2004), but higher in that of Anderson et al. (2008), and highly significant in all four partitions (Supplementary Table 3), showing that loss characters are not necessarily strongly correlated to each other, and that they appear to contain a phylogenetic signal.

Matrices of various sizes support the various hypotheses on lissamphibian origins. Anderson (2008: 234), citing Schoch and Milner (2004), criticizes the "limited number of taxa analyzed” by LH proponents. There is a trade-off between quantity and quality in a data matrix for a given time investment, and quality is as important as quantity for reaching accurate phylogenetic results. Even small matrices are sometimes not coded carefully enough. We recently showed that $35 \%$ of the cells of the first matrix that supported the $\mathrm{PH}$, that by McGowan (2002), were problematic (Marjanović and Laurin, 2008a); with only the original taxa included, our modified version supports the TH, while adding Gerobatrachus and the "lepospondyl” Brachydectes results in the LH.

Until recently, few studies supported the LH, but two recent dissertations which contain large phylogenetic analyses bolster it (Pawley, 2006: 239 and appendix 16; Germain, 2008a). Pawley (2006) built upon the data matrix by Ruta et al. (2003), which originally supported the TH; Germain (2008a) merely took the matrix by Ruta and Coates (2007), which likewise originally supported the $\mathrm{TH}$, did not change its taxon or character sampling (except for fusing four correlated characters), and improved the accuracy of the scoring. Although Germain (2008a) found the LH to be only one step more parsimonious than the TH, continuation of his work by D. M. (supplemented by the fusion of further correlated characters and the addition of information published in or after 2007) has so far increased the difference to eight steps. Incidentally, the LH is no longer supported only by M. L. and his students; neither of us knew of Pawley's dissertation till two years after the defense. 
As with that by McGowan (2002), we find much to disagree with in the matrix of Anderson et al. (2008). Our rescoring and/or recoding of 39 characters and all but five taxa (and ordering of 38 of the multistate characters for reasons explained by Marjanović and Laurin, 2008a: 163, partially overlapping with the set of rescored characters) supports the LH, with the lysorophian Brachydectes as the sister-group of Lissamphibia; the bootstrap and Bremer values for a "lepospondyl”-lissamphibian clade (Amphibia) which excludes all temnospondyls are high. Again as with the matrix by McGowan (2002), our changes range from the correction of probable typographic errors (like the alleged lack of a cleithrum in Triadobatrachus and "frogs" in character 193, or the alleged absence of a caudolateral flange or corner on the pterygoid that constricts the subtemporal fenestra in Seymouria and Limnoscelis in character 120) to disagreements of interpretation; for example, having compared all described temnospondyl tarsi, we are not convinced that an os basale commune (character 207) is present in Gerobatrachus (Marjanović and Laurin, 2008a: 168-169), and although strong cases for tooth pedicely (character 99) in closely related temnospondyls have been made, we do not think the published evidence establishes whether Gerobatrachus shares this feature (Marjanović and Laurin, 2008a: 179), so we had to score these two characters as unknown in Gerobatrachus. See the Electronic Supplementary Material for more information about the cells that were rescored, the supporting references, the methods, the resulting topology, the support values, and the modified matrix.

Furthermore, possibly pedicellate teeth have now been described in an aïstopod (Germain, 2008b) and may be present in another (Carroll, 1998: fig. 4B). In addition, Milner (1980: 392) calls the teeth of the nectridean Scincosaurus "pedicellate [...] without a line of abscission"; to the best of our knowledge, the teeth of Scincosaurus have never been mentioned in the literature before or since (most notably not by Bossy and Milner, 1998). 
Further research will be necessary to determine if pedicely is much more widespread than previously thought.

For all these reasons, we conclude that the polyphyly hypothesis is less likely than suggested by Anderson (2008), and that the lepospondyl hypothesis seems to be at least as well supported as the temnospondyl hypothesis.

\section{Acknowledgments}

J.-C. Rage, D. Wake, and two anonymous referees commented on previous drafts of this paper; we are especially grateful to $\mathrm{D}$. Wake for several constructive suggestions.

\section{References}

Anderson JS. 2002. Revision of the aïstopod genus Phlegethontia (Tetrapoda: Lepospondyli). J Paleont 76:1029-1046.

Anderson JS. 2008. Focal review: The origin(s) of modern amphibians. Evol Biol 35:231247.

Anderson JS, Reisz RR, Scott D, Fröbisch NB, Sumida SS. 2008. A stem batrachian from the Early Permian of Texas and the origin of frogs and salamanders. Nature 453:515-518.

Bolt JR. 1980. New tetrapods with bicuspid teeth from the Fort Sill Locality (Lower Permian, Oklahoma). N Jb Geol Paläont Mh 1980:449-459.

Bossy KA, Milner AC. 1998. Order Nectridea Miall 1875. In: Carroll RL, Bossy KA, Milner AC, Andrews SM, Wellstead CF. Lepospondyli. Part 1 of Wellnhofer P, editor. Encyclopedia of Paleoherpetology. Munich: Dr. Friedrich Pfeil. p 73-131.

Carroll RL. 1998. Cranial anatomy of ophiderpetontid aïstopods: Palaeozoic limbless amphibians. Zool J Linn Soc 122:143-166. 
Germain D. 2008a. Anatomie des Lépospondyles et origine des Lissamphibiens [PhD thesis]. Paris: Muséum National d’Histoire Naturelle. 351 p.

Germain D. 2008b. A new phlegethontiid specimen (Lepospondyli, Aistopoda) from the Late Carboniferous of Montceau-les-Mines (Saône-et-Loire, France). Geodiversitas 30:669-680.

Germain D, Laurin M. 2009. Evolution of ossification sequences in salamanders and urodele origins assessed through event-pairing and new methods. Evol Dev. 11:170-190.

Huelsenbeck JP. 1991. Tree-length distribution skewness: an indicator of phylogenetic information. Syst Zool 40:257-270.

Hugall AF, Foster R, Lee MSY. 2007. Calibration choice, rate smoothing, and the pattern of tetrapod diversification according to the long nuclear gene RAG-1. Syst Biol 56:543563.

Johanson Z, Joss J, Boisvert CA, Ericsson R, Sutija M, Ahlberg PE. 2007. Fish fingers: digit homologues in sarcopterygian fish fins. J Exp Zool B (Mol Dev Evol) 308:757-768.

Marjanović D, Laurin M. 2007. Fossils, molecules, divergence times, and the origin of lissamphibians. Syst Biol 56:369-388.

Marjanović D, Laurin M. 2008a. A reevaluation of the evidence supporting an unorthodox hypothesis on the origin of extant amphibians. Contrib Zool 77:149-199.

Marjanović D, Laurin M. 2008b. Assessing confidence intervals for stratigraphic ranges of higher taxa: the case of Lissamphibia. Acta Palaeont Pol 53:413-432.

McGowan GJ. 2002. Albanerpetontid amphibians from the Lower Cretaceous of Spain and Italy: a description and reconsideration of their systematics. Zool J Linn Soc 135:132.

Milner AC. 1980. A review of the Nectridea (Amphibia). In: Panchen AL, editor. The Terrestrial Environment and the Origin of Land Vertebrates. London and New York: 
Academic Press. p 377-405.

Pawley K. 2006. The postcranial skeleton of temnospondyls (Tetrapoda: Temnospondyli) [PhD thesis]. Melbourne: La Trobe University. 442 p. Downloadable (free access) at http://www.lib.latrobe.edu.au/thesis/public/adt-LTU20061124.124055/index.html

Ruta M, Coates MI. 2007. Dates, nodes and character conflict: addressing the lissamphibian origin problem. J Syst Paleontol 5:69-122.

Schoch RR. 1992. Comparative ontogeny of Early Permian branchiosaurid amphibians from southwestern Germany. Palaeontogr A 222:43-83.

Schoch RR, Milner AR. 2004. Structure and implications of theories on the origin of lissamphibians. In: Arratia G, Wilson MVH, Cloutier R, editors. Recent Advances in the Origin and Early Radiations of Vertebrates. Munich: Dr. Friedrich Pfeil. p 345377.

Vallin G, Laurin M. 2004. Cranial morphology and affinities of Microbrachis, and a reappraisal of the phylogeny and lifestyle of the first amphibians. J Vertebr Paleontol 24:56-72. 


\section{Electronic Supplementary Material 1 to}

\section{The origin(s) of modern amphibians: a commentary}

by

\section{David Marjanović and Michel Laurin}

This supplement contains the methods, materials and results of our reanalysis of the data matrix by Anderson et al. (2008) and of our application of the skewness test by Huelsenbeck (1991) to the matrices by Anderson et al. (2008) and Vallin and Laurin (2004), including supplementary references and the Supplementary Tables. The Supplementary Figure (ESM2), the data matrix (ESM3), and the trees used to find the ancestral states of the "frogs" (ESM4) and "salamanders" OTUs (ESM5) are separate files.

Legend to the Supplementary Figure (ESM2): Strict consensus of the four most parsimonious trees (see Results section). Numbers below internodes are bootstrap percentages (in bold if 50 or higher; “-” indicates clades contradicted by the bootstrap tree, always by clades with bootstrap percentages of 40 or less), numbers above internodes are Bremer values. Some or all of the Bremer values shown as " $\geq 5$ " might actually be 5 , because we were unable to find all trees that were up to 5 steps longer than the most parsimonious trees, although the fact that an earlier iteration of this analysis, with a dataset that differed only in two cells, found the same results makes this possibility unlikely.

All amphibians that are not lissamphibians are "lepospondyls" (alternatively, a case could be made that Lepospondyli is - under the present phylogenetic hypothesis - a junior synonym of Amphibia). Strictly speaking, Amphibia is defined with respect to Amniota and therefore cannot be applied to this tree, which lacks amniotes, but the close relationship of Limnoscelis and Amniota has never been doubted. The temnospondyl Gerobatrachus is marked with an arrow.

\section{Methods}

The matrix was manipulated in Mesquite 2.6+ (Maddison and Maddison, 2009) on an Intel Macintosh; the analyses were conducted in PAUP* 4.0b10 (Swofford, 2003) on a G5 Macintosh.

We treated polymorphism differently from uncertainty (PAUP* command: "pset mstaxa=variable”). For the reasons explained below, characters 103, 146, 163 and 217 were excluded from all analyses (but kept in the matrix to retain the original numbering for all characters); furthermore, characters 137, 161, 188, and (now) 207 are parsimonyuninformative.

The main analysis was a heuristic search with 10,000 addition-sequence replicates (random addition sequence, 10 trees held at each step, TBR swapping, no limit on rearrangements). Five additional analyses were performed to find all trees that are up to one to five steps longer (the search for those up to five steps longer than the minimum length had to be terminated after 370,000 trees due to lack of memory), in order to find Bremer support values; these analyses had otherwise identical settings to the main analysis, except for consisting of only 200 addition-sequence replicates. We also conducted a bootstrap analysis with 200 bootstrap replicates (100 addition-sequence replicates within each, 10 trees held at each step, TBR swapping). 
The term "loss character" seems never to have been defined. We opt for a strict definition: the wholesale loss (on the most parsimonious trees of the publication in question) of entire bones or structures between bones (like fontanelles or the parietal foramen) or on them (canals for the lateral-line system, dermal sculpturing). We have not counted the loss of processes of bones, even conspicuous ones like the tabular "horns", or other potentially continuous characters; we have also not counted meristic characters (like the number of vertebrae in certain parts of the column). The lists of loss characters in the matrices of Anderson et al. (2008) and Vallin and Laurin (2004) are presented in Supplementary Tables 1 and 2 , respectively.

We calculated the $g_{1}$ statistic for the loss characters and the remaining characters of both matrices (using PAUP*; Swofford, 2003). Unfortunately, Huelsenbeck (1991: table 1; reproduced in Supplementary Table 3, left side) only lists the $5 \%$ and $1 \%$ significance thresholds for 6, 7 and 8 taxa; the matrices by Vallin and Laurin (2004) and Anderson et al. (2008) are both much larger. However, from 6 to 8 taxa, the thresholds decrease with increasing taxon number. We conclude that all values (Supplementary Table 3, right side) are most likely highly significant, so that all four partitions contain a phylogenetic signal of comparable and high strength.

\section{Modified scores, character definitions and state delimitations}

All characters were left unordered by Anderson et al. (2008). However, potentially continuous multistate characters should always be ordered, because the assumption that any character state can more easily change into a similar state than into a very different one was already used for subdividing the potential continuum into discrete states (Wiens, 2001; see Marjanović and Laurin, 2008, for a previous application of this principle). Altogether, we ordered characters $1,2,16,29,32,34,39,74,75,82,87,103,115,126,128,130,134,136$, $138,144,145,149,155,159,170,172,179,181,183,195,197,198,200,201,204,208,209$, and 211. In four cases, the state numbers were not in the appropriate order for this. We exchanged states 0 and 1 of characters 16 and 115. The former state 3 of character 34 was put at the other end, so that the new states $0,1,2$ and 3 correspond to the old states $3,0,1$ and 2 . The states of character 145 had to be rearranged more extensively: the new states $0,1,2$ and 3 correspond to the old states 2, 0, 1 and 3, respectively.

More trivially, Anderson et al. (2008) used “?” for missing data and “-” to indicate inapplicable codings, a distinction that no currently existing phylogenetics program can deal with. The hyphen is interpreted as a gap (in a DNA or protein sequence, implying a mixed dataset) by PAUP*; fortunately, the default setting is to interpret gaps as missing data. To avoid problems with the other setting (which is to interpret gaps as a $5^{\text {th }}$ base/ $21^{\text {st }}$ amino acid), we have replaced every hyphen by a question mark in the NEXUS file (ESM3).

Yet more trivially, we have corrected the spelling "Hapsidoparion" to Hapsidopareion.

Because of the size of this matrix and various time constraints, we have not checked the accuracy of every cell; we have revised mostly those characters whose distribution of states across taxa seemed anomalous and those where we redelimited the states. Indeed, we only noticed the errors in character 193 (see below) after the first submission and had to repeat all analyses; it is therefore possible that the matrix still contains errors.

Despite this, only changes are listed below (as in Marjanović and Laurin, 2008); listing the cells we found to be accurate would require too much space and time.

Character 16: lacrimal possesses both dorsal (prefrontal/frontal) and ventral (jugal/maxillary) processes (0), ventral process only (1), or neither (2) (ordered). In Acanthostega, as correctly coded by character 15, the lacrimal does not participate in the orbit 
margin (being excluded by prefrontal-jugal contact), so we have scored it as inapplicable ( = unknown).

At least some specimens of Micropholis possess the caudal process (Schoch and Rubidge, 2005: figs. 3B, E), giving it states 1 and 2 (a polymorphism).

We have also changed Branchiosauridae from state 2 to state 1 , because the morphologically most mature known specimens possess the ventral process (Schoch and Fröbisch, 2006: figs. 1C, D).

The ventral process is likewise present in Albanerpetontidae (McGowan, 2002: fig. 5B).

This also seems to be the ancestral state for those salamanders (that is, the hynobiids) which possess a lacrimal which participates in the orbit margin, for example Hynobius (Carroll and Holmes, 1980: fig. 4A, C).

Limnoscelis appears to lack both processes (Fracasso, 1983: fig. 3A), although this could be a matter of definition.

Character 22: Prefrontal-postfrontal suture (0); frontal participates in margin of orbit (1). Anderson et al. (2008) defined state 0 only as the opposite of state 1, without mentioning the fact that it contains several different states (for example, Brachydectes lacks postfrontals and has a prefrontal-parietal contact which excludes the frontal from the orbit margin). Furthermore, redefining state 0 as we have done makes explicit that many animals that, at face value, show state 1 should actually be scored as inapplicable.

This includes all lissamphibians in the present matrix except Eocaecilia (which was correctly scored as possessing state 0 ), because they all lack postfrontals and therefore cannot help lacking a prefrontal-postfrontal contact.

Character 26: Dorsal process of premaxilla: broad, low, indistinct (0); alary process (broad, vaguely triangular) (1); moderately high, vaguely rectangular, or acutely triangular linked directly to base (2); narrow and long, along the sagittal plane or parasagittal (3) (unordered). This coding differs from that by Anderson et al. (2008) so as to better fit the morphological diversity seen especially in extant amphibians. It is congruent with the findings of Good and Wake (1992), but it recognizes two states within the condition that Good and Wake (1992) considered primitive.

Greererpeton shows state 1 (Smithson, 1982).

Seymouria baylorensis is borderline between states 0 and 2 (see Laurin, 1996); we have decided on state 2 .

Limnoscelis possesses state 2 (Fracasso, 1983).

All states except 0 occur in salamanders: Karaurus has state 1 (Ivachnenko, 1978: fig. 1); Hynobiidae shows states 3 (Hynobius tsuensis), 1 (Batrachuperus sinensis), and indeterminate (Hynobius naevius) (Carroll and Holmes, 1980: fig. 4). According to figure 5 of the same paper, state 2 occurs in Cryptobranchidae. Ambystoma (ibid., fig. 6) and plethodontids (ibid., fig. 7) possess state 3. Salamandrids can have state 3 (ibid., fig. 8A) or be indeterminate (ibid., fig. 8B). Proteidae exhibits state 3 (ibid., fig. 9), as do Amphiumidae (ibid., fig. 10) and Sirenidae (ibid., fig. 11). To code the single OTU "salamanders", we have used the same approach as in Marjanović and Laurin (2008): optimizing this diversity onto the phylogenetic hypothesis shown in fig. 8 of Wiens et al. (2005) when Karaurus is added as the sister-group of Urodela, states 1 and 3 emerge as most parsimoniously plesiomorphic for Caudata as a whole, so we have assigned it state 1 or 3 (partial uncertainty).

Most anurans have state 3 (Duellman and Trueb, 1986: figs. 13-17 and 13-18).

Most “microsaurs" also had to be rescored according to Carroll and Gaskill (1978). 
Character 34: Caudal margin of the skull roof: undulating (0); concave (1); straight (2); convex (3) (ordered). The place of state 0 in this sequence is certainly debatable; an alternative would have been to consider the median caudal projection of the skull roof a separate character, as Ruta and Coates (2007: 96) did (twice: characters POSPAR 4 and POSPAR 8), defensible by the fact that most but not all taxa with an undulating margin would otherwise count as concave.

The margin is straight in Brachydectes (Wellstead, 1991: figs. 2, 3, 8) and undulating in Sauropleura (Bossy and Milner, 1998: fig. 53B), arguably Ptyonius (ibid., fig. 53G), and Eocaecilia (Jenkins et al., 2007: figs. 1, 2).

Character 39: Large otic notch approaching orbit: absent (0); intermediate (1); close (2) (ordered). Because the albanerpetontids lack an otic or other temporal notch or other embayment, we consider this character (which appears to describe the distance between the rostral margin of the "otic notch" and the caudal margin of the orbit) inapplicable to them.

Character 51: Parietal-squamosal contact: absent (0), present (1). This character is only applicable when the supratemporal is absent. (When present, the supratemporal extends from the tabular and/or the caudal margin of the skull roof to the postorbital, unless a temporal fenestra intervenes as it does in many amniotes and aïstopods; in the latter the fenestra separates the parietal from the squamosal, making the present character likewise inapplicable.) The presence of the supratemporal is already coded as state 0 of character 5; keeping state 51(0) for taxa with 5(0) would therefore correlate these two characters.

Both states occur in Microbrachis (Carroll and Gaskill 1978: figs. 77, 78).

Character 59: Tabular: present (0); absent (1). Having examined the only known (and very confusing) specimen of Triadobatrachus (see Marjanović and Laurin, 2008: appendix-table 1), we provisionally disagree with J. Anderson's otherwise unpublished reinterpretation of its skull roof and agree with the literature (e.g., Rage and Roček, 1989) that tabulars are absent in this animal.

Character 74: Number of premaxillary teeth: $\geq 10$ (0); 5-9 (1); < 5 (2) (ordered). All three states occur in salamanders: Karaurus has about 25 premaxillary teeth (Ivachnenko, 1978: 364, fig. 1a); Batrachuperus sinensis (Hynobiidae) possesses 9; Cryptobranchus and Ambystoma both possess more than 10; Phaeognathus hubrichti (Plethodontidae) shows about 8; Salamandra atra exhibits only about 4; more than 10 are present in Notophthalmus viridescens (Salamandridae) and Necturus (Proteidae); only about 5 occur in Amphiuma and in Habrosaurus (Sirenidae). Using the same approach and the same references as for character 26, states 0 and 1 emerge as candidates for the plesiomorphic state, so we have coded the salamander OTU as possessing state 0 or 1 .

Using the same approach, only state 0 (rather than 0 or 1 ) emerges as plesiomorphic for frogs: Yizhoubatrachus (10 on the right, 11 on the left premaxilla: Gao and Chen, 2004), Notobatrachus (reconstructed with 14 to 15: Sanchíz, 1998: fig. 20B), Mesophryne (16 teeth are preserved on an incomplete premaxilla: Gao and Wang, 2001: 461), Eodiscoglossus (at least 15 tooth positions: Evans et al., 1990: 302), and Ascaphus (Carroll and Holmes, 1980: fig. 3A) all show well over 10 teeth; the variation in Leiopelma even includes 15 to 25 teeth (Sanchíz, 1998: 16, fig. 19G).

Both Albanerpeton (McGowan, 2000: 367; Venczel and Gardner, 2005: 1282) and Celtedens (McGowan, 2002: 5) possess both state 0 and state 1 . The only known premaxilla of Anoualerpeton with a complete toothrow preserves 10 teeth (Gardner et al., 2003: 308). Taken at face value, this would make state 0 more parsimonious as the plesiomorphic 
condition of Albanerpetontidae, but because of the limited sample size we have preferred to score Albanerpetontidae as polymorphic.

Character 75: Number of maxillary teeth: $\geq 30$ (0); 20-29 (1); < 20 (2) (ordered). Albanerpeton possesses states 1 and 2 (Gardner, 1999: 536; 2000: 367; Venczel and Gardner, 2005: 1282), while the composite maximum estimate for Anoualerpeton (Gardner et al., 2003: 308 ) is 25 teeth, thus staying in state 1 . In the absence of evidence to the contrary from Celtedens, and due to the small sample size of Anoualerpeton, we have extrapolated the polymorphism of Albanerpeton to Albanerpetontidae as a whole.

Character 84: Occipital condyle: concave (0); convex (1). State 1 was ascribed to Gerobatrachus, but the occipital condyle is not preserved (Anderson et al., 2008: figs. 1, 2). We have therefore scored Gerobatrachus as unknown.

Character 85: Occipital condyle: single (0); double (1). We have changed the score of Gerobatrachus from state 1 to unknown for the reasons mentioned under character 84.

Ecolsonia, on the other hand, possesses a "distinctly double occipital condyle" (Berman et al., 1985: 16).

State 1 is shared by Asaphestera (Carroll and Gaskill, 1978: fig. 6E), Hapsidopareion (ibid., fig. 13B), Pelodosotis (ibid., fig. 48A), Micraroter (ibid., fig. 53), Pantylus (ibid., fig. 25), Cardiocephalus sternbergi (ibid., figs. 30B, C), Cardiocephalus peabodyi (judging from the articular surfaces on the atlas: ibid., fig. 31), Euryodus primus (for the same reason: ibid., figs. 37, 38, 41), Euryodus dalyae (ibid., figs. 42-44), Rhynchonkos (ibid., figs. 63-65), Microbrachis (ibid., figs. 77-79; Vallin and Laurin, 2004: 62), Stegotretus (Berman et al., 1988: 310), Sauropleura scalaris (Bossy, 1976: 96 and fig. 25b), Ptyonius (Bossy, 1976: 145), and Brachydectes (Wellstead, 1991: figs. 2, 15C).

"The surfaces that formed part of the occipital condyle cannot be seen" in Tuditanus (Carroll and Baird, 1968: 12), suggesting that the reconstruction in ventral view by Carroll and Gaskill (1978: fig. 4) is just that - a reconstruction. We have therefore changed its score to unknown.

Much the same holds for Batropetes (Carroll and Gaskill, 1971: 454) and Saxonerpeton (Carroll and Gaskill, 1978: 34).

Bossy (1976: 209) describes the occipital condyle of Urocordylus as "semidouble", suggesting an intermediate morphology which we have coded as unknown for the sake of simplicity.

Character 86: Jugular foramen: between opisthotic and exoccipital (0); through exoccipital (1). This character has not been described in Doleserpeton, so we have changed its score to unknown.

In frogs, the exoccipital is almost always fused to other braincase bones (Duellman and Trueb, 1986: table 13-1), making it impossible to evaluate the position of the jugular foramen relative to the opisthotic and forcing us to score the frogs as unknown.

Character 87: Jaw articulation: caudal to occiput (0); even with occiput (1); rostral to occiput (2); far rostral to occiput (over $20 \%$ of basal skull length) (3) (ordered). The frogs were scored as 0 (a state that really occurs in the separate OTU Triadobatrachus, which was scored correctly; Rage and Roček, 1989), but Notobatrachus (Sanchíz, 1998), Vieraella (Carroll and Holmes, 1980: fig. 3), Ascaphus (same figure, and Noble, 1931: fig. 81A), and others like Pelobates possess state 2. Mesophryne appears to show state 1, but is incompletely preserved and somewhat disarticulated (Gao and Wang, 2001: fig. 4). We have scored it as unknown (though we should have restricted this somewhat). 
Character 89: Palatine fangs: present (0); absent (1). This character originally referred to "palatal teeth" in general, but this would correlate to several others like 94 (presence and arrangement of vomerine teeth) and especially 90, which treated fangs and toothrows as states of the same character, even though both can occur together (like in Acanthostega: Clack, 1994: fig. 11C).

Asaphestera is restored by Carroll and Gaskill (1978: fig. 7) as possessing a row of very large teeth on the palatine and ectopterygoid. We count this as state 0 (see Marjanović and Laurin, 2008: 180), even though we also count it as state 1 of the next character (as originally scored).

The palate of Diceratosaurus is illustrated in Jaekel (1902: plate III); it shows state 1.

The palatine of Adelogyrinus is unknown (Andrews and Carroll, 1991).

Character 90: Palatine teeth (marginal-sized): absent (0); multiple in rows (1); multiple random (2) (unordered). See character 89.

Greererpeton possesses a row of palatine teeth (Smithson, 1982).

Limnoscelis lacks palatine teeth (Fracasso, 1983: fig. 2).

Micropholis possesses a palatine toothrow (Schoch and Rubidge, 2005: fig. 1D).

The only known adult specimen of Amphibamus possesses fangs instead of a toothrow (Daly, 1994).

The palatine teeth of Gerobatrachus are small enough to count as denticles, and are not arranged in rows (Anderson et al., 2008: fig. 2a).

All teeth on the palatine of Microbrachis are small enough to count as denticles (Carroll and Gaskill, 1978); this means state 0.

The palate of Diceratosaurus is illustrated in Jaekel (1902: plate III); it shows state 1.

The palatine of Adelogyrinus is unknown (Andrews and Carroll, 1991).

The palatine of Brachydectes is toothless (Wellstead, 1991).

Triadobatrachus has a preserved and apparently toothless palatine, so we have given it state 1 (Rage and Roček, 1989). 1986: 318).

Palatine teeth are likewise always absent in the "frogs" OTU (Duellman and Trueb,

Character 94: Vomerine teeth: absent (0); forming a single row (1); forming a field (2) (unordered). This definition is new. "Teeth" are about the size of the marginal teeth, markedly larger than denticles and smaller than fangs; state 2 is what is exhibited by the sirenids.

Doleserpeton possesses states 1 and 2; there is both a row (near the choana) and a field (Bolt 1969). This might, however, be an artefact of the fact that the marginal teeth are tiny no teeth of Doleserpeton are sufficiently smaller to count as denticles.

Amphibamus, Gerobatrachus, and Limnoscelis show state 0.

Character 99: Tooth pedicely: absent (0); present (1). We have scored Gerobatrachus as unknown for the reasons explained in Marjanović and Laurin (2008: 179) and done the same with Oestocephalus, Phlegethontia, and Scincosaurus for the reasons explained in the main text of the present paper.

Character 100: Denticles on vomers: present (0); absent (1). Gerobatrachus was scored 0, but, judging from the illustrations rather than the text of Anderson et al. (2008), its vomerine teeth are unambiguously small enough to count as denticles, giving it state 0 .

Character 102: Denticles on parasphenoid: present (0), absent (1). Triadobatrachus, frogs, salamanders and albanerpetontids (Celtedens: McGowan, 2002: fig. 13; denticles are 
also not mentioned for the incomplete parasphenoid part of the os basale of Albanerpeton inexpectatum by Estes and Hoffstetter, 1976: 314) possess state 1, while Eocaecilia shows state 0 (Jenkins et al., 2007).

Character 103: Palatal teeth: larger than marginals (0), equal to marginals (1). This character is correlated to several others (such as 89, 90, 93 and 94); we have therefore excluded it from our analyses.

Character 105: Parasphenoid basal plate: roughly quadrangular, basipterygoid articulations narrowly spaced (0); about as broad as long, articulations moderately distant (1); rectangular laterally, anteroposteriorly narrow, basipterygoid articulations distant (2) (ordered). State 1 was added because the condition in the following OTUs fits neither state 0 nor state 2 (the former state 1 ):

Tuditanus (Carroll and Gaskill, 1978: fig. 4); Hapsidopareion (ibid., fig. 13); Saxonerpeton (ibid., fig. 22); Cardiocephalus sternbergi (ibid., fig. 30); Euryodus primus (ibid., figs. 36-38); Euryodus dalyae (ibid., figs. 42, 43); Pelodosotis (ibid., fig. 48); Micraroter (ibid., fig. 53); Rhynchonkos (ibid., figs. 63-65); Microbrachis (ibid., fig. 77; Vallin and Laurin, 2004: fig. 5B); Stegotretus (Berman et al., 1988: fig. 8); Ptyonius (Bossy, 1976: fig. 49; Bossy and Milner, 1998: fig. 55B); Diploceraspis (Beerbower, 1963: fig. 4); Scincosaurus (Bossy and Milner, 1998: fig. 57D); Oestocephalus (Carroll, 1998: fig. 3); Brachydectes (Wellstead, 1991: fig. 2); Eocaecilia (Jenkins et al., 2007); salamanders (Carroll and Holmes, 1980).

Furthermore, the condition is unknown in the following OTUs: Gerobatrachus (where the caudal part of the palate is very fragmentary and somewhat disarticulated, so that the statement in the text about the shape of the parasphenoid may not be warranted; Anderson et al., 2008); Urocordylus (Bossy and Milner, 1998: fig. 55A); Batrachiderpeton (where the parasphenoid has a unique shape and is incompletely preserved; Bossy and Milner, 1998: fig. 57B); Adelogyrinus (Andrews and Carroll, 1991: fig. 6).

The condition in Phlegethontia counts as state 0 (Anderson, 2002: fig. 4:2).

Character 109: Stapes orientation: lateral, towards quadrate (0); dorsal, towards squamosal embayment, elongate columella (1). Salamanders possess state 0.

Character 120: Pterygoid extending into subtemporal fenestra, constricting it: no (0); yes (1). The pterygoid sometimes extends a corner (especially when a transverse flange is present on the pterygoid, like in Seymouria [Laurin, 1996] or Limnoscelis [Fracasso, 1983]; incidentally, both were erroneously scored as 0 , which we can only explain as a typographic error; but also in the absence of a flange, such corners occur, like in the correctly scored Eryops: Sawin, 1941: plate 2) or a rounded flange (like in the correctly scored Balanerpeton: Milner and Sequeira, 1994) into the subtemporal fenestra, which was erroneously called "posttemp fen" in the supplementary information of Anderson et al. (2008), the posttemporal fenestra being on the occiput.

State 1 is further present in Dendrerpeton (Milner, 1996: fig. 6), Asaphestera, Hapsidopareion, Saxonerpeton (all Carroll and Gaskill, 1978: fig. 108), Euryodus primus and E. dalyae (both Carroll and Gaskill, 1978: fig. 109), Microbrachis (Vallin and Laurin, 2004), and Eocaecilia (Jenkins et al., 2007).

Branchiosauridae is polymorphic (Boy, 1978, 1986, 1987).

The condition in Tuditanus is unknown because the lower jaws are in place (Carroll and Baird, 1968).

In Cardiocephalus sternbergi, the condition is so intermediate (Carroll and Gaskill, 1978: fig. 30) that we score it as unknown. 
The palate of Batropetes is too incomplete to tell (Carroll, 1991: fig. 5B).

The only illustration of the palate of Sauropleura scalaris that we know about is fig. 55C of Bossy and Milner (1998). It shows a juvenile. This may be interesting because the adult of $S$. pectinata, illustrated in fig. 55D, exhibits state 1 . Therefore we do not take fig. 55C at face value and score $S$. scalaris as unknown rather than 0 .

The only illustration of the palate of Ptyonius known to us is fig. 55C of Bossy and Milner (1998). It shows state 0 on the left side and state 1 on the right. Taking into account that this line drawing is a somewhat schematic reconstruction, we have scored Ptyonius as unknown.

The palate is entirely unknown in Adelogyrinus. The only adelogyrinid palate illustrated by Andrews and Carroll (1991: fig. 13C) is that of Adelospondylus (which, incidentally, appears to possess state 1, even though the reconstruction in fig. 13D omits it almost entirely); Adelospondylus is not Adelogyrinus.

State 0 is present in all salamanders (except Hynobius, Ambystoma, and the salamandrid Tylototriton: Ivachnenko, 1978; Carroll and Holmes, 1980), as well as in Triadobatrachus (Rage and Roček, 1989: fig. 2B).

In crown-group frogs, state 0 is present (Duellman and Trueb, 1986: figs. 13-3, 13-4), except, under a generous interpretation, in Ascaphus (Carroll and Holmes, 1980: fig. 3A). State 0 is also found in Vieraella (Carroll and Holmes, 1980: fig. 3B) and Yizhoubatrachus (Gao and Chen, 2004), while Notobatrachus (Sanchíz, 1998: fig. 20B) and Mesophryne (Gao and Wang, 2001) possess state 1. In the continued absence of data from animals like Prosalirus (Shubin and Jenkins, 1995), whether the optimization for the "frogs" OTU is state 0 or ambiguous depends on how generous we are with Ascaphus; because there is no flange or other process in Ascaphus - instead, the rod-shaped pterygoid is bent as a whole to make the medial margin of the subtemporal fenestra concave instead of straight or convex -, we have decided to count Ascaphus and thus the "frogs" as a whole as having state 0 (which happens to be shared by Triadobatrachus and the salamanders, see above).

Character 121: Ectopterygoid: present, with fang-pit pair (0); present, without fang-pit pair (1); absent (2) (unordered). Although this character could be ordered on the grounds that the present sequence of states could be interpreted as a gradual shrinking of the ectopterygoid, we have not ordered it because we have not tested the assumption that there is a strong correlation between the size of the ectopterygoid and the presence of fangs.

State 2 is new (Anderson et al. did not distinguish it from state 1). It occurs in Doleserpeton (Bolt, 1969), both pantylids (Pantylus: Carroll and Gaskill, 1978: fig. 25; Stegotretus: Berman et al., 1988: 308), Brachydectes (Wellstead, 1991: fig. 2), salamanders (Carroll and Holmes, 1980), Triadobatrachus (Rage and Roček, 1989) and the other frogs (Duellman and Trueb, 1986: figs. 13-17 and 13-18).

While the presence of a very small ectopterygoid (too small to bear fangs; known, if indeed homologous to the ectopterygoid, in several extant teresomatan caecilians - see Marjanović and Laurin, 2008: 181, for a list and some discussion) cannot be excluded in Eocaecilia (Jenkins et al., 2007: 304), it is at least as probable that this bone was entirely absent (as reconstructed in Jenkins et al., 2007: fig. 1). We have therefore changed its score to state 1 or 2 .

Character 146: Vertebral development: arches, then centra (0); arches and centra simultaneously (1). In the absence of a very detailed growth series, it is impossible to distinguish state 1 from a simple lack of temporal resolution. There is widespread agreement about this among development biologists (e.g., Bininda-Emonds et al., 2003: 341). Such detailed growth series that show the stages of the ossification of the vertebral column are probably not available in any fossil limbed vertebrates other than the "branchiosaurs", where 
the development of most endochondral bones was delayed (Schoch and Fröbisch, 2006). We have therefore excluded this character, which was already coded for only nine taxa (including two extant ones, one of which is polymorphic), from our analyses.

Perhaps not surprisingly, however, state 0 is known to occur in Utaherpeton (Carroll and Chorn, 1995: fig. 4b).

Character 163: Neural arches of the trunk: paired (0), fused (1). Except (presumably) in Acanthostega (which is polymorphic), this character is correlated to ontogenetic age and paedomorphosis. Therefore, all occurrences of state 0 except (presumably) Acanthostega should be scored as unknown (Wiens et al., 2005); this would make the character parsimonyuninformative. We have excluded this character from all analyses.

Character 168: Cranial surface of atlas centrum: same size as caudal surface (0); laterally expanded (1). The cranial surface is slightly expanded in Sauropleura scalaris (Bossy, 1976: 102 and fig. 25b), giving it state 1.

The same holds for Ptyonius (ibid., fig. 51a) and Urocordylus (ibid., 215).

The only preserved atlas centrum of Keraterpeton we know of (Huxley and Wright, 1867; Jaekel, 1902) is in dorsal view, hiding the cranial and the caudal surface and forcing us to score Keraterpeton as unknown.

The condition seems to be likewise unknown in Diceratosaurus and Scincosaurus.

Brachydectes possesses state 1 (Wellstead, 1991: figs. 11C, 18).

Character 179: Ribs: at least as long as three successive articulated vertebrae and curved in adults (0); like state 0 , but straight (1); shorter than three successive articulated vertebrae in adults (2) (unordered). Anderson et al. (2008) called the states "elongated and sometimes curved", "straight", and "short, simple rod", but rib length and curvature are continua, so quantification was necessary to make reproducible coding possible. We have imported the quantification we used in Marjanović and Laurin (2008: 177); all the cautionary notes mentioned there apply here.

While close to the limit (like, e.g., those of Micraroter: Carroll and Gaskill, 1978: fig. 57), the longest ribs of Greererpeton are longer than three successive vertebrae and are curved ventrally and (slightly) caudally (Godfrey, 1989: figs. 1, 3, 4); they are not outside the range of other OTUs with state 0, unlike the case of Diplocaulus with its long, very straight ribs.

Both the cervical (Berman et al., 1985: fig. 13) and the proximal caudal (ibid., fig. 10C, D) ribs of Ecolsonia - others are not preserved - are longer than three successive vertebrae and "moderately curved" (ibid.: 20).

The ribs of Eocaecilia are slightly curved, but curvature is not mentioned in either the original or our wording of state 2, and the ribs are only about as long as one vertebra (Jenkins et al., 2007); we have accordingly scored Eocaecilia as possessing state 2 (like, incidentally, all other lissamphibians).

As explained in Marjanović and Laurin (2008: 177-178), we have also scored Balanerpeton, Dendrerpeton, Acheloma, Cardiocephalus peabodyi, and Rhynchonkos as having state 1.

In Euryodus primus, no complete ribs seem to be known (Carroll and Gaskill, 1978: 64), and the rib fragments illustrated by Carroll and Gaskill (1978: fig. 39) are much shorter than three vertebrae. We have therefore scored E. primus as unknown.

We are not aware of a description or illustration of the ribs of Stegotretus; Berman et al. (1988: 312) state that "[a]lthough ribs are ubiquitous, none are sufficiently preserved or exposed to warrant description.” Accordingly, we have scored Stegotretus as unknown.

The ribs of Adelogyrinus (Andrews and Carroll, 1991: fig. 6) are very similar to those of Greererpeton, but shorter (and somewhat straighter), fitting the definition of state 2. 
Even though Lethiscus just reaches state 0 (Wellstead, 1982: figs. 1, 9A), the two aïstopods in the present matrix, Ophiderpeton and Phlegethontia, have clear cases of state 2 (Baird, 1964: fig. 1; Anderson, 2002, figs. 9, 10).

With both Greererpeton and Ecolsonia corrected to state 0, state 1 turns out to be unique to Diplocaulus. A case could be made for merging it into state 0 (ribs in state 2 are not necessarily straight), but we deem such a change unnecessary.

Character 181: Number of sacrals: one (0), two (1), three (2) (ordered). Several "microsaurs" were scored as possessing two sacral vertebrae. We cannot replicate this:

Carroll and Baird (1968: 14) argue that Tuditanus has two sacral vertebrae: "[...] two vertebrae with atypical ribs. The rib of the first, best seen in the type specimen, is thickened at the base and is evidently a sacral [rib]; the rib of the second vertebra is obscure. From the narrowness of the iliac blade it is doubtful that more than a single sacral rib could have articulated directly. Aside from its specialized rib, the principal [ = first; Carroll and Gaskill, 1978: 16] sacral vertebra does not appear to differ significantly from its neighbors. The second appears to have a considerably larger transverse process." There are only two specimens. In the type (Carroll and Baird, 1968: figs. 4, 5B) the sacral region (with the pelvis, the proximal part of the left femur, and the entire right hindlimb and the tail) is missing except for the mentioned rib, which is clearly disarticulated and may therefore belong to a vertebra that is not preserved. The referred specimen (ibid., figs. 6, 7) is preserved in ventral view, so that the pelvis obsures the sacral region more or less completely. We find ourselves unable to judge how many sacrals Tuditanus has (even the number 3 cannot be excluded) and therefore have to score it as unknown.

Carroll and Gaskill (1978: 57; see also fig. 31) state that, in the only articulated specimen of Cardiocephalus peabodyi, "[t]here are thirty-seven presacral vertebrae and two sacrals. The block is truncated in the middle of the second sacral, and there is not a trace of caudals.” The second sentence means that state 2 (three sacrals) cannot be excluded.

Two sacral ribs are known from Pelodosotis, but it is apparently not known if they are from the same vertebra, and then the specimen ends (Carroll and Gaskill, 1978: 85; see also fig. 58A). It must therefore be scored as unknown.

The sacral region of Rhynchonkos is apparently known only in the specimen FM-UR 2414, which is stated by Carroll and Gaskill (1978: 109) to possess two sacrals, but illustrated in a way that shows it is much too fragmentary to tell (ibid., fig. 70). We conclude that Rhynchonkos must be scored as unknown.

In Utaherpeton, "[t]wo vertebrae lie adjacent to the central portion of the pelvic girdle. The more anterior is associated with a structure that can be identified as a sacral rib. The second is crushed below the level of the rest of the column and partially covered by the head of the femur. It is uncertain whether it was a second sacral or a first caudal. The ilium is so narrow that it is unlikely to have accommodated more than a single sacral rib." (Carroll et al., 1991: 318) Evidently, Utaherpeton must be scored as possessing one or two sacrals (and, of course, the latter possibility is clearly less probable than the former).

Character 183: Number of caudal rib pairs: 5 or more (0), 4 (1), 3 (2), 2 or fewer (3) (ordered). Triadobatrachus was given states 0 or 3; we have changed this to unknown because we cannot see a reason to exclude all other states (Rage and Roček, 1989: 11).

Character 191: Cleithrum head: aligned along cranial rim of scapula (0); caudodorsally enlarged head wrapping around dorsal scapula (1). Sauropleura scalaris (Bossy, 1976: fig. 33) and Brachydectes (Wellstead, 1991: fig. 19D) show state 1. 
Character 192: Cleithrum head: dorsally greatly expanded, much wider than shaft (0); simple rod without or with slight dorsal expansion (1). Sauropleura scalaris and Brachydectes again possess state 1 (same references as above). So does Ptyonius (Bossy, 1976: fig. 57a).

Character 193: Cleithrum: ossified (0); unossified (1). Triadobatrachus and frogs possess state 0 (Rage and Roček, 1989; Duellman and Trueb, 1986), leaving state 1 only to Albanerpetontidae and salamanders.

Character 201: Deltopectoral crest: weak (0), intermediate (1), prominent (2) (ordered). State 2 occurs in Acanthostega (Coates, 1996: fig. 16), Proterogyrinus (Holmes, 1984: fig. 26) and Greererpeton (Godfrey, 1989: fig. 18), while Eocaecilia possesses state 0 (Jenkins et al., 2007: fig. 41).

The plesiomorphic condition for salamanders appears to be state 0 , judging from Chunerpeton (assigned to Cryptobranchidae; Gao and Shubin, 2003: figs. 1, 2), Ranodon (Hynobiidae; Averianov, 1995: fig. 4), Palaeoamphiuma (Amphiumidae; Rieppel and Grande, 1998: fig. 5), and Necturus (Proteidae; Wischnitzer, 1979: fig. 2-8), even though Parahynobius betfianus (Hynobiidae; Venczel, 1999: fig. 2E).

Character 203: Humerus length: long, $>4$ trunk centra (0); short (1). Where known (Celtedens: McGowan, 2002: fig. 3), albanerpetontids possess state 1.

Character 206: Carpals: fully or partly ossified (0); unossified (1). Where known (Celtedens: McGowan, 2002: 11), albanerpetontids possess state 0.

Character 207: Basale commune: absent (0); present (1). For the reasons explained in Marjanović and Laurin (2008) - such as comparisons to all other known temnospondyl tarsi and the fact that the tarsus of Gerobatrachus is highly incomplete and disarticulated from the lower leg on both sides -, we have changed the score of Gerobatrachus to unknown. This makes the character parsimony-uninformative.

Character 208: Number of digits in manus: 5 or more (0), 4 (1), 3 (2) (ordered). Apparently like Anderson et al. (2008), we have not counted the prepollex as a digit, and we have counted the metacarpal as part of the digit (so that Scincosaurus, which possesses what "may represent a very reduced fifth" metacarpal, retains state 0; Bossy and Milner, 1998: 99, fig. 66G).

We have furthermore accepted the decision by Anderson et al. (2008) to score Eocaecilia as having three digits per hand (and foot: character 219), something that Jenkins et al. (2007) consider highly likely but not certain.

Greererpeton was long interpreted as having four fingers per hand, and was scored accordingly. However, Coates (1996: 415) mentions and illustrates a fairly well preserved specimen with five fingers and mentions another that preserves four, one of which is the (distinctively small) fifth. Consequently, there is no evidence for four fingers (state 1) in any specimen of $G$. in the literature, and we code $G$. as pentadactyl (state 0 ).

Dendrerpeton preserves four distal carpals (Holmes et al., 1998), which means that four or more fingers were present (state 0 or 1 ).

We infer that Acheloma had four or more fingers (state 0 or 1 ) because it appears to have had five distal carpals (Olson, 1941), of which the tiny cranialmost one could belong to a prepollex. As in Dendrerpeton, no metacarpals or fingers are preserved.

Micropholis possessed four fingers per hand (Schoch and Rubidge, 2005: 512), giving it state 1 . 
Tambachia was scored as unknown, but state 2 can be excluded (Sumida et al., 1998), so we have scored it as showing state 0 or 1 .

Saxonerpeton, on the other hand, is so incompletely preserved that none of the states can be ruled out (Carroll and Gaskill, 1978: 38).

Rhynchonkos was scored as 1 , but while four metacarpals are preserved, a higher number cannot be excluded based on the preservation (Carroll and Gaskill, 1978: 111).

Urocordylus has state 0 (Bossy and Milner, 1998: 98-99, fig. 66A).

Bossy and Milner (1998) say Keraterpeton has state 1 as originally scored. However, Jaekel (1902) provides a line drawing of Keraterpeton (fig. 2) that shows articulated but incomplete hands which may well have had five fingers. Huxley and Wright (1867) claim five metacarpals and fingers to be present, but their plate XIX (or at least our bad photocopy of it) appears to show only four; Bossy (1976:304), contradicting Bossy and Milner (1998), writes "My own investigations corroborate the existence of the five-digit manus in this genus." Awaiting a reply from Milner, we have scored Keraterpeton as possessing state 0 or 1.

Jaekel (1902) says three times explicitly that Diceratosaurus had pentadactyl hands, and illustrates a convincing pentadactyl hand in the specimen drawing (plate IV-6), even though Bossy \& Milner (1998) explicitly disagree, stating the animal to be tetradactyl as originally coded. This is all the more surprising because Bossy earlier (1976: 304) wrote "Diceratosaurus definitely has five forefingers (pers. obs.)". Because we have not been able to find the reason for this discrepancy, we have scored Diceratosaurus as possessing state 0 or 1 .

Character 217: Number of distal tarsals: 6 (0), 5 or fewer (1). Three OTUs were scored as possessing six distal tarsals: Acanthostega, Tuditanus, and part of the salamanders (the "salamanders" OTU is scored as having state 0 or 1 , but polymorphism was clearly intended). Regardless of which condition is plesiomorphic for salamanders, we think the extra distal tarsal is not homologous between any of these taxa. In Acanthostega, the caudalmost "distal tarsal", to which three "metatarsals" attach directly, is better interpreted as the fibulare (e.g., Coates, 1996: fig. 24; Johanson et al., 2007: fig. 1); in the fully articulated referred specimen of Tuditanus, the distal tarsal that does not correspond to a metatarsal lies on the caudal side (Carroll and Baird, 1968: figs. 6, 7) and could therefore represent a postminimus (or, of course, something entirely different like a sesamoid), but neither the fibulare nor a prehallux; in the salamanders with an extra distal tarsal, this is the prehallux (as the first digital ray in the foot of Acanthostega, including the "first" distal tarsal rather than the "sixth", might be) or the centrale 1 (the so-called "prehallux" in Duellman and Trueb, 1986: fig. 13-33B; the "centrale" in that figure is the centrale 4). We have therefore excluded this character from our analyses.

\section{Results and conclusion}

Four most parsimonious trees were found (length $=1264$ steps, consistency index excluding parsimony-uninformative characters $=0.2659$, retention index $=0.6003$, rescaled consistency index $=0.1610$ ). Their only differences lie in whether Ecolsonia (in two trees) or Tambachia (in the two others) is the sister-group of Acheloma, and in whether Pantylidae ( = Pantylus + Stegotretus) is the sister-group of Ostodolepididae ( = Pelodosotis + Micraroter) (in two trees) or of Batropetes + (Rhynchonkos + Gymnarthridae [ = Cardiocephalus + Euryodus]) (in the two others). The strict consensus is shown in the Supplementary Figure.

All most parsimonious trees support the lepospondyl hypothesis, with a monophyletic Lissamphibia as the sister-group of Brachydectes and nested inside the "microsaurs", even though the positions of the paraphyletic "nectrideans" and the aïstopods (Oestocephalus, Phlegethontia) as well as the topology of the "microsaurs" differ from those found by Vallin and Laurin (2004). 
The bootstrap values (see the Supplementary Figure) are generally low - indeed, several clades are contradicted by the bootstrap tree, which for example finds Nectridea to be monophyletic (if only in 39\% of the replicates) and arranges the "microsaurs" in a rather different way. The monophyly of Lissamphibia is found in only $23 \%$ of the bootstrap replicates, and the Brachydectes-Lissamphibia clade in only 22.

Nonetheless, Amphibia ( = everything more closely related to Lissamphibia than to Amniota, here including Lissamphibia and the "lepospondyls") has a bootstrap percentage of 68. A clade composed of all temnospondyls and all lissamphibians but no "lepospondyls" does not occur in the list put out by PAUP* that shows all clades found in $5 \%$ or more of the bootstrap replicates (reproduced below as Supplementary Table 4), arguing strongly against the temnospondyl hypothesis.

No clade that includes Gerobatrachus and some or all lissamphibians but no "lepospondyls" has a bootstrap percentage greater than 14 (Supplementary Tables 4 and 5), and no clade that includes all temnospondyls and some lissamphibians, but no "lepospondyls", has a bootstrap value greater than 7. We think that the support for a special relationship between Gerobatrachus and some lissamphibians is not significant, because it is not only small in absolute terms and much smaller than the support for the clade composed of all "lepospondyls" and lissamphibians (68, see above), but also smaller than the support for clades which contain frogs, salamanders and lepospondyls but neither any temnospondyls nor Eocaecilia, contradicting both the monophyly of extant amphibians and all existing versions of the polyphyly hypothesis (18 and smaller); see Supplementary Table 5 for a more detailed comparison. At 22, the highest bootstrap percentage for any clade compatible with the polyphyly and not the lepospondyl hypothesis is not significantly higher either (the clade in question consists of Eocaecilia and the "microsaur" Rhynchonkos, and is the only clade with a bootstrap value above $14 \%$ that is compatible with the polyphyly hypothesis).

127 trees have the minimum length or are one step longer. Their strict consensus is poorly resolved (all nodes marked " 1 " in the supplementary figure collapse), e.g., Eocaecilia is no longer guaranteed to be the sister-group of the clade composed by the other "lissamphibians", but it still contains a "nectridean"-aïstopod-“lissamphibian"-Brachydectes clade nested inside two more clades of amphibians, from which all of the "temnospondyl" clades (Temnospondyli having collapsed) are excluded. The majority-rule consensus is practically identical in topology to the strict consensus of the most parsimonious trees.

1635 trees are up to two steps longer than the minimum length. In the strict consensus, Amphibia survives and still excludes all "temnospondyls" while still including the fully resolved Albanerpetontidae + (salamanders + (Triadobatrachus + frogs)) clade. The topology of the majority-rule consensus has not changed.

13,396 trees are up to three steps longer than the minimum length. The only noteworthy change in the strict consensus is that Albanerpetontidae is no longer guaranteed to be the sister-group of the salamanders + (Triadobatrachus + frogs)); Amphibia survives. The topology of the majority-rule consensus has changed imperceptibly.

The same holds for the 81,754 trees that are up to four steps longer than the minimum.

Because the computer had run out of memory, the search for trees up to five steps longer than the minimum length was terminated after 367,200 trees had been found. Their strict consensus does not contain Amphibia anymore (Amphibia thus has a Bremer value of 5); even salamanders and (Triadobatrachus + frogs) take part in the basal polytomy. The majority-rule consensus has changed imperceptibly in topology and is still almost completely resolved; Amphibia, for example, still occurs in all but four of the 367,200 trees.

The lepospondyl hypothesis is thus strongly supported by the present matrix, even though no characters or taxa were added to the matrix by Anderson et al. (2008), and even though the taxon sampling outside of Amphibamidae and Amphibia is poor. For further conclusions regarding errors in data matrices see Marjanović and Laurin (2008). 


\section{References}

Anderson JS. 2002. Revision of the aïstopod genus Phlegethontia (Tetrapoda: Lepospondyli). J Paleontol 76:1029-1046.

Anderson JS, Reisz RR, Scott D, Fröbisch NB, Sumida SS. 2008. A stem batrachian from the Early Permian of Texas and the origin of frogs and salamanders. Nature 453:515-518.

Andrews SM, Carroll RL. 1991. The order Adelospondyli: Carboniferous lepospondyl amphibians. Trans R Soc Edinburgh 82:239-275.

Averianov AO. 1995. Ranodon cf. sibiricus (Amphibia, Caudata) from the upper Pliocene of southern Kazakhstan: the first fossil record of the family Hynobiidae. Paläontol $\mathrm{Z}$ 69:257-264.

Baird D. The aïstopod amphibians surveyed. Breviora Mus Comp Zool 206:1-17.

Berman DS, Reisz RR, Eberth DA. 1985. Ecolsonia cutlerensis, an Early Permian dissorophid amphibian from the Cutler Formation of north-central New Mexico. Circ 191 N Mex Bureau Mines \& Mineral Resources:1-31.

Berman DS, Eberth DA, Brinkman DB. 1988. Stegotretus agyrus[,] a new genus and species of microsaur (amphibian) from the Permo-Pennsylvanian of New Mexico. Ann Carnegie Mus 57:293-323.

Bininda-Emonds ORP, Jeffrey JE, Richardson MK. 2003. Is sequence heterochrony an important evolutionary mechanism in mammals? J Mammal Evol 10:335-361.

Bolt JR. 1969. Lissamphibian origins: possible protolissamphibian from the Lower Permian of Oklahoma. Science 166:888-891.

Bossy KVH. 1976. Morphology, paleoecology, and evolutionary relationships of the Pennsylvanian urocordylid nectrideans (subclass Lepospondyli, class Amphibia [PhD thesis]. New Haven: Yale University. $370+108$ p.

Bossy KA, Milner AC. Order Nectridea MiAll 1875. In: Carroll RL, Bossy KA, Milner AC, Andrews SM, Wellstead CF. Lepospondyli. Part 1 of Wellnhofer P, editor. Encyclopedia of Paleoherpetology. Munich: Dr. Friedrich Pfeil. p 73-131.

Carroll RL. 1991. Batropetes from the Lower Permian of Europe - a microsaur, not a reptile. J Vertebr Paleontol 11:229-242.

Carroll RL, Baird D. 1968. The Carboniferous amphibian Tuditanus [Eosauravus] and the distinction between microsaurs and reptiles. Am Mus Nov 2337:1-50. [Brackets in the original.]

Carroll RL, Chorn J. 1995. Vertebral development in the oldest microsaur and the problem of "lepospondyl” relationships. J Vertebr Paleontol 15:37-56.

Carroll RL, Gaskill P. 1971. A captorhinomorph reptile from the Lower Permian of Europe. J Paleontol 45:450-463.

Carroll RL, Gaskill P. 1978. The order Microsauria. Philadelphia: American Philosophical Society.

Carroll RL, Holmes R. 1980. The skull and jaw musculature as guides to the ancestry of salamanders. Zool J Linn Soc 68:1-40.

Carroll RL, Bybee P, Tidwell WD. 1991. The oldest microsaur (Amphibia). J Paleontol 65:314-322.

Clack JA. 1994. Acanthostega gunnari, a Devonian tetrapod from Greenland; the snout, palate and ventral parts of the braincase, with a discussion of their significance. Medd Grøn Geosci 31:1-24.

Coates MI. 1996. The Devonian tetrapod Acanthostega gunnari Jarvik: postcranial anatomy, basal tetrapod interrelationships and patterns of skeletal evolution. Trans R Soc Edinburgh 87:363-421.

Daly E. 1994. The Amphibamidae (Amphibia: Temnospondyli), with a description of a new genus from the upper Pennsylvanian of Kansas. Univ Kans Mus Nat Hist Misc Publ 
85:1-40.

Duellman WE, Trueb L. 1986. Biology of Amphibians. New York: McGraw-Hill.

Evans SE, Milner AR, Mussett F. 1990. A discoglossid frog from the Middle Jurassic of England. Palaeontology 33:299-311.

Estes R, Hoffstetter R. 1976. Les urodèles du Miocène de la Grive-Saint-Alban (Isère, France). Bulletin du Muséum national d'Histoire naturelle de Paris $3^{\text {ème }}$ série 398:297343.

Fracasso MA. 1983. Cranial osteology, functional morphology, systematics and paleoenvironment of Limnoscelis paludis Williston [PhD thesis]. New Haven: Yale University. $624 \mathrm{p}$.

Gao K, Chen S. 2004. A new frog (Amphibia: Anura) from the Lower Cretaceous of western Liaoning, China. Cret Res 25:761-769.

Gao K, Shubin NH. 2003. Earliest known crown-group salamanders. Nature 422:424-428.

Gao K, Wang Y. 2001. Mesozoic anurans from Liaoning Province, China, and phylogenetic relationships of archaeobatrachian anuran clades. J Vertebr Paleontol 21:460-476.

Gardner JD. 1999. The amphibian Albanerpeton arthridion and the Aptian-Albian biogeography of albanerpetontids. Palaeontology 42:529-544.

Gardner JD. 2000. Albanerpetontid amphibians from the Upper Cretaceous (Campanian and Maastrichtian) of North America. Geodiversitas 22:349-388.

Gardner JD, Evans SE, Sigogneau-Russell D. 2003. New albanerpetontid amphibians from the Early Cretaceous of Morocco and Middle Jurassic of England. Acta Palaeont Pol 48:301-319.

Godfrey SJ. 1989. The postcranial skeletal anatomy of the Carboniferous tetrapod Greererpeton burkemorani Romer, 1969. Phil Trans R Soc Lond B 323:75-133.

Good DA, Wake DB. 1992. Geographic variation and speciation in the torrent salamanders of the genus Rhyacotriton (Caudata: Rhyacotritonidae). Univ Cal Publ Zool 126:1-91.

Holmes R. 1984. The Carboniferous amphibian Proterogyrinus scheelei Romer, and the early evolution of tetrapods. Phil Trans R Soc Lond B 306:431-527.

Holmes RB, Carroll RL, Reisz RR. 1998. The first articulated skeleton of Dendrerpeton acadianum (Temnospondyli, Dendrerpetontidae) from the lower Pennsylvanian locality of Joggins, Nova Scotia, and a review of its relationships. J Vertebr Paleontol 18:64-79.

Huelsenbeck JP. 1991. Tree-length distribution skewness: an indicator of phylogenetic information. Syst Zool 40:257-270.

Huxley TH, Wright EP. 1867. On a collection of fossil Vertebrata, from the Jarrow Colliery, county of Kilkenny, Ireland. Trans R Ir Acad XXIV:351-368.

Ivachnenko MF. 1978 [English translation 1979]. Urodelans from the Triassic and Jurassic of Soviet Central Asia. Paleont Jour 1978:362-368.

Jaekel O. 1902. Ueber Ceraterpeton [sic], Diceratosaurus und Diplocaulus. Z dt geol Ges 54 109-134.

Jenkins FA Jr, Walsh DM, Carroll RL. 2007. Anatomy of Eocaecilia micropodia, a limbed caecilian of the Early Jurassic. Bull Mus Comp Zool 158:285-365.

Johanson Z, Joss J, Boisvert CA, Ericsson R, Sutija M, Ahlberg PE. 2007. Fish fingers: digit homologues in sarcopterygian fish fins. J Exp Zool B (Mol Dev Evol) 308:757-768.

Laurin M. 1996. A redescription of the cranial anatomy of Seymouria baylorensis, the best[-] known seymouriamorph (Vertebrata: Seymouriamorpha). PaleoBios 17:1-16.

Laurin M. 1998. The importance of global parsimony and historical bias in understanding tetrapod evolution. Part I. Systematics, middle ear evolution and jaw suspension. Ann Sci Nat 1:1-42.

Maddison WP, Maddison DR. 2009. Mesquite: a modular system for evolutionary analysis. Version 2.6+ (build 490). http://mesquiteproject.org. 
Marjanović D, Laurin M. 2008. A reevaluation of the evidence supporting an unorthodox hypothesis on the origin of extant amphibians. Contrib Zool 77:149-199.

McGowan GJ. 2002. Albanerpetontid amphibians from the Lower Cretaceous of Spain and Italy: a description and reconsideration of their systematics. Zool J Linn Soc 135:132.

Milner AR. 1996. A revision of the temnospondyl amphibians from the Upper Carboniferous of Joggins, Nova Scotia. Spec Pap Palaeontology 52:81-103.

Milner AR, Sequeira SEK. 1994. The temnospondyl amphibians from the Viséan of East Kirkton, West Lothian, Scotland. Trans R Soc Edinburgh 84:331-361.

Olson EC. 1941. The family Trematopsidae. J Geol 49:149-176.

Rage J-C, Roček Z. 1989. Redescription of Triadobatrachus massinoti (Piveteau, 1936)[,] an anuran amphibian from the Early Triassic. Palaeontographica A 206:1-16.

Rieppel O, Grande LA. 1998. A well-preserved fossil amphiumid (Lissamphibia: Caudata) from the Eocene Green River Formation of Wyoming. J Vertebr Paleontol 18:700708.

Ruta M, Coates MI. 2007. Dates, nodes and character conflict: addressing the lissamphibian origin problem. J Syst Palaeontol 5:69-122.

Sanch[í]z B. 1998. Salientia. Part 4 of Wellnhofer P, editor. Encyclopedia of Paleoherpetology. Munich: Dr. Friedrich Pfeil.

Sawin HJ. 1941. The cranial anatomy of Eryops megacephalus. Bull Mus Comp Zool 88:407-463.

Schoch RR, Fröbisch NB. 2006. Metamorphosis and neoteny: alternative pathways in an extinct ampibian clade. Evolution 60:1467-1475.

Schoch RR, Rubidge BS. 2005. The amphibamid Micropholis from the Lystrosaurus Assemblage Zone of South Africa. J Vertebr Paleontol 25:502-522.

Shubin NH, Jenkins FA Jr. 1995. An Early Jurassic jumping frog. Nature 377:49-52.

Smithson TR. 1982. The cranial morphology of Greererpeton burkemorani Romer (Amphibia: Temnospondyli). Zool J Linn Soc 76:29-90.

Sumida SS, Berman DS, Martens T. 1998. A new trematopid amphibian from the Lower Permian of central Germany. Palaeontology 41:605-629.

Swofford DL. 2003. PAUP*: Phylogenetic Analysis Using Parsimony (*and other methods). Version 4.0b10. Sunderland, Massachusetts: Sinauer Associates.

Vallin G, Laurin M. 2004. Cranial morphology and affinities of Microbrachis, and a reappraisal of the phylogeny and lifestyle of the first amphibians. J Vertebr Paleontol 24:56-72.

Venczel M. 1999. Land salamanders of the family Hynobiidae from the Neogene and Quarternary of Europe. Amphibia-Reptilia 20:401-412.

Venczel M, Gardner JD. 2005. The geologically youngest albanerpetontid amphibian, from the Lower Pliocene of Hungary. Palaeontology 48:1273-1300.

Wellstead CF. 1982. A Lower Carboniferous aïstopod amphibian from Scotland. Palaeontology 25:193-208.

Wellstead CF. 1991. Taxonomic revision of the Lysorophia, Permo-Carboniferous lepospondyl amphibians. Bull Am Mus Nat Hist 209:1-90.

Wiens JJ. 2001. Character analysis in morphological phylogenetics: problems and solutions. Syst Biol 50:689-699.

Wiens JJ, Bonett RM, Chippindale PT. 2005. Ontogeny discombobulates phylogeny: paedomorphosis and higher-level salamander relationships. Syst Biol 54:91-110.

Wischnitzer S. 1979. Atlas and dissection guide for comparative anatomy. Vol. 1. New York: W. H. Freeman and company. 
Supplementary Table 1: List of loss characters in the matrix by Anderson et al. (2008). All of them are retained in our version of the matrix (ESM3), although 137 is parsimonyuninformative.

4 Intertemporal: present (0), absent (1)

5 Supratemporal: present (0), absent (1)

10 Squamosal-tabular [contact]: absent (0), present (1), fused (2) ${ }^{1}$

13 Lacrimal: present (0), absent (1)

18 Quadratojugal: present (0), absent (1)

24 Nasals: present (0), absent (1)

27 Internarial fontanelle: absent (0), present (1)

28 Septomaxilla: ossified (0), unossified $(1)^{2}$

38 Otic notch: present (0), absent (1)

45 Postorbital: present (0), absent (1)

53 Postparietals: paired (0), fused (1), absent (2)

54 Parietal foramen: present (0), absent (1)

59 Tabular: present (0), absent (1)

64 Lateral line canal grooves: present (0), absent (1)

65 Dermal sculpturing: circular pits (0), shallow ridges and grooves (1), little to none (2)

81 Labyrinthine in-folding [sic]: present (0), absent (1)

83 Supraoccipital: absent (0), present (1)

89 Palatal teeth: present (0), absent (1)

92 Anterior [part of] palatine: short anteromedial process articulating with vomer at choana

(0), long anteromedial process, more medial than lateral (1), palatine absent (2)

93 Vomerine teeth: present (0), absent (1)

96 Intervomerine rostral fenestration: absent (0), present (1)

97 Denticles on pterygoid: present (0), absent (1)

98 Teeth on pterygoid: absent (0), present (1)

100 Denticles on vomers: present (0), absent (1)

101 Denticles on palatines: present (0), absent (1)

102 Denticles on parasphenoid: present (0), absent (1)

107 Basicranial articulation: loose (0), sutured or fused (1)

108 Stapes: perforated stem (0), imperforate stem (1), no stem (2) ${ }^{3}$

114 Sphenethmoid: ossified (0), unossified (1)

115 Interpterygoid vaccuities [sic]: narrow (“closed”) (0), wide (1), fused at midline (2)

121 Ectopterygoid: present with fang-pit pair (0), present[,] lacking fang-pit pair (1), absent

$(2)^{5}$

126 Surangular: normal (0), reduced (1), absent (2)

128 Number of splenials: 2 (0), 1 (1), 0 (2)

130 Meckelian fossae [sic - actually fenestrae, lacking a bony floor]: 2 or more (0), 1 (1), 0

(2)

136 Number of coronoids: 3 (0), 2 (1), 1 (2), 0 (3)

137 Coronoid teeth: present (0), absent (1)

140 Jaw sculpture: present (0), absent (1)

141 Ossified hyoids: present (0), absent (1)

148 Trunk intercentra: present (0), absent (1)

156 Haemal arches: present (0), absent (1)

167 Atlas-axis intercentra: present (0), absent (1)

169 Atlas centrum: multipartite (0), single notochordal (1), single odontoid (2) ${ }^{8}$

174 Proatlantes: present (0), absent (1)

176 Atlas ribs: one pair (0), two pairs (1), absent (2) ${ }^{9}$ 
190 Interclavicle sculpture: present (0), absent (1)

193 Cleithrum: ossified (0), unossified $(2)^{2}$

196 Supraglenoid foramen: present (0), absent (1)

208 Number digits - manus: 5 or more (0), $4(1), 3(2)^{10}$

219 Number of digits, pes: 5 or more (0), 4 or less $(1)^{11}$

${ }^{1}$ State 2 , the presence of a single bone in the area normally occupied by the squamosal and the tabular, can at least as easily be interpreted as the loss of the tabular with replacement by the squamosal (or imaginably the other way around).

2 These are dermal bones, so "unossified" equals "absent".

${ }^{3}$ State 1 refers to the loss of the stapedial foramen.

4 This obviously refers to the pterygoids touching each other and/or the parasphenoid throughout the length of their medial margins, in other words, the loss of the interpterygoid vacuities as seen for example in Seymouria and Batrachiderpeton.

${ }^{5}$ This character refers to the loss of the fangs and the loss of the bone that carries them and therefore counts as two loss characters.

${ }^{6}$ This character refers to the sequential loss of two bones and therefore counts as two loss characters. We have opted not to treat character 53 the same way, because there is evidence for the fusion of the two postparietals (left and right), but none for the fusion of the two splenials ("presplenial" and "postsplenial" in each hemimandible).

${ }^{7}$ Referring to the sequential loss of three bones, this character counts as three loss characters.

${ }^{8}$ States 1 and 2 both refer to the absence of the atlas intercentrum, so this character counts as a single loss character.

${ }^{9}$ State 1 refers to the fusion of atlas and axis, so this character counts as a single loss character.

${ }^{10}$ Counted as two loss characters.

${ }^{11}$ Counted as one loss character.

Supplementary Table 2: List of loss characters in the matrix by Vallin and Laurin (2004). Except for character 3, taken from the NEXUS file of Vallin and Laurin (2004), the spellings of the names of the characters and their states are taken from Laurin (1998); the six characters added later are not loss characters.

1 Lateral-line location in adults: in channels below the surface of the dermal bones (0), in grooves at the surface of the dermal bones (1), in soft tissues or absent (2)

2 Lateral-line grooves in ontogeny: present at least in the adults (may also be present in larvae) (0), present only in the larvae (1), never present (2)

3 Dermal sculpturing: 'honeycomb' pattern of ridges and pits (0), cosmine (1), shallow pits widely spaced from each other on an otherwise smooth surface (2), narrowly separated protuberances (3), smooth (4), broadly separated low tubera (5) ${ }^{1}$

4 Rostrum: absent, mouth terminal (0), short, high rostrum protruding anterior to the premaxillary teeth (1), long, low (2)

5 Orbit shape: ovoid (0), confluent with a large antorbital fenestra (1), open posteriorly $(2)^{2}$

10 Anterior tectal: present (0), absent (1)

15 Pineal foramen: present (0), absent (1)

16 Intertemporal: present (0), absent (1)

17 Supratemporal: present (0), absent (1)

18 Tabular: present (0), absent (1)

22 Postparietal number: two (paired) (0), single, median (1), none (2)

25 Prefrontal: present (0) absent (1)

27 Postfrontal: present (0), absent (1) 
28 Postorbital: reaches orbit (0), excluded from orbit (1), absent (2)

29 Lacrimal: reaches orbit (0), excluded from orbit (1), absent (2)

30 Jugal: borders orbit (0), excluded from orbit (1), absent (2)

31 Temporal emargination: absent, area covered by opercular bones (0), present, bordered by squamosal, tabular, and (sometimes) supratemporal (1), absent, area covered by squamosal, supratemporal, and tabular (2), present, bordered by quadrate (3), present, bordered by squamosal (4) ${ }^{3}$

35 Quadratojugal: present (0), absent (1)

37 Lateral palatal tooth row: present, complete (0), incomplete (1), absent (2)

39 Palatal recess: median (0), divided medially (1), absent (2)

40 Vomerine fangs: present (0), absent (1)

41 Vomerine shagreen of denticles: absent (0), present (1)

42 Palatine: discrete (0), fused or absent (1)

44 Palatine fangs: present (0), absent (1)

45 Palatine shagreen of denticles: absent (0), present (1)

46 Ectopterygoid: present (0), absent (1)

47 Ectopterygoid fangs: present (0), absent (1)

48 Ectopterygoid shagreen of denticles: absent (0), present (1)

51 Pterygoid shagreen of denticles: present (0), absent (1)

54 Interpterygoid vacuity: narrow (0), broad (1), absent (2)

58 Parasphenoid denticles: present (0), absent (1)

60 Ventral cranial fissure: present (0), absent (1)

65 Braincase endochondral roof: ossified as a unit (0), unossified (1), composed of exoccipital (2), composed of a discrete supraoccipital (3) ${ }^{4}$

67 Basioccipital and exoccipital: indistinguishably fused in adults (0), suturally distinct throughout ontogeny (1), basioccipital never distinct $(2)^{5}$

70 Preopercular: present (0), absent (1)

71 Subopercular: present (0), absent (1)

72 Epipterygoid ossification: present (0), absent (1)

74 Basicranial articulation: not fused, potentially mobile (0); sutured, immobile (1)

78 Stapedial foramen: present (0), absent (1)

79 Mandibular fenestrae: absent (0), small fenestrae present in splenial, postsplenial, and angular (1), large fenestra(e) present between angular, postsplenial, splenial, and prearticular

(2)

80 Anterior coronoid: present (0), fused or absent (1)

81 Middle coronoid: resent (0), fused or absent (1)

82 Posterior coronoid: present (0), fused or absent (1)

83 Anterior splenial: present (0), fused or absent (1)

84 Postsplenial: present (0), fused or absent (1)

85 Angular: present (0), fused or absent (1)

86 Surangular: present (0), fused or absent (1)

88 Coronoid fangs: present $(0)$, absent (1)

89 Coronoid denticles: absent (0), present (1)

90 Dentary: dentigerous (0), edentulous

92 Medial mandibular tooth row: on coronoids (0), absent (1), on pseudodentary (2)

96 Labyrinthine infolding: present (0), absent (1)

98 Presacral centra (excluding atlas-axis complex): large, crescentic intercentra and small, paired, dorsal pleurocentra (0); cylindrical intercentra only (1); crescentic intercentra only (2); crescentic intercentra and cylindrical pleurocentra (3); circular intercentra and pleurocentra (4); cylindrical pleurocentra only (5) ${ }^{6}$

109 Atlantal intercentrum: present (0), absent (1) 
115 Number of sacral vertebrae: none (0), one (1), two or more (2)

117 Discrete dorsal fin: present (0), absent (1)

118 Radials in caudal fin: present (0), absent (1)

120 Interclavicle: without a parasternal process (0), with a parasternal process (1), absent (2)

121 Clavicle: present (0), absent (1)

123 Cleithrum: with a dorsal expansion (0), slender, without a discrete dorsal expansion (1),

with a ventral expansion (2), absent (3)

125 Anocleithrum: present (0), absent (1)

126 Lateral extrascapular: present (0), absent $(1)^{7}$

127 Median extrascapular: present (0), absent $(1)^{7}$

130 Humerus: present (0), absent (1)

141 Number of digits in manus: none (0), eight (1), five (2), four (3) ${ }^{8}$

142 Number of pelvic ossifications: one (0), three (1), two (2) ${ }^{9}$

150 Number of pedal digits: none (0), seven (1), five (2), four (3) ${ }^{10}$

151 Number of phalanges in second pedal digit: two (0), three (1)

152 Number of phalanges in third pedal digit: three (0), four (1)

153 Number of phalanges in fourth pedal digit: four (0), five (1), three (2)

154 Number of phalanges in fifth pedal digit: four (0), five (1), three (2), two (3)

155 Lepidotrichia in caudal fin: present (0), absent (1)

${ }^{1}$ State 4 refers to the loss of sculpturing.

${ }^{2}$ State 2 refers to the loss of bones such as the postorbital.

${ }^{3}$ State 2 refers to loss of the emargination.

${ }^{4}$ Under the lepospondyl hypothesis, loss of the suproccipital (from state 3 to state 1 ) is a lissamphibian autapomorphy; this disappears under the temnospondyl hypothesis, however. This character could thus be said to be a loss character that supports the temnospondyl hypothesis.

${ }^{5}$ State 2 refers to the loss of the basioccipital: "The basioccipital of lissamphibians is never distinct and there does not appear to be a discrete ossification centre for this element (2)." (Laurin, 1998)

${ }^{6}$ States 1 and 2 refer to the loss of pleurocentra, and state 5 to the loss of intercentra. Therefore this character is counted as two loss characters.

${ }^{7}$ Counted as a single loss character because a functional correlation is hypothesized and no taxon is known to possess either lateral extrascapulars or the median one but not both.

${ }^{8}$ Counted as three loss characters: no taxon with seven manual digits is known, but one with six (Tulerpeton) is, even though it is not present in the matrix.

${ }^{9}$ State 2 refers to loss of ossification of the pubis.

${ }^{10}$ Counted as three loss characters (even though the only known taxon with six pedal digits, Tulerpeton, is not present in the matrix). 
Supplementary Table 3: Left: Significance thresholds for the $g_{1}$ statistic for different numbers of taxa (from Huelsenbeck, 1991: table 1); right: rounded values of the $g_{1}$ statistic for the loss characters and the remaining characters of the matrices of Anderson et al. (2008) and Vallin and Laurin (2004). Note that these are actually two separate tables that should be compared to each other and are put side-by-side here for this purpose.

" $g_{1}$ values less than the values in the table are outside of the $95 \%$ or $99 \%$ confidence limits for tree-length distributions from random data.” (Huelsenbeck, 1991: legend of table 1)

Abbreviations: "Loss", loss characters as defined in the text and listed in Supplementary Tables 1 and 2; "Others”, all other characters of the same matrix.

\begin{tabular}{|llll|lll|}
\hline $\begin{array}{l}\text { Significance } \\
\text { (1991: thresholds from }\end{array}$ & Huelsenbeck & $\begin{array}{l}\text { Character } \\
\text { type }\end{array}$ & $\begin{array}{l}\text { Anderson } \text { et } \\
\text { al. (2008) }\end{array}$ & $\begin{array}{l}\text { Vallin and } \\
\text { Laurin (2004) }\end{array}$ \\
\hline P value & 6 taxa & 7 taxa & 8 taxa & & 54 taxa & 48 taxa \\
0.05 & -0.51 & -0.45 & -0.34 & Loss & -0.31 & -0.55 \\
0.01 & -0.67 & -0.60 & -0.47 & Others & -0.35 & -0.37 \\
\hline
\end{tabular}

Supplementary Table 4: Table of results of the bootstrap analysis, put out by PAUP* (Swofford, 2003). Temnospondyls marked in green, lissamphibians in red; the taxa between these two blocks are the "lepospondyls". Clades that are compatible with the polyphyly hypothesis (by containing some or all temnospondyls, frogs, and salamanders, but not Eocaecilia or any "lepospondyls", or by containing Eocaecilia and some or all "lepospondyls" but no temnospondyls, frogs or salamanders) are underlined; clades that contradict both the monophyly of extant amphibians and the polyphyly hypothesis (by containing frogs, salamanders and lepospondyls but neither any temnospondyls nor Eocaecilia) are marked in bold and italics. See Supplementary Table 5 for more explanation.

Bipartitions found in one or more trees and frequency of occurrence (bootstrap support values):

\begin{tabular}{|c|c|c|}
\hline 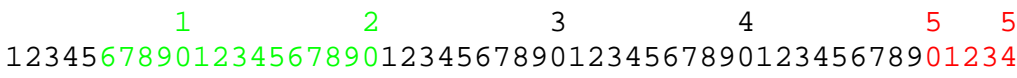 & Freq & \\
\hline 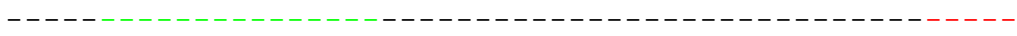 & & \\
\hline$\ldots{ }^{* *} \ldots \ldots \ldots$ & 199.27 & 99 \\
\hline$\ldots \ldots \ldots \ldots \ldots \ldots \ldots \ldots \ldots$ & 194.20 & 97.1 \\
\hline$\ldots \ldots \ldots * * \ldots \ldots$ & 191.54 & 95.8 \\
\hline$\ldots \ldots \ldots$ & 185.08 & 92.5 \\
\hline$\ldots \ldots *$ & 182.37 & 29 \\
\hline$\ldots \ldots \ldots \ldots$ & 175.80 & $.9 \%$ \\
\hline$\ldots \ldots \ldots \ldots \ldots * *$ & 175.33 & $.7 \%$ \\
\hline$\ldots \ldots \ldots \ldots$ & 6.14 & . $1 \%$ \\
\hline$\ldots \ldots \ldots * \ldots * \ldots$ & 5.15 & $82.6 \%$ \\
\hline$\ldots \ldots \ldots \ldots$ & 56 & 39 \\
\hline$\ldots{ }^{*} \ldots \ldots \ldots \ldots$ & 2.97 & $76.5 \%$ \\
\hline$\ldots \ldots \ldots$ & .99 & $75.5 \%$ \\
\hline$\ldots \ldots \ldots$ & 58 & $69.8 \%$ \\
\hline 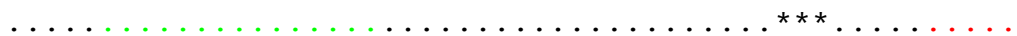 & .91 & $69.0 \%$ \\
\hline$\ldots \ldots \ldots$. & 5.68 & $67.8 \%$ \\
\hline$\ldots \ldots *$ & 5.01 & $.5 \%$ \\
\hline$\ldots \ldots \ldots \ldots$ & 4.38 & $.2 \%$ \\
\hline$\ldots * *$ & 122.21 & $.1 \%$ \\
\hline$\ldots *$ & 104.44 & $52.2 \%$ \\
\hline$\ldots *$ & 104.21 & $52.1 \%$ \\
\hline$* * * \ldots * * *$ & 103.06 & $.5 \%$ \\
\hline$\ldots{ }^{*} \ldots{ }^{*} \ldots$ & $10 \odot .4 \odot$ & $50.2 \%$ \\
\hline$\star * \star * \ldots$ & 100.23 & $.1 \%$ \\
\hline.$^{*}$ & 94.83 & $47.4 \%$ \\
\hline$* * * * * * *$ & 91.23 & $.6 \%$ \\
\hline . * & 87.15 & $.6 \%$ \\
\hline$\ldots{ }^{*} \ldots{ }^{* *}$ & 82.27 & $.1 \%$ \\
\hline$\ldots \ldots$ & 79.27 & 39.6 \\
\hline
\end{tabular}




\begin{tabular}{|c|c|c|}
\hline 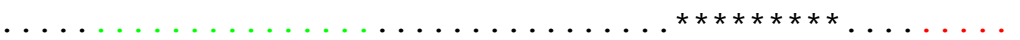 & 78.56 & $39.3 \%$ \\
\hline$\ldots \ldots \ldots \ldots \ldots \ldots \ldots . \ldots . \ldots$ & 77.15 & $8.6 \%$ \\
\hline$\ldots \ldots * * * * * * * * * * * * * * * \ldots \ldots \ldots \ldots \ldots \ldots$ & 73.01 & $36.5 \%$ \\
\hline 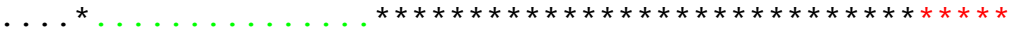 & 71.65 & $5.8 \%$ \\
\hline 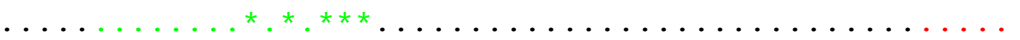 & 70.02 & $5.0 \%$ \\
\hline 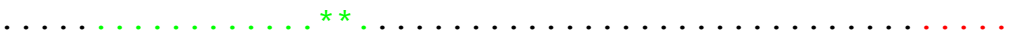 & 69.70 & $4.9 \%$ \\
\hline 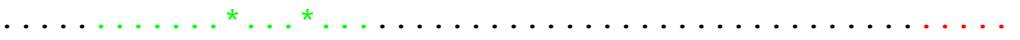 & 67.41 & $.7 \%$ \\
\hline 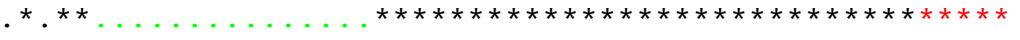 & 60.55 & $30.3 \%$ \\
\hline$\ldots \ldots \ldots \ldots \ldots \ldots \ldots \ldots$ & 60.19 & $0.1 \%$ \\
\hline 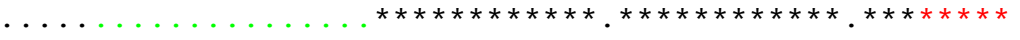 & 57.17 & $8.6 \%$ \\
\hline 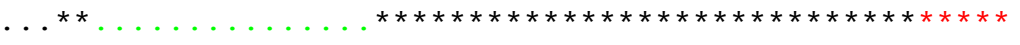 & 55.51 & $27.8 \%$ \\
\hline 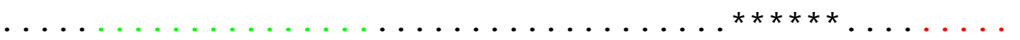 & 55.29 & $27.6 \%$ \\
\hline 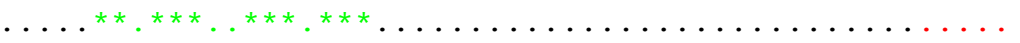 & 51.79 & $25.9 \%$ \\
\hline 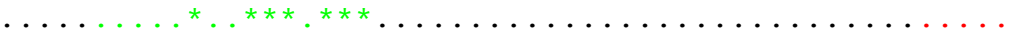 & 50.69 & $25.3 \%$ \\
\hline 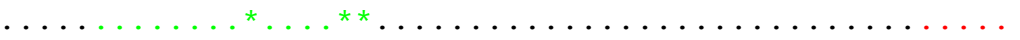 & 48.15 & $24.1 \%$ \\
\hline 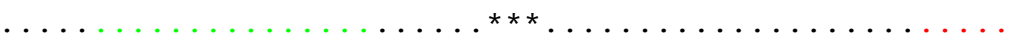 & 48.04 & $24.0 \%$ \\
\hline 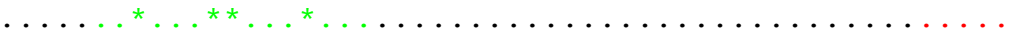 & 47.39 & $3.7 \%$ \\
\hline 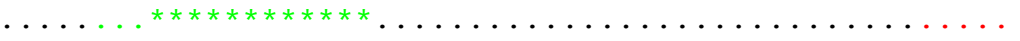 & 46.21 & $23.1 \%$ \\
\hline 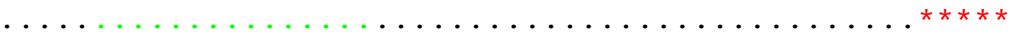 & 45.39 & $22.7 \%$ \\
\hline 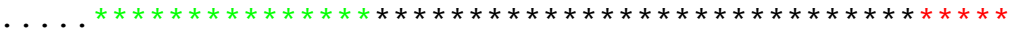 & 44.91 & $22.5 \%$ \\
\hline 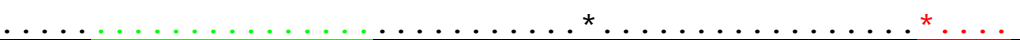 & 44.81 & $22.4 \%$ \\
\hline 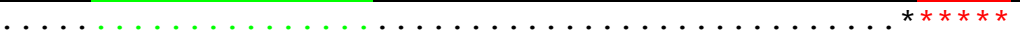 & 44.24 & $22.1 \%$ \\
\hline 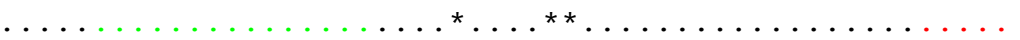 & 40.50 & $20.3 \%$ \\
\hline 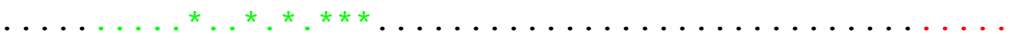 & 40.20 & $20.1 \%$ \\
\hline 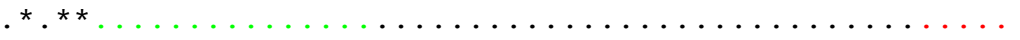 & 39.81 & $19.9 \%$ \\
\hline 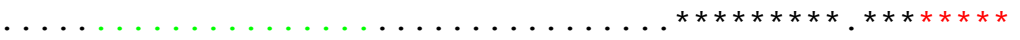 & 38.59 & $19.3 \%$ \\
\hline 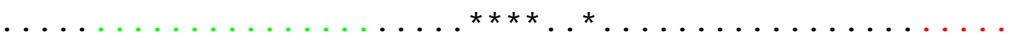 & 38.55 & $19.3 \%$ \\
\hline 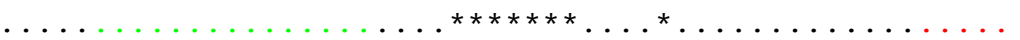 & 38.37 & $19.2 \%$ \\
\hline 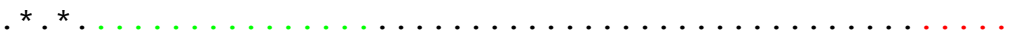 & 37.35 & $18.7 \%$ \\
\hline$\ldots * * * * * * * * * * * * * * * * * * * * * * * * * * * * * * * * *$ & 36.94 & $18.5 \%$ \\
\hline 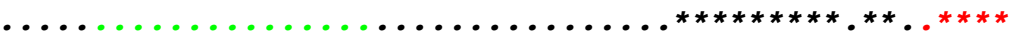 & 36.29 & $18.1 \%$ \\
\hline$\ldots \ldots * * * * * * * * * * * * *$. & 36.23 & $18.1 \%$ \\
\hline 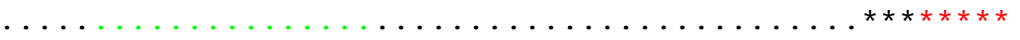 & 34.55 & $17.3 \%$ \\
\hline 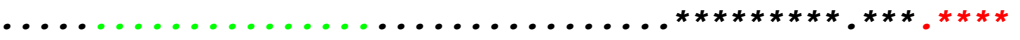 & 33.98 & $17.0 \%$ \\
\hline 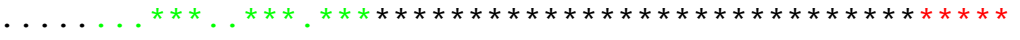 & 33.13 & $16.6 \%$ \\
\hline$\ldots \ldots \ldots \ldots \ldots_{\ldots} \ldots \ldots \ldots \ldots \ldots \ldots$ & 33.05 & $16.5 \%$ \\
\hline 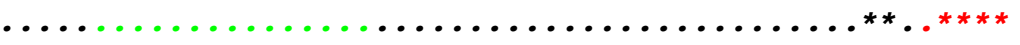 & 31.88 & $15.9 \%$ \\
\hline$\ldots \ldots{ }^{*} \ldots{ }^{*} \ldots * * \ldots \ldots$ & 30.42 & $15.2 \%$ \\
\hline 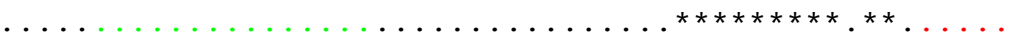 & 30.37 & $15.2 \%$ \\
\hline$\ldots \ldots \ldots \ldots \ldots \ldots$ & 29.52 & $14.8 \%$ \\
\hline$\ldots * * * * * * * * * * * * * * * * * *$ & 28.82 & $14.4 \%$ \\
\hline 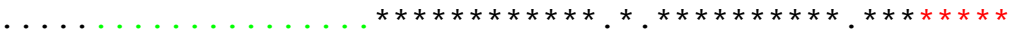 & 28.78 & $14.4 \%$ \\
\hline$\ldots \ldots \ldots \ldots \ldots \ldots \ldots \ldots \ldots \ldots \ldots \ldots$ & 28.24 & $14.1 \%$ \\
\hline 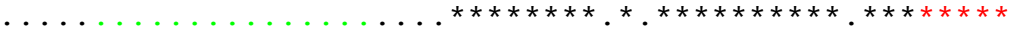 & 28.16 & $14.1 \%$ \\
\hline$\ldots \ldots \ldots{ }^{*} \ldots \ldots \ldots \ldots \ldots \ldots{ }^{*}$ & 27.88 & $13.9 \%$ \\
\hline 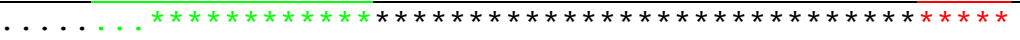 & 27.79 & $13.9 \%$ \\
\hline$\ldots \ldots \ldots \ldots \ldots \ldots \ldots \ldots \ldots \ldots \ldots \ldots \ldots$ & 27.64 & $13.8 \%$ \\
\hline 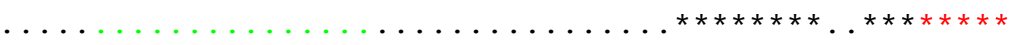 & 24.39 & $12.2 \%$ \\
\hline$\ldots \ldots \ldots$ & 24.39 & $12.2 \%$ \\
\hline 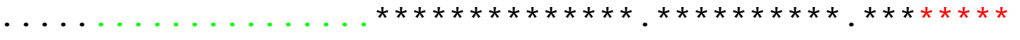 & 24.39 & $12.2 \%$ \\
\hline$\ldots \ldots \ldots \ldots \ldots$ & 24.28 & $12.1 \%$ \\
\hline$\ldots \ldots{ }_{*}^{*} \ldots \ldots^{*} \ldots \ldots .$. & 24.15 & $12.1 \%$ \\
\hline$\ldots \ldots *^{*} \ldots{ }^{*} \ldots \ldots \ldots \ldots \ldots \ldots$ & 23.86 & $11.9 \%$ \\
\hline 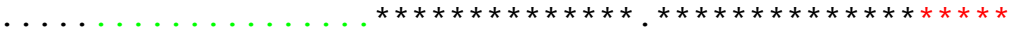 & 22.20 & $11.1 \%$ \\
\hline$\ldots \ldots * * * * * * * * * * * *$. & 22.08 & $11.0 \%$ \\
\hline$\ldots \ldots \ldots \ldots \ldots$ & 21.73 & $10.9 \%$ \\
\hline . & 21.69 & $10.8 \%$ \\
\hline$\ldots \ldots * * \ldots * * * * *$. & 20.51 & $10.3 \%$ \\
\hline$\ldots \ldots \ldots \ldots \ldots \ldots \ldots{ }^{*} \ldots \ldots^{*} \ldots \ldots^{*} \ldots$ & 20.32 & $10.2 \%$ \\
\hline$\ldots \ldots \ldots \ldots \ldots$ & 20.03 & $10.0 \%$ \\
\hline$\ldots \ldots \ldots \ldots$ & 19.14 & $9.6 \%$ \\
\hline 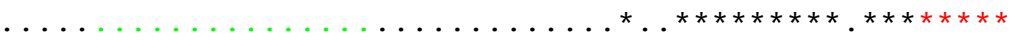 & 18.89 & $9.4 \%$ \\
\hline 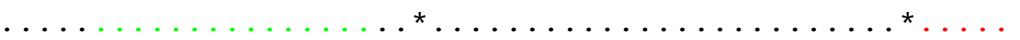 & 18.80 & $9.4 \%$ \\
\hline$\ldots \ldots \ldots \ldots \ldots \ldots{ }^{*}{ }^{*}{ }^{*} \ldots{ }^{*} \ldots \ldots \ldots \ldots \ldots \ldots$ & 18.70 & $9.3 \%$ \\
\hline 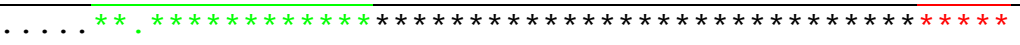 & 18.69 & $9.3 \%$ \\
\hline$\ldots \ldots \ldots * \ldots * * * *$ & 18.49 & $9.2 \%$ \\
\hline$\ldots * \ldots \ldots \ldots \ldots \ldots \ldots \ldots \ldots \ldots \ldots$ & 18.24 & $9.1 \%$ \\
\hline 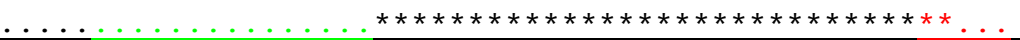 & 18.04 & $9.0 \%$ \\
\hline$* * \ldots * * \ldots * *, *$ & 18.04 & ๑\% \\
\hline$\ldots \ldots \ldots * \ldots \ldots \ldots \ldots \ldots$ & 17.94 & $9.0 \%$ \\
\hline
\end{tabular}




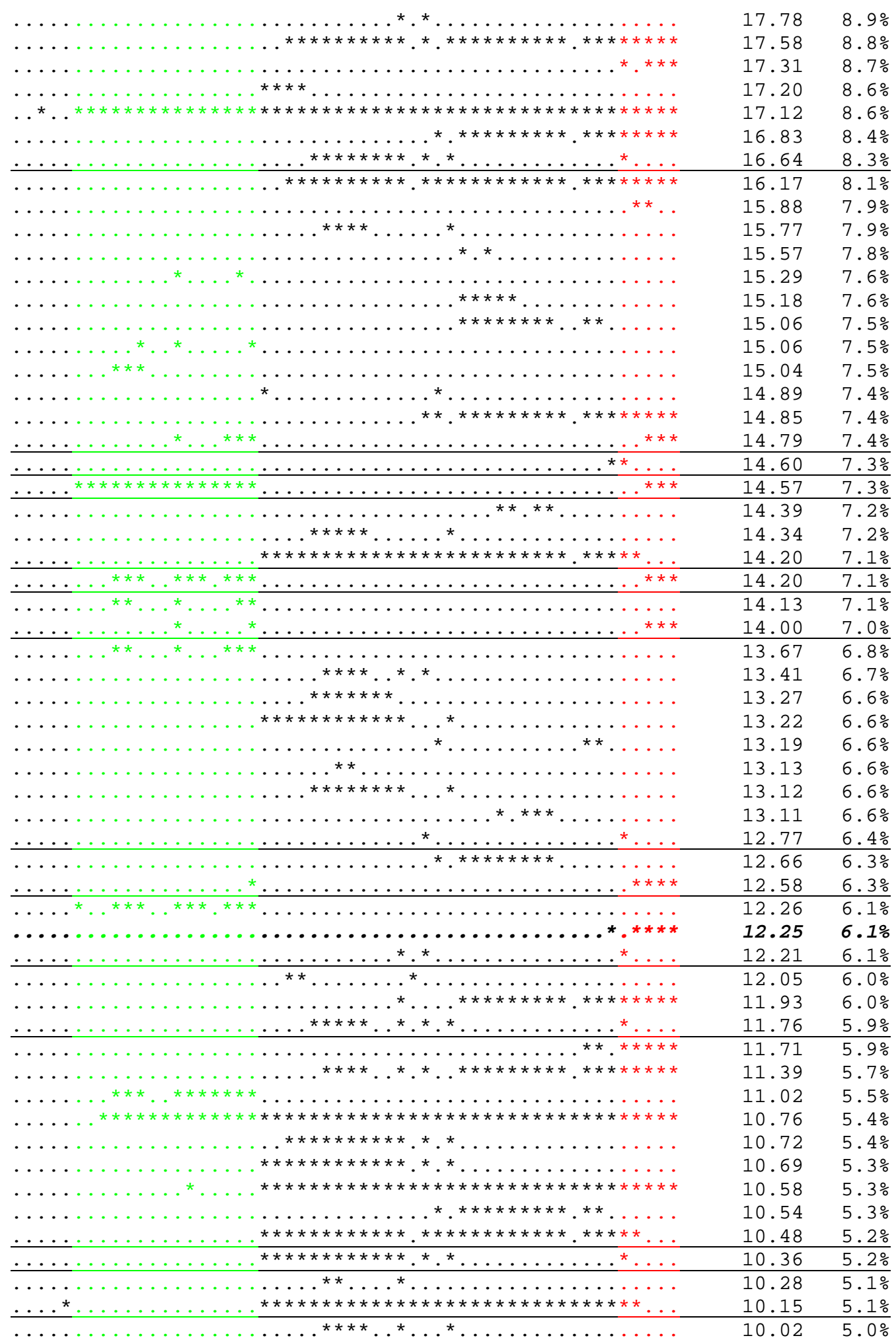

2102 groups at (relative) frequency less than $5 \%$ not shown

Supplementary Table 5: List of the clades found in the bootstrap analysis which are compatible with the polyphyly hypothesis (Supplementary Table 4, underlined) and of those that are incompatible with both the monophyly of extant amphibians and the polyphyly hypothesis (Supplementary Table 4, bold and italics), with others added for comparison. Clades that contradict the lepospondyl hypothesis but not the polyphyly hypothesis are marked in bold. 
Abbreviations: LH, lepospondyl hypothesis; PH, polyphyly hypothesis; TH, temnospondyl hypothesis; Salientia: Triadobatrachus and the "frogs" OTU.

\section{Contents of the clade}

all "lepospondyls", Lissamphibia

all "lepospondyls” except Adelogyrinus, Lissamphibia

Temnospondyli

all "lepospondyls”, Lissamphibia, Limnoscelis

all "lepospondyls", Lissamphibia, Limnoscelis, Seymouria, Proterogyrinus

all "lepospondyls" except Adelogyrinus and

all "lepospondyls", Lissamphibia, Limnoscelis, Seymouria

all temnospondyls except Eryops, Ecolsonia, Acheloma and Tambachia

Tersomius, Doleserpeton, Micropholis, Eoscopus, Platyrhinops, Amphibamus, Gerobatrachus (thus same as above except Balanerpeton, Dendrerpeton, Branchiosauridae and Micromelerpetontidae)

Doleserpeton, Amphibamus, Gerobatrachus

all temnospondyls except Balanerpeton, Dendrerpeton and Eryops

Lissamphibia

\section{Rhynchonkos, Eocaecilia}

Brachydectes, Lissamphibia

Tersomius, Doleserpeton, Eoscopus, Platyrhinops, Amphibamus, Gerobatrachus

all "nectrideans", Aïstopoda, Brachydectes,

Lissamphibia

all "nectrideans", Aïstopoda, Albanerpetontidae, y salamanders, Salientia

Aïstopoda, Brachydectes, Lissamphibia

all "nectrideans", Aïstopoda, Brachydectes, Albanerpetontidae, salamanders, Salientia

all temnospondyls except Balanerpeton,

Dendrerpeton, Eryops, Ecolsonia, Acheloma and

Tambachia, all "lepospondyls”, Lissamphibia

Aïstopoda, Albanerpetontidae, salamanders, Salientia

all “lepospondyls” except Microbrachis, Utaherpeton

and Adelogyrinus, Lissamphibia

Hapsidopareion and Saxonerpeton

\section{Gerobatrachus, salamanders, Salientia}

all temnospondyls except Balanerpeton, Dendrerpeton

and Eryops, all "lepospondyls", Lissamphibia

all "nectrideans" except Scincosaurus, Aïstopoda,

Brachydectes, Lissamphibia
Clade contradicts: Bootstrap

LH $\quad \mathrm{PH}$ TH percentage

no yes yes 67.5

no yes yes 43.6

no yes yes 36.5

no yes yes 35.8

$\begin{array}{lll}\text { no yes } & \text { yes } \quad 30.3\end{array}$

$\begin{array}{lll}\text { no } & \text { yes } \quad \text { yes } \quad 28.6\end{array}$

$\begin{array}{llll}\text { no } & \text { yes } & \text { yes } & 27.8\end{array}$

no yes yes 25.9

no rather rather 25.3

yes yes

no rather rather

24.1

no no

no yes yes

23.1

no

yes no

22.7

yes

no

no yes

22.4

22.1

20.1

rather rather

yes yes

19.3

18.1

17.3

17.0

yes yes yes

16.6

yes

yes yes yes

15.9

14.4

$\begin{array}{cccc}\text { yes } & \text { no } & \text { no } & \mathbf{1 3 . 9} \\ \text { no } & \text { no }^{1} & \text { rather } & 13.9\end{array}$

yes

yes yes

12.2

12.2 
Adelogyrinus, Lissamphibia

Doleserpeton, Platyrhinops, Gerobatrachus

all “lepospondyls” except Utaherpeton, Lissamphibia

Greererpeton, Temnospondyli

Rhynchonkos, Batropetes, all "nectrideans",

Aïstopoda, Brachydectes, Lissamphibia

same as above except Rhynchonkos

Hapsidopareion, Brachydectes

Gymnarthridae, Rhynchonkos, Eocaecilia

all temnospondyls except Eryops, all "lepospondyls", no
Lissamphibia

Aïstopoda, Brachydectes, Lissamphibia except yes

Eocaecilia

all "lepospondyls", Eocaecilia, Albanerpetontidae

all temnospondyls except Eryops, Ecolsonia,

Acheloma and Tambachia, all "lepospondyls",

Lissamphibia

Platyrhinops, Amphibamus, Gerobatrachus

Lissamphibia without Albanerpetontidae

Utaherpeton, all "nectrideans", Aïstopoda, no

Brachydectes, Lissamphibia

Pantylidae, Gymnarthridae, Ostodolepididae, yes

Rhynchonkos, Batropetes, Eocaecilia

all "lepospondyls" except Tuditanus, Asaphestera, no

Microbrachis and Adelogyrinus, Lissamphibia

Albanerpetontidae, salamanders no

Batropetes, Utaherpeton, all "nectrideans”, Aïstopoda, no

Brachydectes, Lissamphibia

Doleserpeton, Platyrhinops, Amphibamus, y

Gerobatrachus, salamanders, Salientia

Brachydectes, Eocaecilia

Temnospondyli, salamanders, Salientia

all "lepospondyls" except Adelogyrinus, Eocaecilia, yes

Albanerpetontidae

Doleserpeton, Gerobatrachus, salamanders, yes

Salientia

Batropetes, Eocaecilia

Gerobatrachus, Lissamphibia except Eocaecilia

Brachydectes, Lissamphibia except Eocaecilia

Rhynchonkos, Batropetes, Eocaecilia

Pantylidae, Gymnarthridae, Rhynchonkos, yes

Batropetes, Eocaecilia

all "lepospondyls" except Utaherpeton and yes

Adelogyrinus, Eocaecilia, Albanerpetontidae

same as above except Albanerpetontidae and all

“nectrideans" other than Ptyonius (!)
11.9

11.1

10.8

9.6

9.4

9.4

9.3

9.3

9.2

9.0

no $^{1} \quad$ rather $\quad 9.0$

no

no

rather rather

9.0

no no

yes no

8.7

8.4

8.3

8.1

7.9

7.4

7.4

7.3

7.3

7.1

7.0

yes no yes $\quad 6.4$

$\begin{array}{llll}\text { yes no } & \text { yes } & 6.3\end{array}$

yes yes yes 6.1

$\begin{array}{llll}\text { yes no } & \text { yes } & 6.1\end{array}$

no yes 5.9

no yes $\quad 5.2$

yes no yes 
1 This only holds if highly unconventional arrangements like those found by McGowan (2002), where "lepospondyls" and lissamphibians are found inside Temnospondyli, are counted as acceptable within the polyphyly hypothesis. 


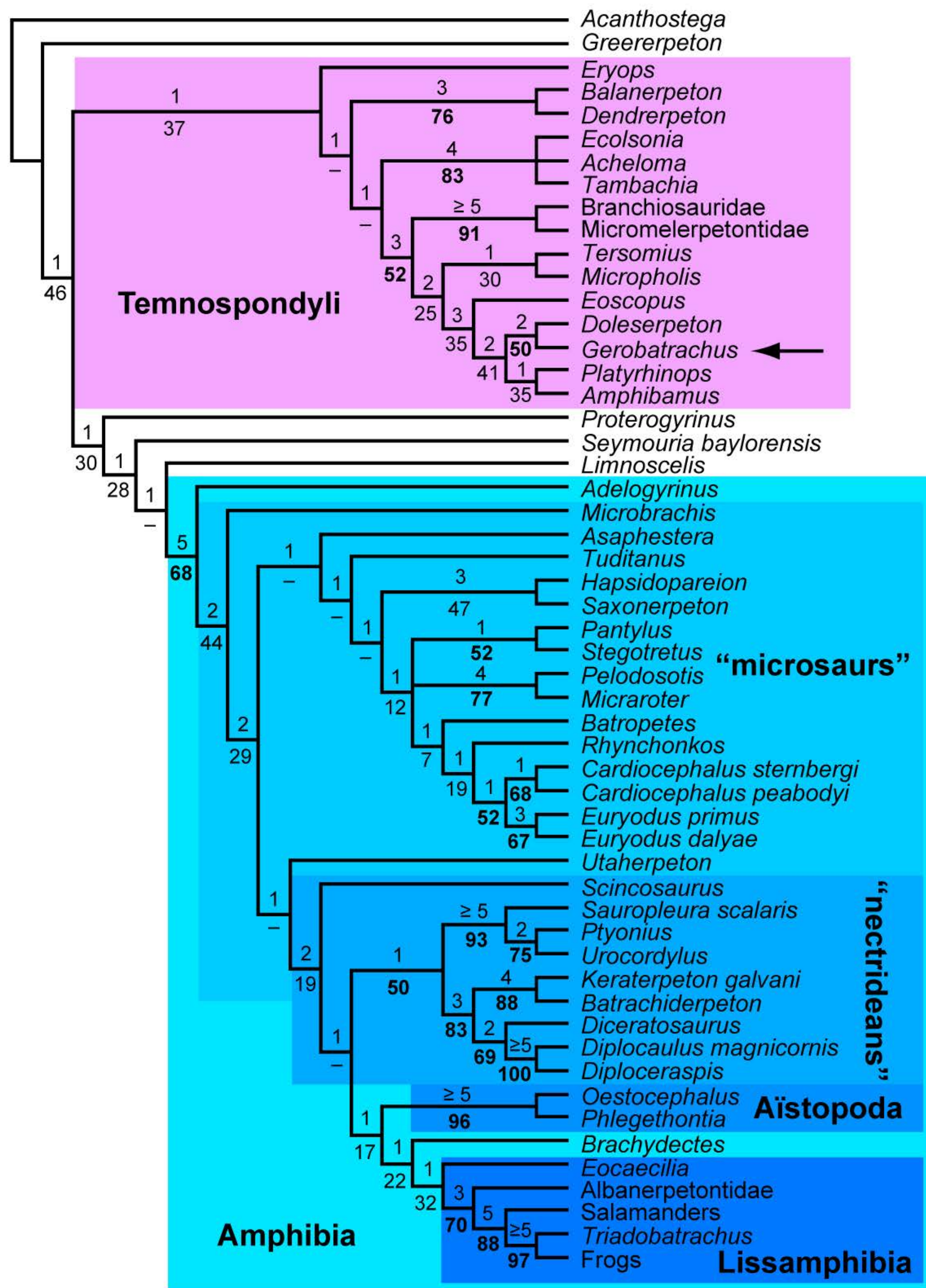




\section{BEGIN TAXA;}

TITLE Untitled_Taxa_Block;

DIMENSIONS NTAX=54;

\section{TAXLABELS}

Acanthostega Proterogyrinus Greererpeton Seymouria_baylorensis Limnoscelis Balanerpeton Dendrerpeton Eryops Branchiosauridae Micromelerpetontidae Tersomius Ecolsonia Acheloma Doleserpeton Micropholis Eoscopus Tambachia Platyrhinops Amphibamus Gerobatrachus Tuditanus Asaphestera Hapsidopareion Saxonerpeton Pantylus Cardiocephalus_sternbergi Cardiocephalus_peabodyi Euryodus_primus Euryodus_dalyae Pelodosotis Micraroter Rhynchonkos Microbrachis Batropetes Utaherpeton Stegotretus Sauropleura_scalaris Ptyonius Urocordylus Keraterpeton_galvani Batrachiderpeton Diceratosaurus Diplocaulus_magnicornis Diploceraspis Scincosaurus Adelogyrinus Oestocephalus Phlegethontia Brachydectes Eocaecilia Albanerpetontidae Salamanders Triadobatrachus Frogs

\section{END;}

\section{BEGIN CHARACTERS;}

TITLE morphology; DIMENSIONS NCHAR=219;

FORMAT DATATYPE = STANDARD GAP = - MISSING = ? SYMBOLS = " 012 3";

\section{CHARSTATELABELS}

1 Basal_Skull_Length / '>70mm' '50-70mm' '30-50mm' '<30mm', 2 'Skull:trunk' / '>=0.45' '0.30-0.45' '0.20-0.29' '<0.20', 3 Skull_proportions / longer_than_wide wider_than_long, 4 Intertemporal / present absent, 5 Supratemporal / present absent, 6 ST_exposure_on_occiput / absent present, 7 'Tabular-postorbital' / absent Present, 8 'T-PF' / absent present, 9 Postfrontal_shape / broadly_quadrangular falciform, 10 'Squamosal-Tabular' / absent present fused, 11 'Squamosal-Temporal area' / weakly_overlapping sutural, 12 'Lacrimal-prefrontal suture' / simple_butt_joint interdigitating prefrontal_broadly_underplates_lacrimal, 13 Lacrimal / present absent, 14 L_to_naris / present absent, 15 L_to_orbit / absent present, 16 lacrimal_orbital_processes / dorsal_and_ventral_present only_ventral_present neither_present, 17 'lacrimal-jugal contact' / present absent, 18 Quadratojugal / present absent, 19 'Quadratojugal-Jugal contact' / present absent, 20 'Quadratojugal-Maxillary contact' / present absent, 21 Frontals / paired_along_midline fused, 22 Prefrontal_and_postfrontal / 'meet, excluding frontal from orbit' fail_to_meet, 23 Anterior_laterally_flaring_frontals / absent present, 24 Nasals / present absent, 25 Narial_flange / absent present, 26 Dorsal_processes_of_premax / 'broad, low, indistinct dorsal process' 'alary process (broad, vaguely triangular process)' 'moderately high, vaguely rectangular process, or acutely triangular linked directly to base' 'narrow, long dorsal process, along the midline or parasagittal', 27

Internarial_fontanelle / absent present, 28 Septomaxilla / ossified unossified, 29 Prefrontal_into_external_naris / distant_from near present, 30 external_naris_in_dorsal_view / exposed not_exposed, 31 External_naris_shape / circular 'posteriorly_extended,_along_L-PF_suture' 'posteriorly_extended,_excavation_of_L_only', 32 dorsal_exposure_of_premax / broad narrow none, 33 Dorsal_shape_of_skull / triangular diamond rounded, 34 Posterior_skull_margin / undulating. concave straight convex, 35 snout / blunt pointed, 36 snout / short long, 37 'Q -internal flange of Sq' / absent present, 38 otic_notch / present absent, 39 Large_otic_notch_approaching_orbit / absent intermediate close, 40 otic_notch / open_posteriorly closed_posteriorly, 41 semilunar_flange_of_supratempor / absent present, 42 supratympanic_flange / absent 'present_"trematopid"' 'present_"dissorophid"', 43 supratympanic_shelf / absent present, 44 raised_orbital_rim / absent present, 45 Postorbital / present absent, 46 'J-PO interfingered processes' / absent present, 47 PO_in_orbital_margin / present absent, 48 shape_of_postorbital / irregular_trapezoid 'triangular,_apex_caudal', 49 Palpebral_ossifications / absent mosaic_of_bone_plates_present_in_orbit, 50 'Parietal-postorbital contact' / absent present, 51 'parietal-squamosal contact' / absent present, 52 'parietal-tabular contact' / absent present, 53 Postparietals / paired fused absent, 54 parietal_foramen / present absent, 55 postparietals / moderate large, 56 'postparietal-squamosal contact' / absent present, 57 Postparietal_length / 'large,_quadrangular' 'abbreviated_anteroposteriorly,_elongate_lateral_rectangle', 58 'squamosal-jugal contact' / present absent, 59 Tabular / present absent, 60 Posterolateral_projection_from_lateral_margin_of_tabular_above_squamosal_embayment / absent present, 61 "'Tabular horns"' / absent present, 62 Tabular_horns / parallel_or_slightly_divergent widely_divergent, 63 
Sq_forms_base_of_tabular_horn / absent present, 64 Lateral_line_canal_grooves / present absent, 65 Dermal_sculpturing / circular_pits shallow_ridges_and_grooves little_to_none, 66 premaxilla_anterior_margin / vertical overturned, 67 Maxilla_into_orbit / no yes, 68 Maxilla_into_external_naris / present absent, 69 Maxilla_entire_ventral_naris / absent present, 70 maxilla / longer_than_palatine shorter_than_palatine, 71 marginal_teeth / vertical turned_medially, 72 marginal_teeth_largest_anterior / absent present, 73 marginal_teeth / pointed_pegs blunt_pegs large_cones, 74 Number_of_premax_teeth / ' $>=10$ ' '5-9' ' $<5$ ', 75 Number_of_max_teeth / '>=30' '20-29' '<20', 76 teeth_laterally_compressed / no yes, 77 'Enlarged teeth mid-toothrow' / absent present, 78 teeth / simple_points multiple_cusps, 79 Multiple_Cusp_Orientation / 'Labio-lingual' 'antero-posterior', 80 Enamel_fluting / absent present, 81 'labyrinthine in-folding' / present absent, 82 occipital_profile / low_and_wide high_and_wide high_and_narrow, 83 supraoccipital / absent present, 84 Occipital_condyle / concave convex, 85 occipital_condyle / 'single,_with_basioccipital' double, 86 jugular_foramen / between_opistotic_and_exoccipit through_exoccipital, 87 jaw_articulation / posterior_to_occiput even_with_occiput anterior_to_occiput 'far_anterior_(>20\%_BSL)', 88 Internal_nares / widely_separated narrowly_separated, 89 Palatine_fangs / present absent, 90 Palatine_teeth / absent multiple_in_rows multiple_random, 91 LEP / absent present, 92 Anterior_palatine / short_anteromedial_process_articulating_with_vomer_at_choana 'long_anteromedial_process,_more_medial_than_lateral' palatine_absent, 93 Vomerine_fangs / present absent, 94 Vomer_teeth / absent 'present, in a signle row' 'present, as a field', 95 Intervomerine_depression / absent present, 96 Intervomerine_rostral_fenestration / absent present, 97 denticles_on_pterygoid / present absent, 98 teeth_on_pterygoid / absent present, 99 tooth_pedicely / absent present, 100 denticles_on_vomers / present absent, 101 denticles_on_palatines / present absent, 102 denticles_on_parasphenoid / present absent, 103 DELETED_was_Palatal_teeth / larger_than_marginals equal_to_marginals smaller_than_marginals, 104 parasphenoid / medial_of_stapes under_footplate_of_stapes, 105 Parasphenoid_basal_plate / 'roughly_quadrangular,_basipterygoid_articulations_narrowly_spaced' 'about as broad as long, articulations moderately distant' 'rectangular_laterally,_anteroposteriorly_narow,_basipterygoid_articulations_distant', 106 cultriform_process_contact_with_vomer / narrow broad, 107 basicranial_articulation / loose sutured_or_fused, 108 stapes / perforated_stem imperforate_stem no_stem, 109 Stapes_orientation / 'lateral,_towards_quadrate' 'dorsal,_towards_squamosal_embayment,_elongate_columella', 110 footplate_of_stapes / oval round palmate, 111 dorsal_process_of_stapes / absent present, 112 "'accessory ossicle"' / absent present, 113 pleurosphenoid / unossified ossified, 114 sphenethmoid / ossified unossified, 115 interpterygoid_vaccuities / wide 'narrow_("closed")' fused_at_midline, 116 pterygoids_contact_anteriorly / present absent, 117 'pterygoid-exoccipital contact' / absent present, 118 'Pterygoid-palatine suture' / present absent, 119 'Pterygoid-vomer contact' / present absent, 120 'lat process of pt into subtemp (transverse flange)' / absent present, 121 ectopterygoid / 'present_with_fang-pit_pair' 'present_lacking_fang-pit_pair' absent, 122 'Ectopterygoid-palatine width' / wider_than_maxilla narrower_than_maxilla, 123 "'pharangeobranchial pouches"' / absent present, 124 dentary / long short, 125 dentary_forms_coronoid_process / absent present, 126 surangular / normal reduced absent, 127 angular / narrow deep, 128 number_of_splenals / 21 0, 129 splenal_exposed_laterally / present absent, 130 meckelian_fossae / 2_or_more 1 0,131 'Ventral border of Meckel"s foss' / splenal angular, 132 retroarticular_process / absent present, 133 retroarticular_process / straight hooked, 134 articulation_to_tooth_row / above equal below, 135 'angular extends to (lat view)' / posterior_tooth_row middle_of_tooth_row, 136 number_of_coronoids / 321 0, 137 coronoid_teeth / present absent, 138 coronoid_teeth / larger_than_marginals equal_to_marginals smaller_than_marginals, 139 symphysis / dentary_and_splenal dentary_alone, 140 jaw_sculpture / present absent, 141 ossified_hyoids / present absent, 142 Gill_Osteoderms / absent 'present,_noninterdigitating' 'toothed,_intergiditating_rakers', 143 parahyoid / absent present, 144 number_of_accessory_articulation / 01 2_or_more, 145 number_of_presacrals / '>35' '25-35' '20-24' '<20', 146 DELETED_was_vertebral_development / 'arches,_then_centra' centra_and_arches_simultaneously, 147 caudal_processes_btw_depression / absent present, 148 trunk_intercentra / present absent, 149 trunk_neural_arch_to_centrum / loosely_articulated sutured fused, 150 base_of_neural_spine / equal_to_or_wider_than_haemal smaller_than_haemal_spine, 151 height_of_neural_spines / even alternating, 152 dorsal_neural_spine / narrow_and_smooth laterally_broad_and_sculpted, 153 'neural spine shape (lat)' / 'antpost_sides_parallel_(rect)' 'non-parallel_(triangular)', 154 Neural_spine_lateral_suface / smooth crenulated, 155 Pleurocentra / paired_rhachitomous closely_approaching_ventrally 'fused,_dominant_weight_bearing_element', 156 haemal_arches / present absent, 157 haemal_arches / 'loosely_articulated_(intercentr' 'fused_to_midlength_of_centrum', 158 haemal_arches / longer_than_or_equal_to_neurals shorter_than_neurals, 159 haemal_accessory_articulations / none one two, 160 haemal_arch_shape / 'non-parallel_(triangular)' 'parallel_(rectangular)', 161 tail / tapers deep_with_sudden_end, 162 Tail / 'elongate,_equal_to_or_exceeding_trunk_and_skull_length' 'forshortened,_markedly_shorter_than_trunk', 163 DELETED_was_trunk_arches / paired fused, 164 spinal_nerve_foramina / absent present, 165 
extended_transverse_processes / absent present, 166 transverse_process / on_arch_pedicle on_centrum, 167 'atlasaxis intercentra' / present absent, 168 Atlas_Anterior_centrum / same_size_as_posterior laterally_expanded, 169 atlas_centrum / multipartite single_notochordal single_odontoid, 170 atlas_neural_arch / loosely_articulated sutured_to_centrum fused_to_centrum, 171 atlas_parapophyses / on_centrum on_transverse_process absent, 172 atlas_neural_arch / paired sutured_at_midline fused_at_midline, 173 atlas_acessory_articulation / absent zygosphene zygantra, 174 Proatlantes / present absent, 175 second_cervical_arch / expanded_to_more_posterior equal_to_more_posterior shorter_than_more_posterior, 176 atlas_ribs / one_pair two_pairs absent, 177 cervical_rib_distal_shape / spatulate pointed, 178 ribs_anterior_to_sacrum / short long, 179 Ribs / 'at least as long as 3 vertebrae, curved' 'at least as long as 3 vertebrae, straight' shorter_than_3_vertebrae, 180 Costal_Process_at_rib_head / absent present, 181 number_of_sacrals / 12 3, 182 sacral_parapophysis / on_centrum on_transverse_process, 183 number_pairs_of_caudal_ribs / 5_or_more 43 2_or_fewer, 184 interclavicle_posterior_stem / no_or_short long, 185 interclavicle_posterior_stem / wide narrow, 186 interclavicle / diamond_shaped 't-shaped', 187 interclavicle_anterior_plate / broad narrow, 188 'interclavicle shape-diamond' / broad_diamond narrow_diamond, 189 interclavicle_anterior_fimbrati / present absent, 190 interclavicle_sculpture / present absent, 191 Cleithrum_head / aligned_along_anterior_rim_of_scapula posterodorsally_enlarged_head_wrapping_around_dorsal_scapula, 192 Cleithrum_head / 'dorsally_greatly_expanded,_much_wider_than_shaft' simple_rod_without_or_slight_dorsal_expansion, 193 Cleithrum / ossified unossified, 194 cleithrum / rounded_or_pointed_dorsally 't-_or_y-shaped', 195 proximal_clavicle_blades / widely_separate articulate_medially interdigitate, 196 supraglenoid_foramen / present absent, 197 number_coracoid_foramina / 01 2, 198 scapulocoracoid_occification / both scapula_only absent, 199 entepicondylar_foramen / present absent, 200 tortion_in_humerus / absent less_than_80_degrees more_than_80_degrees, 201 deltopectoral_crest / weak intermediate prominent, 202 Supinator_process / absent present, 203 humerus_length / 'long_(>4_trunk_centra)' short, 204 'radius:humerus' / '>=0.7' '0.5-0.7' '<0.5', 205 olecranon_process / unossified ossified, 206 carpals / fully_or_partially_ossified unossified, 207 basale_commune / absent present, 208 'number digits-manus' / 5_or_more 4 3, 209 pelvis / fused sutured poorly_ossified, 210 Anteriorly_inclined_ilium / absent present, 211 illiac_blade / 2_dorsal_processes narrowly_bifurcate single_blade, 212 'internal trochanter-articulatio' / disctinct continuous, 213 femoral_shaft / robust slender, 214 femur / long short, 215 tarsals / ossified unossified, 216 elongate_tibiale_and_fibulare / absent present, 217 DELETED_was_number_of_distal_tarsals / 6 5_or_fewer, 218 '"astragalus"' / absent present, 219 'number of digits, pes' / 5_or_more 4_or_less ;

\section{MATRIX}

Acanthostega $\quad 000100000100000 ? 0000000000100000010000000000000001 ? 0000000010$ ? 000000000000000 ?0000??00001000000000000000000000000100000000000000000?010000000001? 0000000000000000(0 1)00000000000000000000000000000000000002000000000001000000

Proterogyrinus $\quad 01000000(01) 00\{01\} 001 ? 00010000000 ? 0000010000000000000000 ? 1000000010$ ?? 000000000010000?0020000000000????000?1000000?0??000100000000000000?00?00\{0 12\}001000001? 00000000200001?0100000000000000?000000000010000000200120?1010010111000100

Greererpeton $\quad 02010000010001110000000001012(0$ 1)00000001000000000001?000(0 1)000000?? 000000000000000?000000?0001000000000110(0 1)00000000000100000000000000100?001010010000? 00000000000000??10100000?0000211100000?0100000001110012011110000201010??0

Seymouria_baylorensis $\quad 01000000000100110000000002000000020000100000000000$ ? 1000000000 ?? 000000000012010?000000000000000000000001020011??0102000010000000000(0 1)\{0 1\}?200020001002? 000000(0 1)020000100100000000001100000100110001001001020022101000000111100?00

Limnoscelis $\quad 01010100010100110001000002000000011001000000000001 ? 1100010000$ ?? 121000001022010 ?0001000111000100001000010000?0??0001100000000000101(0 1)0?001020110001? 000001002000000010000000000100000010011000 ??0100?0?0022101010010111000110

Balanerpeton $\quad 000000001011001100000000 ? 1010000010000000000000110 ? 0000000000$ ?? $100000000000000 ? 0000 ? 000000000000000000000000100000010001000000100000 ? 0001 ? 1010002$ ? 000000000000000?00000000?000020020000000000000000??0022001100110211000100

Dendrerpeton $\quad 000000000011001100000000 ? 1100000010000000000000100 ? 0000000000$ ?? $100000000000000 ? 000000 ? 000000000000000000000010000 ? 010001000000001110 ? 00$ ???1010002? 00000000000001 ??10000000?00?0?0020000000000000000010022001100\{0 1\}002?00?0??0

Eryops $\quad 01010000 ? 1$ (1000?000000?001??0000010100?00000000000?0000000000?? 100000000000010 ?000001?0000000?0??00???0?001?0????00100010000?00????0???????0?0?02? 00000000000000001000??????????0000??00?000?000000??0???????0?10?1???0?000

Branchiosauridae $\quad 311100001010001110000000 ? 100100002000020 ? ? ? 0000(0$ 1)10?0000010010?? 110100000010000?0000???(0 1)00(0 1)00001000?0001?200??????101001(0 1)010????????0????????020020000? 
00?0000?0?0000000?????0?1200200?00?000??000????210000101?120211010??0

Micromelerpetontidae (2 3)11100001010001110000100?1\{0 1\}000000(1 2)000000???0000110? 1000010010??010000000000000?00000???00(0 1)10001(0 1)0000000?0(0 1)0?0????

1010011000?????????????????010010000?00?0000?0?00000?0?????0?1210000?00?000??000????210001101? $120211010 ? ? 0$

Tersomius

$2 ? 010000\{01\} 0110011\{01\} 000011011100000020000(0$ 1)00010000110?0001000000?? $110\{01\} 0000000000(0$ 1)00(0 1)0001000001000100000000?0001?00?000100110100000000(0 1)0?010021010? 0??????????1????????????????????????????????????????????????????????????0???

Ecolsonia

0 ? $110000011100101000010011002010010000011210000000 ? 0001000000 ? ?$ $10000000001\{01\} 010 ? 000001$ ?000010001?0000000?000?0??00?01000100000000?0(0 1)0?0?00200?000?? 00010000000001011000????????????000?????????0000?0101?11??0?0?100110?0???

Acheloma $\quad 0 ? 010000011100 ? ? 000001001 ? 1020100100000111100 ? 0000 ? 0001000000$ ? 100000 ?

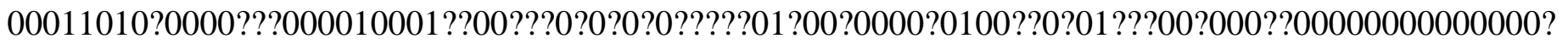
01000??????????002???????????000????01???????0\{0 1\}?0?????0???

Doleserpeton 3?0100001011001100000100111?0000020000200000000110?0000010000?? 1100000000000010010001 ?0011101(1 2)0?001000(0 1)?200?1???00010111210000000000?01002?010002?00(1 2)?0000200?0??110000?12220??2??200?????????010?????????????0??0?????0???

Micropholis $\quad 20(0$ 1)100000(0 1)11001(1 2)100000(0 1)011?0\{0 1\}000010000000000000(0 1)10? 0000001000 ??1?00000000\{0 1\}\{0 1\}000?000001?000110001100000000(0 2)10000? 0000100110100000011110010??1000003?000?00001?????011010?0002?0?1200200??0?00000010001? 1120001100100201000100

Eoscopus $\quad 2 ? 0100001 ? 11001110000110111 ? 000001000020(0$ 1)210000110?0000010010?? $110100000000000 ? 0000$ ???00001000000000000?0000100??101001101000000?\{0 1\}?0??0?0200? 0002000000000100001011000???0200?(0 1)200200100?00000010????01110?21001(0 1)0201000100

Tambachia 2?010000011100110000010011002010010000001110000000?0001000000?? 110100000011010 ?0000???000010000?0001110??000?00???0100010000??1 101 1\}1??0?01????01000??0???00? 00??????01?0???????????00?0?????????????????011001????\{0 1\}?0?????0???

Platyrhinops 11010000?011001?10000010?1010020210000200000000010?0000010010?? 11110000000000100 ?0?01?000010000???0?????010?1????00101110100000201?0??0????010001??02?0000100?? 0?110000102?2?1?200200?00?0????0100???0?1??0111010?2?1000??0

Amphibamus 31110000?011001110000000?1000020210000200000000110?000001001??? 1111000000000010010 ?0??000010?00?0010000?210010??01010111010000?????0?0??????10002??00?0000200?? 00110000?00?2?1?200200?00?00000010000?0??1?0100?1102?1?00??0

Gerobatrachus 311100001011001?100001101??000?02200002000000???0??0000010010???? 0100000000000?010????20100110??10?0??20??0??????00101111100???????0??1????1?0??3??01?????2??????11? 0??12??2?1?201200?????????0100?????1?00?1???1?2???0???0

Tuditanus $\quad 31011 ? 110111001000010000 ? 2000000010001 ? ? 000100000001 ? 000 ? 00 ? 0$ ? 110000 ? 00011000?011????10??001200000000?0100200000?10000???01001002?0?21???0010001?012?001021?????? $100011220201101000 ? 021111$ ??100001??2022001000110001000010

Asaphestera 22011?110111001100010000?20100000000010?0001000010010000000?0??\{0 $1\} 10000001010000$ ?0121010200100????01000?0??00????001110001?000?0100????20????110001??12? 00102???????10001122??011??000???1110??0????102002100?1???200?10?????

Hapsidopareion 3?011?010101001101??0000?2001000020001??0000000010010000110?0?? 120001000011000 ?0101110201100??0000011010100101010?1100010000110112?0?20???110000????0??0? 02????????00011212001?01??0????????????????????????00??202????????

Saxonerpeton

31011?110101001100010100?2011000020001??0001000000010000100?0?? 020001000011000?0110???201000??00000000??100??????11100010000110\{0 1\}1??1020????1100011011? 001021??????10001121?2011001000?21111?1110001??0020002100?10201000100

Pantylus 10011?11011100110001000002000101021001??0000000000010110000?0?? $101000000222010 ? 010101011020012000000011100010011$ ?01000002000100011(0 1)10202010000002? 01101010200000011000012202011101000 ?01111?1010002010022002100110211000110

Cardiocephalus_sternbergi 3?011?110111001010010000??000101031001??0001000000010(0 1)10000?0?? 12110001022211??1100010301100110011011121100100010010000?00001?0012?0?20202111000????????? 0?????????????????????????????????????????????????????????????????

Cardiocephalus_peabodyi 32011?110111001000010000?2001101131001??0001000010010(0 1)10000?0?? 121000?10222111011000103???0???????0??????0??0???????0????0?0111?1??0?20????110000??01?00102??????? $100001220 ? 01100020\{12\} 0$ ????????1000?0?1121012?0??202010????? 
Euryodus_primus

2?011?110111001000000000?2001102121001??0001000000010110000?0???? 1000010222010 ?1100011201100110000000121100?0???0?1000010000111112?11203??1?1000???02? 00102???????1000?????????????0???1111?1?????1??0(0 1)2101?100?102010?0???

Euryodus_dalyae $\quad 2 ? 011 ? 110111001000010000 ?(0$ 2)001102021001??0001000000010010000?0?? 121000010222010 ?010001020110?????00000021100000010?1000010000111112?0?203??111000???02? 00102???????10000122000100???0?0??????????????????????1????0?????????

Pelodosotis 13011?110111001000110000?2001000001001??0000000000010110010?0??12101? 010012010?01210102?1100????000??0211001021100110000?000\{0 1\}0111111020?021100000??01? 10102???????10001121?101100100?0?0111?11100011?10220021???00201000???

Micraroter 13011 ?110111001110110000?2000000000001??00010000100101(0 1)0010?0?? $121100010112010 ? 0101011201100120000000020100001010 ? 100000000010101$ ??1020???1100001? 00101010200001001000012200011000002?????????1000?0?1???0??????102110?????

Rhynchonkos 33011?110111001100010000?2000102131001??0001000010010010000?0?? 121000010012000 ?010111131110011001001101110000001101100010000100001110101011110000??02? 00102???????10000122?201121020??3??????????0????122012100\{0 1\}1020100010?

Microbrachis $\quad 32011$ ? $100111011100010000 ? 2010000020001$ ??0000000011(0 1)10000100?0?? 010000000(0 1)11000?010?01?201000??00000000?

110000000011100010000101001110000021001000101100010200000011010112121011000000020110 ? 00010000?102001100?21011110??00

Batropetes 32011?10111100110???01000?012102100001??00000000011120???00?0??12101?? 10012001101111??3???00????100110?120010000001?0?????001??11??101????1110003?

0120001020010000100011220?011000000001110?11???0102002201210?10020110?110

Utaherpeton 310????00??100101???0000??0?20000?0001??0000000?01???0???0??0??12010??001?

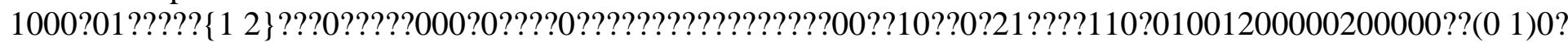
01?????????0000\{0 1\}?00?000(0 1)????????102201011?11?1?101???0

Stegotretus $3 ? 011$ ?1101110010000\{0 1\}0000?2001101020001??000100000001001000000?? 111001010222010?0101010210200120001000011100?????0010000020001?001110?00?0(0 1)0?10?0???11? 00102???????10001121?????????0???1111???????011012200210??2?00100????

Sauropleura_scalaris 210100000100001010001000?0012000001101??0000010101?10000000?0??1101(0 1)0001012000?011??1?000100????01011120000?????001?000?1100000100010003??1000011?01200011201010? 01010111222111210000010?0010011000??0100110000100211100?10

Ptyonius 110101000101001000010000?0012000001001??0000010101?10000000?0?? 110000000012000 ?011??1?001100110010001120100?????0100000?0100001?1??1101???1000022?112100(0 1)1201021001010112222211211000020?0000001000???10001001?12021111???1

Urocordylus 22010??0??000010000??????????0?00?1001?????00100?1???????0??0??1100???010?? 000?01?????00110?????000?1?2???0?????0010?0???1000?0?0??1100???100??22?1121001120111(0 1)10101011122221?210000030?000?000000??010201111?01021011???0

Keraterpeton_galvani 32011?000111001100010000?00120000100?1??00000000?1110010000? 101010000?00022000?010?11?20110?????0000111??0??????0020??????0100010111111???0000013? 012000112011000010101?1222111210000030?000?010012???10001011?\{0 1\}2021111???0

Batrachiderpeton ??011?000111001100010000?0011000010011??0000000001110010000? 110010100100012000?011?11?20110011000000111??01?????0020000011\{0 1\}10001011111120(1 2)0000013? 012000(0 1)12011000010101112221122?0?00?10?000?010012?????????????20?????????

Diceratosaurus ?1011?000111001110010000?2012000010011??00000000011100100000100010100? 00????00?010?11?2?110???????0??????01?????00101?????000?11011102?2011000013? 012001012010000010101?1222111210000030?000?010012??210001011?\{0 1\}2021111???0

Diplocaulus_magnicornis 01011?000111000?1001110102011100010011?? 00000010011100100000111010000100012000?010011\{0 1\}301100110010011110001????? 000110101010020010(0 1)0?202010000013?01200101201000001011111222112200100130000010???12?? 200001101?120??111???0

Diploceraspis 0 ?111?00011?1???0001110102012000010001?? 00000010011100100000111010000100012000?0100110301100??0010011110101????? 00011010001010110111020201000002??012001012010100?10111122221122???0?1?0?00010??? 12 ????????????????????????

Scincosaurus 33011?110111001100010000?20120000\{0 2\}0011??00000000000120???0000?? 010100000012000?01??11?301?00??0010?101?0101?????00110000100?0???????????01?000012? 012100012011110010001?1222?11210000?20?000?000002??0022001000010201000?10 
Adelogyrinus $\quad 2$ ? $\quad 211$ ?10021?1????0000000?20110000000000?00000010?111000000\{0 1\}10?? 0101???000?0000?01000012???0?????0?0001?0?00??????01??0??000000?00??100(0 1)???100000??010? 00102????????0001020220112??20???0?00000???0???2?????????????????????

Oestocephalus 230100?0010100111011000002012101030001??00001???0??0001001000?? 120100100010000 ?01200000011??????10??101?1?0????000100000100000001110?003??1110010?012? 000021????00111010122200121?21??0?????????00?????????????????????????

Phlegethontia 23011???0?1?1???????110002012000031001???0001???1???21???01?0??120101? 00022000?012000?2????????:10???1?0??020000001?0??010000??2?2?0?0?3??11100101012?000021???? 00111010\{1 2\}22200121?21??0?????????00?????????????????????????

Brachydectes 33011????1110010?1??0-000\{1 2\}012000?20001??00001???0?1101110?000?? 120100000012000?012101031100011001001111110?10100101100002001100111110203??1100000? 011000102000010100101121200112100000311000101100010011001(0 1)11?12021110??00

Eocaecilia 33011??0011?1????0000000?2012101101001??00011???0?110111000?0?? 1201000000000010010011 ?3011001100001110111000000??0110011\{1 2\}000???2???10103??1110000?002?00? 02?????0111010122?201121020013??????????????01200121002?0?011001?1

Albanerpetontidae ??011?????01001011??1-00?20?2000120001??00001???1?0?21???01?0??110100? 0001(1 2)1011011011?2???0???????0???????????????????????002?2?1110213??01?000(1 2)?012?00002?????? 011001122220122002001??????????1????01???1??00??0??10?0?0?

Salamanders ?2(0 1)11?????000010?0110-00?(1 3)1000002\{2 3\}0001??00001???0?1?21????1?0?? 120100?000(0 1)00010010011?(2 3)01(1 2)021\{1 2\}011011?110110(0 1)0\{0 1\}00?1010?102?0002?2?2?0?10\{2 3\} \{0 1\}1010(1 2)003(0 1)0120000020100100111011222201120020013????????1??111110001001120211000\{0 $1\} 00$

Triadobatrachus $\quad 31111$ ???1????????0??0-00????????22???020?0101???0?0?20????100??12?

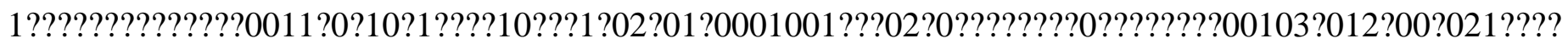
011010?1???20?1?002001??????????00???0110001100?(1 2)12?1001?0?

Frogs ?1111?????0?1????1??\{0 1\}-00?310?0002200002000101???0?0?20????1?0??120100? 000000010010011 ??0100111011011?1102(0 1)011\{0 1\}00?001011\{0 1\}2?0002?\{1 2\}12?0?113??01001030012? 000021?????1101011122201120020013?????????001100111001000101211001100

END;

BEGIN TREES;

Title Results;

LINK Taxa = Untitled_Taxa_Block;

TRANSLATE

1 Acanthostega,

2 Proterogyrinus,

3 Greererpeton,

4 Seymouria_baylorensis,

5 Limnoscelis,

6 Balanerpeton,

7 Dendrerpeton,

8 Eryops,

9 Branchiosauridae,

10 Micromelerpetontidae,

11 Tersomius,

12 Ecolsonia,

13 Acheloma,

14 Doleserpeton,

15 Micropholis,

16 Eoscopus,

17 Tambachia,

18 Platyrhinops,

19 Amphibamus,

20 Gerobatrachus,

21 Tuditanus, 
22 Asaphestera,

23 Hapsidopareion,

24 Saxonerpeton,

25 Pantylus,

26 Cardiocephalus_sternbergi,

27 Cardiocephalus_peabodyi,

28 Euryodus_primus,

29 Euryodus_dalyae,

30 Pelodosotis,

31 Micraroter,

32 Rhynchonkos,

33 Microbrachis,

34 Batropetes,

35 Utaherpeton,

36 Stegotretus,

37 Sauropleura_scalaris,

38 Ptyonius,

39 Urocordylus,

40 Keraterpeton_galvani,

41 Batrachiderpeton,

42 Diceratosaurus,

43 Diplocaulus_magnicornis,

44 Diploceraspis,

45 Scincosaurus,

46 Adelogyrinus,

47 Oestocephalus,

48 Phlegethontia,

49 Brachydectes,

50 Eocaecilia,

51 Albanerpetontidae,

52 Salamanders,

53 Triadobatrachus,

54 Frogs;

TREE Strict_consensus_of_MPs = (1,(3,((8,((6,7),((12,13,17)Trematopidae, $((9,10),((11,15),(16,((14,20)$, $(18,19))))))$ Dissorophoidea))Temnospondyli,(2,(4,(5,(46,(33,((22,(21,((23,24)Hapsidopareiontidae, ((25,36)Pantylidae,(30,31)Ostodolepididae,(34,(32,((26,27),(28,29))Gymnarthridae)))Recumbirostra))),(35,(45, (((37,(38,39))Urocordylidae,((40,41),(42,(43,44)))Diplocaulidae),((47,48)Aïstopoda,(49,(50,(51,(52, (53,54)Salientia)Batrachia)Parotoidia)Lissamphibia))))))))Amphibia)Tetrapoda)))));

TREE MP_1_of_4 = (1,(3,((8,((6,7),((17,(12,13))Trematopidae, $((9,10),((11,15),(16,((14,20),(18,19)))))))),(2$, (4,(5,(46,(33,((22,(21,((23,24),(((25,36),(30,31)),(34,(32,((26,27),(28,29)))))Recumbirostra))),(35,(45,(((37,(38,39)), $((40,41),(42,(43,44)))),((47,48),(49,(50,(51,(52,(53,54))))))))))))))))))$;

TREE MP_2_of_4 = (1,(3,((8,((6,7),((17,(12,13))Trematopidae, $((9,10),((11,15),(16,((14,20),(18,19)))))))),(2$, (4,(5,(46,(33,((22,(21,((23,24),((30,31),((25,36),(34,(32,((26,27),(28,29))))))Recumbirostra))),(35,(45,(((37,(38,39)), $((40,41),(42,(43,44)))),((47,48),(49,(50,(51,(52,(53,54))))))))))))))))))$;

TREE MP_3_of_4 = $(1,(3,((8,((6,7),((12,(13,17))$ Trematopidae,$((9,10),((11,15),(16,((14,20),(18,19)))))))),(2$, (4,(5,(46,(33,((22,(21,((23,24),(((25,36),(30,31)),(34,(32,((26,27),(28,29)))))Recumbirostra))),(35,(45,(((37,(38,39)), $((40,41),(42,(43,44)))),((47,48),(49,(50,(51,(52,(53,54))))))))))))))))))$;

TREE MP_4_of_4 = (1,(3,((8,((6,7), $((12,(13,17))$ Trematopidae, $((9,10),((11,15),(16,((14,20),(18,19)))))))),(2$, (4,(5,(46,(33,((22,(21,((23,24),((30,31),((25,36),(34,(32,((26,27),(28,29))))))Recumbirostra))),(35,(45,(((37,(38,39)), $((40,41),(42,(43,44)))),((47,48),(49,(50,(51,(52,(53,54))))))))))))))))))$;

TREE Strict_consensus_of_trees_up_to_1_step_longer $=(1,(2,3,4,5,8,(6,7),(12,13,17)$ Trematopidae, $((9,10)$, (11,15,(16,(18,19,(14,20))))),(46,(33,(21,22,25,26,27,32,34,35,36,(23,24)Hapsidopareiontidae,(28,29),

(30,31)Ostodolepididae,(45,49,50,(47,48)Aïstopoda,(37,(38,39))Urocordylidae,((40,41),(42,(43,44)))Diplocaulidae, (51,(52,(53,54)Salientia)Batrachia)Parotoidia))))Amphibia)Tetrapoda);

TREE Strict_consensus_of_trees_up_to_2_steps_longer $=(1,(2,3,4,5,(6,7), 8,(12,13,17)$ Trematopidae, $((9,10), 11,15,(14,16,18,19,20)),(46,21,22,(23,24) H a p s i d o p a r e i o n t i d a e, 25,26,27,(28,29)$, (30,31)Ostodolepididae,32,33,34,35,36,(37,38,39)Urocordylidae,((40,41),42,(43,44))Diplocaulidae,45, 
(47,48)Aïstopoda,49,50,(51,(52,(53,54)Salientia)Batrachia)Parotoidia)Amphibia)Tetrapoda);

TREE Strict_consensus_of_trees_up_to_3_steps_longer $=(1,(2,3,4,5,6,7,8,(9,10), 11$,

$(12,13,17)$ Trematopidae,14,15,16,18,19,20,(46,21,22,23,24,25,26,27,28,29,(30,31)Ostodolepididae,32,33,34,35,36,

(37,38,39)Urocordylidae,(40,41),42,(43,44),45,(47,48)Aïstopoda,49,50,51,(52,

(53,54)Salientia)Batrachia)Amphibia)Tetrapoda);

TREE Strict_consensus_of_trees_up_to_4_steps_longer $=(1,(2,3,4,5,6,7,8$,

$(9,10), 11,12,13,14,15,16,17,18,19,20,(46,21,22,23,24,25,26,27,28,29,30,31,32,33,34,35,36$,

(37,38,39)Urocordylidae,40,41,42,(43,44),45,(47,48)Aïstopoda,49,50,51,(52,

$(53,54)$ Salientia)Batrachia)Amphibia)Tetrapoda);

TREE Strict_consensus_of_trees_up_to_5_steps_longer $=(1,(2,3,4,5,6,7,8$,

$(9,10), 11,12,13,14,15,16,17,18,19,20,21,22,23,24,25,26,27,28,29,30,31,32,33,34,35,36$,

(37,38,39)Urocordylidae,40,41,42,(43,44),45,46,(47,48)Aïstopoda,49,50,51,52,(53,54)Salientia)Tetrapoda);

TREE [!Percentage not marked if 100. Four of the 367200 trees do not contain Amphibia.] 'Majority-rule consensus of trees up to 5 steps longer' $=(1,(3,((8),(6,7) 99,((17,(12,13) 61)$ Trematopidae, $((9,10),(11,15,(16$, ((14,20)91,(18,19)68)98)97)89)99)69)59)94_Temnospondyli,(2,(4,(5,(46,(33,((21,22,((23,24)99,((25,36)96,(30,31), (34,(32,((26,27)78,(28,29)97)89_Gymnarthridae)66)56)59_Recumbirostra)63)62,35,(45,(((37, (38,39)98)Urocordylidae,((40,41),(42,(43,44))89)99_Diplocaulidae)54,((47,48)Aïstopoda,(49,(50,(51,(52, (53,54)Salientia)Batrachia)99_Parotoidia)66_Lissamphibia)71)66)66)93)91)91)Amphibia)60_Tetrapoda)77)83)76))

TREE Bootstrap_tree $=(1: 0.0,(3: 100.0,(((8: 50.0,(17: 100.0$, (12:100.0,13:100.0)61:67.207458)83_Trematopidae:91.315681)24:50.0,((6:100.0,7:100.0)76:73.432388, ((9:100.0,10:100.0)91:87.416183,((11:100.0,15:100.0)30:29.816542,(16:100.0,((14:100.0,20:100.0)50:63.010063, (18:100.0,19:100.0)35:34.675461)41:45.568012)35:39.394554)25:23.766048)52:42.3649065)26:42.3649065)37_Te mnospondyli:62.265249999999995,(2:100.0,((4:100.0,5:100.0)39:43.098595,(46:100.0,(33:100.0,(35:100.0, ((21:100.0,22:100.0)40_Tuditanidae:33.360523,((23:100.0,24:100.0)47_Hapsidopareiontidae:51.669201, ((((25:100.0,36:100.0)52_Pantylidae:56.898338,(30:100.0,31:100.0)77_Ostodolepididae:79.032425)10:7.018339, (34:100.0,(32:100.0,((26:100.0,27:100.0)68:70.956215,

(28:100.0,29:100.0)67:64.295372)52_Gymnarthridae:52.899769)19:10.173872)7:10.173872)12_Recumbirostra:21. 328098,((45:100.0,((37:100.0,(38:100.0,39:100.0)75:78.576607)93_Urocordylidae:98.166664,

$((40: 100.0,41: 100.0) 88: 88.51355,(42: 100.0$,

(43:100.0,44:100.0)100:100.0)69:72.758209)83_Diplocaulidae:79.589012)50:48.661064)39_Nectridea:34.552895, ((47:100.0,48:100.0)96_Aïstopoda:97.81675,(49:100.0,(50:100.0,(51:100.0,(52:100.0,

(53:100.0,54:100.0)97_Salientia:99.193863)88_Batrachia:94.06057)70_Parotoidia:83.267189)23_Lissamphibia:30. 000544)22:25.682316)17:21.598787)19:29.115671)14:12.156971)9:10.932807)14:13.878294)29:35.719635)44:52. 283924)68_Amphibia:78.760185)28_Tetrapoda:35.696217)30:36.594379)46:40.75029):100.0);

END;

BEGIN ASSUMPTIONS;

OPTIONS DEFTYPE $=\quad$ unord PolyTcount $=\quad$ MINSTEPS;

TYPESET * UNTITLED = unord: 3 - 1517 - 2830 - 313335 - 3840 - 7376 - 8183 - 8688 - 102104 - 114116 - 125127129131 - 133135137139 - 143146 - 148150 - 154156 - 158160 - 169171173 - 174 176 - 178180182184 - 194196199202 - 203205 - 207210212 - 219, ord: 1 - 2162932343974 - 7582 87103115126128130134136138144 - 145149155159170172175179181183195197 - 198200 - 201 204208 - 209 211;

WTSET $*$ UNTITLED $=1: 1-219$;

\section{END;}

begin paup;

pset mstaxa = variable;

exclude 103146163 217;

END;

BEGIN NOTES; 
TEXT CHARACTER = 12 TEXT = recode_to_remove_lower_orbital_process;

TEXT TAXON = 1 CHARACTER = 16 TEXT = 'Neither process present, but lacrimal is excluded from orbit. See Clack, 2002: fig. 6A. Lacrimal excluded from orbital margin, apparently as in Gerobatrachus. Thus, inapplicable.';

TEXT TAXON $=4$ CHARACTER $=16$ TEXT $=$ Fine.;

TEXT TAXON $=5$ CHARACTER $=16$ TEXT $=$ 'Borderline, but OK.';

TEXT TAXON $=9$ CHARACTER $=16$ TEXT $=$ 'Fröbisch \& Schoch, 2009, fig. c clearly show that the absence of the ventral process reflects the immature status of the other specimens.';

TEXT TAXON $=11$ CHARACTER $=16$ TEXT $=$ FIne.;

TEXT TAXON $=12$ CHARACTER $=16$ TEXT $=$ LEP_covers_ventral;

TEXT TAXON = 15 CHARACTER $=16$ TEXT = 'See Schoch \& Rudibge 2005, fig. 3 B, E. At least some specimens have the ventral process.';

TEXT TAXON $=25$ CHARACTER $=16$ TEXT $=$ Fine.;

TEXT TAXON $=37$ CHARACTER $=16$ TEXT $=$ Probably_correct.;

TEXT TAXON = 51 CHARACTER $=16$ TEXT = 'Both processes present. See McGowan, 2002: fig. 5B.';

TEXT TAXON $=52$ CHARACTER $=16$ TEXT $=$ 'In Karaurids, the lacrimal is excluded from the orbit. See Ivachnenko, 1978: fig. 1a. But in Hynobius, the lacrimal has both processes ; see Carroll \& Holmes, 1980, fig. 4A.';

TEXT $\quad$ TAXON $=22$ CHARACTER $=22$ TEXT $=$ Fine.;

TEXT TAXON = 23 CHARACTER = 22 TEXT = 'Borderline. See Carroll \& Gaskill, 1978: 27 and fig. 13.';

TEXT TAXON = 24 CHARACTER = 22 TEXT = 'Fine. Borderline. See Carroll \& Gaskill, 1978: fig. 22.';

TEXT TAXON = 25 CHARACTER $=22$ TEXT = 'Fine. See Carroll \& Gaskill, 1978: fig. 25.';

TEXT TAXON $=26$ CHARACTER $=22$ TEXT $=$ 'Fine. See Carroll \& Gaskill, 1978: fig. 30.';

TEXT TAXON $=27$ CHARACTER $=22$ TEXT = 'Fine. See Carroll \& Gaskill, 1978: fig. 31 32. ';

TEXT TAXON $=28$ CHARACTER $=22$ TEXT = 'Fine. See Carroll \& Gaskill, 1978: fig. 37.';

TEXT TAXON = 29 CHARACTER = 22 TEXT = 'Fine. See Carroll \& Gaskill, 1978: fig. 43.';

TEXT TAXON = 3 CHARACTER $=26$ TEXT $=$ 'Greererpeton changed from 0 to 1 . See Smithson (1982).^n';

TEXT TAXON $=5$ CHARACTER $=26$ TEXT = 'Limnoscelis changed from 0 to 2. See Fracasso 1983.^n';

TEXT TAXON = 21 CHARACTER = 26 TEXT = 'See Carroll \& Gaskill, 1978: fig. 4.';

TEXT TAXON = 22 CHARACTER = 26 TEXT = 'See Carroll \& Gaskill, 1978: figs 6, 7.';

TEXT TAXON $=23$ CHARACTER $=26$ TEXT = 'See Carroll \& Gaskill, 1978: fig. 4.';

TEXT TAXON = 24 CHARACTER = 26 TEXT = 'See Carroll \& Gaskill, 1978: figs 17, 22.';

TEXT TAXON = 25 CHARACTER = 26 TEXT = 'See Carroll \& Gaskill, 1978: fig. 25.';

TEXT TAXON $=26$ CHARACTER $=26$ TEXT $=$ Premaxilla_apparently_not_well_preserved.;

TEXT TAXON = 27 CHARACTER $=26$ TEXT = 'See Carroll \& Gaskill, 1978: fig. 32.';

TEXT TAXON $=28$ CHARACTER $=26$ TEXT = 'See Carroll \& Gaskill, 1978: figs 36, 37.';

TEXT TAXON = 29 CHARACTER = 26 TEXT = 'See Carroll \& Gaskill, 1978: figs 43, 43.';

TEXT TAXON $=30$ CHARACTER $=26$ TEXT = 'See Carroll \& Gaskill, 1978: fig. 48.';

TEXT TAXON = 31 CHARACTER = 26 TEXT = 'See Carroll \& Gaskill, 1978: figs 52-54.';

TEXT TAXON $=32$ CHARACTER $=26$ TEXT = 'See Carroll \& Gaskill, 1978: figs 63, 64';

TEXT TAXON = 33 CHARACTER = 26 TEXT = 'See Carroll \& Gaskill, 1978: fig. 76.';

TEXT TAXON $=34$ CHARACTER $=26$ TEXT $=$ 'Not well preserved. See Carroll \& Gaskill, 1971.';

TEXT TAXON = 35 CHARACTER = 26 TEXT = 'Not well preserved. See: Carroll R. L., P. Bybee, \& W. D. Tidwell. 1991. The oldest microsaur (amphibia). Journal of Paleontology 65: 314-322. $\wedge \mathrm{n}^{\wedge} \mathrm{n}^{\prime}$;

TEXT TAXON = 36 CHARACTER = 26 TEXT = 'See figs. 6, 10, in: Berman D. S., D. A. Eberth, \& D. B. Brinkman. 1988. Stegotretus agyrus a new genus and species of microsaur (amphibian) from the PermoPennsylvanian of New Mexico. Annals of Carnegie Museum 57: 293-323. $n^{\wedge} n^{\prime}$;

TEXT TAXON = 37 CHARACTER = 26 TEXT = 'See Bossy \& Milner, 1998: fig. 53A, B.';

TEXT TAXON = 38 CHARACTER = 26 TEXT = 'See Bossy \& Milner, 1998: fig. 53G.';

TEXT TAXON = 39 CHARACTER = 26 TEXT = 'See Bossy \& Milner, 1998: fig. 53F.';

TEXT TAXON $=40$ CHARACTER $=26$ TEXT $=$ 'See Bossy \& Milner, 1998: fig. 56, 57.';

TEXT TAXON = 41 CHARACTER $=26$ TEXT = 'See Bossy \& Milner, 1998: fig. 56B.';

TEXT TAXON = 42 CHARACTER = 26 TEXT = 'See Bossy \& Milner, 1998: fig. 56C.';

TEXT TAXON = 43 CHARACTER = 26 TEXT = 'See Bossy \& Milner, 1998: fig. 56E.'; 
TEXT TAXON = 44 CHARACTER = 26 TEXT = 'See Bossy \& Milner, 1998: fig. 56D.';

TEXT TAXON = 45 CHARACTER = 26 TEXT = 'See Bossy \& Milner, 1998: fig. 56C.';

TEXT TAXON $=46$ CHARACTER $=26$ TEXT = 'Andrews \& Carroll, 1991: fig. 7';

TEXT TAXON $=47$ CHARACTER $=26$ TEXT $=$ 'Carroll, 1998: fig. 7.';

TEXT TAXON $=48$ CHARACTER $=26$ TEXT $=$ 'Figs 2, 3 in: Anderson J. S. 2002. Revision of the Aïstopod genus Phlegethontia (Tetrapoda-Lepospondyli). Journal of Paleontology 76: 1029-1046.';

TEXT TAXON = 49 CHARACTER = 26 TEXT = 'Wellstead, 1991, figs. 2, 3 (reconstructions), suggest state 2. Figs 7, 8 (specimen drawings) suggest states 1 or 2. ;';

TEXT TAXON = 50 CHARACTER $=26$ TEXT $=$ 'See Jenkins et al., figs 1, 2, 4, 7.';

TEXT TAXON = 51 CHARACTER = 26 TEXT = 'See Estes, 1969: fig. 2; Fox \& Naylor, 1982: figs 1, 2; McGowan, 2002: fig. 5.';

TEXT TAXON = 52 CHARACTER = 26 TEXT = 'Karaurus has state 1 (Ivachnenko, 1978: fig. 1). Hynobiidae has states 3 (Hynobius tsuensis) or 1 (Batrachuperus sinensis), or indeterminate (Hynobius naevius), according to Carroll \& Holmes, 1980: fig. 4. Cryptobranchidae has state 2, according to Carroll \& Holmes, 1980: fig. 4. Ambystomatidae has state 2 (fig. 6). Plethodontids have state 3 (fig. 7). Salamandrids have state 3 (fig. 8A) or indeterminate (fig. 8B). Proteidae has state 3 (fig. 9). Amphiumidae has state 3 (fig. 10). Sirenidae has state 3 (fig. 11). If this is optimized (unordered) on the phylogeny in fig. 8 of this paper:^nWiens J. J., R. M. Bonett, \& P. T. Chippindale. 2005. Ontogeny discombobulates phylogeny: paedomorphosis and higher-level salamander relationships. Systematic Biology 54: 91-110.^nStates 1 or 3 may be primitive for the whole clade (including Karaurus). Coded as such.';

TEXT TAXON = 54 CHARACTER = 26 TEXT = 'According to Duellman \& Trueb, 1986, we find the following conditions (figs. 13-17 and 13-18): Barbourula busuquanensis (Discoglossidae), state 3. Rhinophryus dorsalis (Rhinophrynidae), state 3, etc. Most have state 3, although a few may have state 0.';

TEXT TAXON = 49 CHARACTER = 34 TEXT = 'Changed Brachydectes from 2 (convex) to 1 (straight). See Wellstead, 1991: figs 2, 3, and especially, 8.^n';

TEXT TAXON = 50 CHARACTER = 34 TEXT = 'Changed Eocaecilia from 2 (convex) to 3 (undulating). See Jenkins et al, 2007: figs 1, 2.^n';

TEXT TAXON = 51 CHARACTER = 39 TEXT = 'Changed from 2 to ? (there is no otic notch).';

TEXT CHARACTER = 43 TEXT = not_as_margin_of_otic_notch;

TEXT CHARACTER = 51 TEXT = 'Inapplicable when the supratemporal is present (5(0)).';

TEXT TAXON = 33 CHARACTER = 51 TEXT = 'Polymorphic. See Carroll \& Gaskill, 1978; figs 77, 78.';

TEXT TAXON = 53 CHARACTER = 59 TEXT = Triadobatrachus_changed_from_0_to_1.;

TEXT TAXON = 50 CHARACTER = 74 TEXT = '10-12 positions (Jenkins et al., 2007: 298).';

TEXT TAXON $=51$ CHARACTER $=74$ TEXT $=$ 'Changed Albanerpetontidae from $?$ to 1. McGowan (2000: 367) wrote, about Albanerpeton nexuosus, that ?Premaxillae with a complete tooth row have eight $(n=4)$ or nine $(n$ = 5) loci.? McGowan 2002: 5, ?there are 8?10 teeth in Celtedens?, so the average is presumably about 9 teeth. In Albanerpeton pannonicus, Vencel \& Gardner, 2005: 1282 wrote: ?The number of tooth positions ranges from 7 to 10 $(\mathrm{x}=8 ; \mathrm{n}=25)$ on the premaxilla, 15 ?21 $(\mathrm{x}=18 ; \mathrm{n}=16)$ on the maxilla and 22 ?29 $(\mathrm{x}=25 ; \mathrm{n}=27)$ on the dentary.? $\wedge$ n';

TEXT TAXON = 52 CHARACTER $=74$ TEXT $=$ 'Salamanders were dealt with as for the dorsal process of the premaxilla, character 26 (same phylogeny and references). Distribution: Karaurus, about 25 teeth, according to the text (Ivachnenko, 1978: 364); 9 teeth in Batrachuperus sinensis (Hynobiidae); more than 10 in Cryptobranchus, Ambystoma; about 8 in Phaeognathus hubrichti (Plethodontidae), about 4 in Salamandra atra (Salamandridae), but more than 10 in Notophthalmus viridescens (Salamandridae), more than 10 in Necturus (Proteidae). About 5 in Amphiuma (Amphiumidae) and in Habrosaurus (Sirenidae). The ancestral condition is ambiguous. Coded as polymorphic. $\wedge^{\prime}$ ';

TEXT TAXON $=54$ CHARACTER $=74 \mathrm{TEXT}=$ 'Frogs were dealt in the same way. Viaerella seems to have numerous teeth, although this is based only on the reconstruction of Shubin \& Jenkins (1995: fig. 3a).

Eodiscoglossus has at least 15 tooth positions (Evans et al., 1990: 302). Ascaphus has well over 10 teeth (Carroll \& Holmes, 1980: fig. 3).^nEvans S. E., A. R. Milner, \& F. Mussett. 1990. A discoglossid frog from the Middle Jurassic

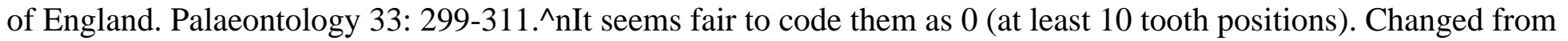


TEXT TAXON = 51 CHARACTER $=75$ TEXT $=$ 'Changed Albanerpetontidae from $?$ to 1\&2. McGowan (2000: 367) wrote, about Albanerpeton nexuosus, that ?No maxilla available to me has an intact tooth row: UALVP 39973 (Fig. 3C) and 39977 (Fig. 3E) preserve the anterior 17 and 18 tooth positions, respectively, and I estimate that each bone probably held about 25 loci when complete.? In Albanerpeton pannonicus, Vencel \& Gardner, 2005: 1282 wrote: The number of tooth positions ranges from 7 to $10(x=8 ; n=25)$ on the premaxilla, 15 ? 21 $(x=18 ; n=16)$ on the maxilla and 22?29 ( $x=25 ; n=27)$ on the dentary. I believe that $x$ represents the average. McGowan $(1999$ : 536) wrote, about Albanerpeton arthridion: ?Neither maxilla has an intact tooth row: OMNH 33284 preserves the posteriormost 14 loci; OMNH 34072 preserves 12 loci along the anterior part of the tooth row, but the anteriormost end of the row may be absent. Judging by the overlap between OMNH 33284 and 34072, I estimate that the maxilla held about 23 loci when complete.?^n';

TEXT TAXON $=52$ CHARACTER $=75$ TEXT $=$ 'Urodeles were dealt with as for the dorsal process of the premaxilla (ch. 26), except that the states were ordered. Karaurus, up to 40 positions (Ivachnenko, 1979: 364). Batrachuperus sisnesis (Hynobiidae) has 16 ?20 teeth (Carroll \& Holmes, 1980: fig. 4B). Cryptobranchus and Ambystoma, Salamandra, and Plethodon glutinosus (Noble, 1931: fig. 81) have more than 30. Notophthalmus (Salamandridae) has about 22 teeth, and Tylotriton (Salamandridae), barely 20. Amphiuma has 17-18 teeth and Habrosaurus (Sirenidae) has about 9 teeth. The ancestral condition is unambiguously $0 . \wedge n^{\prime}$;

TEXT TAXON = 20 CHARACTER $=84$ TEXT $=$ 'In Gerobatrachus, the occipital condyle is apparently not preserved! Anderson et al. (2008) wrote: ?The parabasisphenoid complex is fragmentary, preserving only portions of the basicranial articulation, and a portion of the cultriform process; however, the overall shape of the parasphenoid plate can be determined to have been much wider than long, as is common for amphibamids, branchiosaurids, frogs and salamanders.? The figures show no condyle. Coding changed from 1 to ?^${ }^{\wedge}$;

TEXT TAXON = 12 CHARACTER = 85 TEXT = 'Ecolsonia $:$ Changed from 0 to 1. See Berman et al., 1985: p. 16 "...the fused basioccipital-exoccipital comples has been somewhat rotated anteriorly so that the articular surfaces of the distinctly double occipital condyle face mainly ventrallyt rather than posteriorly."';

TEXT TAXON $=14$ CHARACTER $=85$ TEXT $=$ Fine.;

TEXT TAXON = 20 CHARACTER $=85$ TEXT = 'In Gerobatrachus, the occipital condyle is apparently not preserved! Anderson et al. (2008) wrote: "The parabasisphenoid complex is fragmentary, preserving only portions of the basicranial articulation, and a portion of the cultriform process; however, the overall shape of the parasphenoid plate can be determined to have been much wider than long, as is common for amphibamids, branchiosaurids, frogs and salamanders." The figures show no condyle. Coding changed from 1 to ?^n';

TEXT TAXON $=21$ CHARACTER $=85$ TEXT $=$ 'Tuditanus. Changed from 0 to ?. See Carroll \& Baird, 1968: 12 : « The surfaces that formed part of the occipital condyle cannot be seen. This is confirmed by the illustrations, although a non-diagnostic reconstruction of this area in venteral is given in Carroll \& Gaskill, 1978 : fig. 4.^n';

TEXT TAXON = 22 CHARACTER = 85 TEXT = 'Asaphestera. Changed from 0 to 1 . See Carroll \& Gaskill, 1978 : fig. $6 \mathrm{E} . \wedge$ n';

TEXT TAXON $=23$ CHARACTER $=85$ TEXT $=$ 'Hapsidopareion. Changed from 0 to 1 . See Carroll \& Gaskill, 1978 : fig. 13B.^n';

TEXT TAXON $=24$ CHARACTER $=85$ TEXT = 'Saxonerpeton. Changed from 0 to ?. See Carroll \& Gaskill, 1978: 34 . The condyle was probably double, but this area is poorly preserved. $\wedge^{n}$;

TEXT TAXON = 25 CHARACTER = 85 TEXT = 'Pantylus. Changed from 0 to 1 . See Carroll \& Gaskill, 1978 : fig. $25 . \wedge n^{\prime} ;$

TEXT TAXON = 26 CHARACTER $=85$ TEXT $=$ 'Cardiocephalus sternbergi. Changed from 0 to 1 . See Carroll \& Gaskill, 1978 : fig. 30B, C. $\wedge^{\prime}$;

TEXT TAXON = 27 CHARACTER $=85$ TEXT $=$ 'Cardiocephalus peabodyi. Changed from 0 to 1 . See Carroll \& Gaskill, 1978 : fig. 31. Although this area is poorly exposed, the shape of the atlantal articular surfaces indicate a typical microsaurian cotyle. $\wedge^{n}$;

TEXT TAXON = 28 CHARACTER = 85 TEXT = 'Euryodus primus. Changed from 0 to 1 . See Carroll \& Gaskill, 1978: figs 37, 38, 41. Although this area is poorly exposed, the shape of the atlantal articular surfaces indicate a typical microsaurian cotyle. $\wedge^{n}$;

TEXT TAXON = 29 CHARACTER = 85 TEXT = 'Euryodus dalyae. Changed from 0 to 1 . See Carroll \& Gaskill, 1978: figs 42?44. ^n';

TEXT TAXON $=30$ CHARACTER $=85$ TEXT $=$ 'Pelodosotis. Changed from 0 to 1 . See Carroll \& Gaskill, 
1978 : fig. $48 \mathrm{~A} . \wedge^{\prime}{ }^{\prime} ;$

TEXT TAXON $=31$ CHARACTER $=85$ TEXT $=$ 'Micraroter. Changed from 0 to 1 . See Carroll \& Gaskill, 1978 : fig. 53.^n';

TEXT TAXON = 32 CHARACTER $=85$ TEXT = 'Rhynchonkos. Changed from 0 to 1 . See Carroll \& Gaskill, 1978 : figs 63 ?65 (under the name Goniorhynchus). $\wedge$ ';

TEXT TAXON = 33 CHARACTER = 85 TEXT = 'Microbrachis. Changed from 0 to 1 . See Carroll \& Gaskill, 1978: fig. 77?79; Laurin \& Vallin, 2004: 62.^n';

TEXT TAXON = 34 CHARACTER = 85 TEXT = 'Batropetes. Changed from 0 to ?. See Carroll \& Gaskill, $1971: 454$. This area is not well exposed. ${ }^{\wedge} \mathrm{n}^{\prime}$;

TEXT TAXON = 36 CHARACTER = 85 TEXT = 'Stegotretus. Changed from 0 to 1 . See Berman et al., 1988: 310.';

TEXT TAXON = 37 CHARACTER = 85 TEXT = 'Sauropleura scalaris. Changed from 0 to 1. See Bossy, 1976: 96 and fig. 25b.^n';

TEXT TAXON = 39 CHARACTER = 85 TEXT = 'Urocordylus. Changed from 0 to ?. See Bossy, 1976: 209. She wrote that it must be ?semidouble?, which suggests an intermediate morphology. ${ }^{\wedge} \mathrm{n}$;

TEXT TAXON = 14 CHARACTER = 86 TEXT = 'In Doleserpeton, it was not described, so we changed the coding from 1 to ? ';

TEXT TAXON = 54 CHARACTER $=86 \mathrm{TEXT}=$ 'In anurans, there is no prootic, and the exoccipital is fused in most taxa to form a compound bone, so the position of this foramen cannot be assessed relative to the opisthotic. There is no place for it to exit but through the exoccipital. Anurans were thus changed from 1 to ?';

TEXT TAXON = 54 CHARACTER = 87 TEXT = 'Highly variable in frogs. Unknown in Viaerella. Posterior in Barbourula (Discoglossidae) (Duellman \& Trueb, 1986: fig. 13-17), Caudiverbera (Leptodactylidae). Even with occiput in Leptodactylus. Anterior in Ascaphus (Noble, 1932: fig. 81A; Carroll \& Holmes, 1980: fig. 3), Pelobates (Pelobatidae), Rhamphophyrne (Bufonidae). Far anterior in Rhinophyus (check spelling) (Rhinophyrnidae), Notaden (Myobatrachidae), Brachycephalus (Brachycephalidae). Highly variable in hylids (Duellman \& Trueb, 1986: fig. 1318). Can conservatively be scored ? (initially 0$). \wedge n^{\prime}$;

TEXT CHARACTER $=89$ TEXT = 'Characters 89 and 90 remade, see text.';

TEXT TAXON = 53 CHARACTER = 89 TEXT = 'Triadobatrachus has a preserved palatine, illustrated and described by Rage \& Rocek (1989). It appears to be edentulous, so it was coded as such (changed from ?).^n';

TEXT TAXON = 54 CHARACTER = 89 TEXT = 'Frogs never have palatine teeth (Duellman \& Trueb, 1986: 318).';

TEXT CHARACTER = 90 TEXT = 'Characters 89 and 90 remade, see text.';

TEXT TAXON $=3$ CHARACTER $=90$ TEXT = Smithson_1982.;

TEXT TAXON = 5 CHARACTER $=90$ TEXT = Fracasso_1983_fig._2.;

TEXT TAXON = 15 CHARACTER $=90$ TEXT = Schoch_\&_Rubidge_2005_fig._1D.;

TEXT TAXON $=33$ CHARACTER $=90$ TEXT = Carroll_\&_Gaskill_1978.;

TEXT TAXON $=49$ CHARACTER $=90$ TEXT $=$ 'Brachydectes changed from 1 to $0 . \wedge n$;

TEXT TAXON $=53$ CHARACTER $=90 \mathrm{TEXT}=$ 'Triadobatrachus has a preserved palatine, illustrated and described by Rage \& Rocek (1989). It appears to be edentulous, so it was coded as such (changed from ?).';

TEXT TAXON $=54$ CHARACTER $=90 \mathrm{TEXT}=$ 'Frogs changed from $1 \& 2$ to 0 , since there are no teeth on the palatine. ${ }^{\wedge} \mathrm{n}$;

TEXT CHARACTER = 91 TEXT = 'if_ex_fused_in_os_basiale,_if_pt_contacts_the_ex_area';

TEXT TAXON $=5$ CHARACTER $=94$ TEXT $=$ 'Limnoscelis changed from 2 to $0 . \wedge$ n';

TEXT TAXON = 14 CHARACTER = 94 TEXT = 'Doleserpeton, changed from $1 / 2$ to $1 \& 2$. ';

TEXT TAXON = 19 CHARACTER $=94$ TEXT = 'Amphibamus changed from 1 to $0 . \wedge n$ ';

TEXT TAXON $=20$ CHARACTER $=94$ TEXT $=$ Gerobatrachus_changed_from_1_to_0.;

TEXT TAXON = 54 CHARACTER = 94 TEXT = 'Correct. See Duellman \& Trueb, 1986: 317. Also see Carroll \& Holmes, 1980, fig 3B (Vieraella), Duellman \& Trueb, 1986: fig. 13-17 A (Barbourula busuquanensis, Discoglossidae), C (Pelobates fuscus, Pelobatidae), E (Leptodactylus bolivianus, Leptodactylidae), Noble, 1931, fig. 80b (Rana adspersa), 81A (Ascaphus truei).^n'; 
TEXT TAXON = 37 CHARACTER = 97 TEXT = 'Fine. See Bossy, 1976: fig 24.';

TEXT TAXON = 39 CHARACTER = 97 TEXT = 'Fine. See Bossy, 1976: fig 69.';

TEXT TAXON $=41$ CHARACTER $=97$ TEXT $=$ 'Eocaecilia: Changed from 1 to 0. See Jenkins et al., 2007: figs $1,3,7 .{ }^{\prime} \mathrm{n}^{\prime}$;

TEXT TAXON $=20$ CHARACTER $=99$ TEXT $=$ 'Changed Gerobatrachus from 0 to ?. See Marjanovic \& Laurin, 2008: 179.^n';

TEXT TAXON = 45 CHARACTER = 99 TEXT = 'Milner 1980: 392 says they"re pedicellate. No answer yet. The teeth of Scincosaurus have never been mentioned before or since.';

TEXT TAXON = 47 CHARACTER = 99 TEXT = 'Interpretation of Carroll, 1998: fig. 4B.';

TEXT TAXON = 48 CHARACTER = 99 TEXT = 'Germain, 2008.';

TEXT TAXON $=20$ CHARACTER $=100$ TEXT $=$ 'Changed from 1 to 0 . Gerobatrachus has denticles, not teeth, according to the illustrations (contra the text) provided by Anderson et al. (2008). They are much smaller than the marginal teeth (about a third).^n';

TEXT TAXON = 54 CHARACTER = 100 TEXT = 'Frogs also sometimes have teeth, but not denticles.';

TEXT TAXON $=52$ CHARACTER $=102$ TEXT $=$ 'Changed frogs and salamanders from 0 to 1. Carroll \& Holmes (1980) show no denticles on the parasphenoid of any urodele, although salamandrids are shown as having a row of teeth. Noble (1931: fig. 81b) shows that plethodontids can have patches of teeth (I would not call these denticles, given that they are as large as marginal teeth). Given the deeply nested position of salamandrids and plethodontids, this is surely not the primitive condition for urodeles. $\wedge^{n}$;

TEXT TAXON = 53 CHARACTER = 102 TEXT = 'Triadobatrachus also lacked denticles (Rage \& Rocek, 1989).^n';

TEXT TAXON = 54 CHARACTER $=102$ TEXT $=$ 'Noble (1931: fig. 81a) shows that Ascaphus lacks denticles on the parasphenoid. Duellman \& Trueb (1986: figs 13-17 and 13-18) show no parasphenoid denticles on any anuran. $\wedge$ n';

TEXT CHARACTER = 103 TEXT = 'Correlated to lots of other stuff, see text.';

TEXT TAXON = 20 CHARACTER $=105$ TEXT $=$ 'The parasphenoid of Gerobatrachus is extremely fragmentary; it seems fair to score it as ? See Anderson et al., 2008 (the illustration; the text contradicts it).';

TEXT TAXON $=21$ CHARACTER $=105$ TEXT = 'Tuditanus. Changed from 0 to 1 . See Carroll \& Gaskill, 1978 : fig. $4 . \wedge$ n';

TEXT TAXON = 23 CHARACTER $=105$ TEXT = 'Hapsidoparerion. Changed from 0 to 1 . See Carroll \& Gaskill, 1978 : fig. 13.^n';

TEXT TAXON = 24 CHARACTER $=105$ TEXT = 'Saxonerpeton. Changed from 0 to 1. See Carroll \& Gaskill, 1978 : fig. 22.^n';

TEXT TAXON = 26 CHARACTER = 105 TEXT $=$ 'Cardiocephalus sternbergi. Changed from 0 to 1 . See Carroll \& Gaskill, 1978 : fig. 30.^n';

TEXT TAXON $=28$ CHARACTER $=105$ TEXT $=$ 'Euryodus primus. Changed from 0 to 1 . See Carroll \& Gaskill, 1978 : fig. 36?38.^n';

TEXT TAXON = 29 CHARACTER $=105$ TEXT = 'Euryodus delyae. Changed from 0 to 1 . See Carroll \& Gaskill, 1978 : fig. 42?43.^n';

TEXT TAXON $=30$ CHARACTER $=105$ TEXT $=$ 'Pelodosotis. Changed from 0 to 1 . See Carroll \& Gaskill, 1978 : fig. $48 . \wedge$ n';

TEXT TAXON = 31 CHARACTER = 105 TEXT = 'Microrator. Changed from 0 to 1. See Carroll \& Gaskill, 1978 : fig. $53 . \wedge n^{\prime}$;

TEXT TAXON = 32 CHARACTER = 105 TEXT = 'Rhynchonkos. Changed from 0 to 1 . See Carroll \& Gaskill, 1978 : figs 63?65.^n';

TEXT TAXON $=33$ CHARACTER $=105$ TEXT $=$ 'Microbrachis. Changed from 0 to 1 . See Carroll \& Gaskill, 1978 : fig. $77 . \wedge$ n';

TEXT TAXON = 36 CHARACTER $=105$ TEXT = 'Stegotretus. Changed from 0 to 1 . See Berman et al., 1988: fig. 8.^n';

TEXT TAXON $=37$ CHARACTER $=105$ TEXT $=$ Borderline.;

TEXT TAXON = 38 CHARACTER = 105 TEXT = 'Ptyonius. Changed from 0 to 1. See Bossy, 1976: fig. 49 and Bossy \& Milner, 1998: fig. 55B.^n'; 
TEXT TAXON = 39 CHARACTER = 105 TEXT = 'Urocordylus. Changed from 0 to ?. Bossy \& Milner, 1998: fig. 55A.^n';

TEXT TAXON $=41$ CHARACTER $=105$ TEXT $=$ 'Batachiderpeton. Changed from 0 to ?. See Bossy \& Milner, 1998: fig. 57B. The parasphenoid is shown, but has a strange morphology unlike any other state, and seem poorly preserved, if at all, posteriorly. $\wedge$ n';

TEXT TAXON = 44 CHARACTER $=105$ TEXT $=$ 'Diploceraspis. Changed from 0 to 1. See Beerbower, 1963: fig. 4. A bit unlike others, but closer to 2 than to $0 . \wedge$ ';

TEXT TAXON $=45$ CHARACTER $=105$ TEXT = 'Scincosaurus. Changed from 0 to 1. See Bossy \& Milner, 1998: fig. 57D.^n';

TEXT TAXON = 46 CHARACTER $=105$ TEXT = 'Adelogyrinus. Changed from 0 to ?. See Andrews \& Carroll, 1991: fig. 6. If it was like Palaeomolgophis, it probably had state 1 (fig. 2).^n';

TEXT TAXON $=47$ CHARACTER $=105$ TEXT $=$ 'Oestocephalus. Changed from 0 to 1. See Carroll, 1998: fig. $3 . \wedge n^{\prime} ;$

TEXT TAXON = 49 CHARACTER $=105$ TEXT $=$ 'Brachydectes changed from 1 to 1. See Wellstead, 1991: fig. 2.^n';

TEXT TAXON $=50$ CHARACTER $=105$ TEXT = 'Eocaecilia changed from 1 to 1 . See Jenkins et al., 2007.^n';

TEXT TAXON = 52 CHARACTER = 105 TEXT = 'Salamanders changed from 1 to 1 . See Carroll \& Holmes, 1980.^n';

TEXT TAXON = 4 CHARACTER = 113 TEXT = '=orbitosphenoid_of_White_1938_(Romer,_1956)';

TEXT TAXON $=4$ CHARACTER $=120$ TEXT $=$ Changed_from_0_to_1.;

TEXT TAXON $=5$ CHARACTER $=120$ TEXT $=$ Changed_from_0_to_1.;

TEXT TAXON $=7$ CHARACTER $=120$ TEXT $=$ Milner_1996_fig._6.;

TEXT TAXON = 9 CHARACTER = 120 TEXT = 'Boy 1978, 1986, 1987.';

TEXT TAXON = 21 CHARACTER = 120 TEXT = 'Unknown (C\&G fig. 108, Carroll \& Baird 1968).';

TEXT TAXON $=22$ CHARACTER $=120$ TEXT $=$ C\&G_fig._108;

TEXT TAXON $=23$ CHARACTER $=120$ TEXT $=$ C\&G_fig._108;

TEXT TAXON $=24$ CHARACTER $=120$ TEXT = C\&G_fig._108;

TEXT TAXON = 26 CHARACTER = 120 TEXT = 'Precisely intermediate (C\&G fig. 30).';

TEXT TAXON $=28$ CHARACTER $=120$ TEXT = C\&G_fig._109;

TEXT TAXON $=29$ CHARACTER $=120$ TEXT = C\&G_fig._109;

TEXT TAXON $=32$ CHARACTER $=120$ TEXT $=$ 'C\&G fig. 64 is somewhat borderline, but can still be counted. Fig. 63 is unambiguously state 1.';

TEXT TAXON = 33 CHARACTER $=120$ TEXT = Vallin_\&_Laurin_2004.;

TEXT TAXON = 34 CHARACTER $=120$ TEXT = 'Too incomplete to tell (Carroll 1991 fig. 5B).';

TEXT TAXON $=37$ CHARACTER $=120$ TEXT $=$

Bossy_\&_Milner_1998_fig._55C_is_juvenile._This_is_interesting_because_S._pectinata_has_state_1.;

TEXT TAXON = 38 CHARACTER = 120 TEXT = 'Bossy \& Milner 1998 fig. 55B: absent on the left side, present on the right...';

TEXT TAXON = 46 CHARACTER $=120$ TEXT = 'Palate unknown (Andrews \& Carroll 1991).';

TEXT TAXON $=50$ CHARACTER $=120$ TEXT $=$ Jenkins_et_al._2007.;

TEXT TAXON $=52$ CHARACTER $=120$ TEXT $=$ 'Changed from 0\&1 to 0. See Carroll \& Holmes, 1980. Hynobiids seem to be polymorphic, but the flange is absent in Cryptobranchus and all other urodeles figured in that paper, except for very weak flanges in Ambystoma maculatum and Tylotriton, but even in these two genera, the structure is so slight that it can be considered absent.';

TEXT TAXON = 53 CHARACTER = $120 \mathrm{TEXT}=$ 'Changed from 0/1 to 0. See Rage \& Rocek, 1989: fig. 2B.';

TEXT TAXON $=54$ CHARACTER $=120$ TEXT $=$ 'Changed from 0\&1 to 0/1. See text.';

TEXT CHARACTER = 121 TEXT = 'triangular=non_parallel-sided_rect=parallel-sided';

TEXT TAXON $=14$ CHARACTER $=121$ TEXT $=$ 'Changed Doleserpeton from 1 to 2. See Bolt, 1969. ${ }^{\wedge}$ ';

TEXT TAXON $=25$ CHARACTER $=121$ TEXT $=$ 'Changed Pantylus from 1 to 2. See Carroll \& Gaskill, 1978: fig. 25.^n';

TEXT TAXON = 36 CHARACTER = 121 TEXT = 'Changed from 1 to 2: Berman et al. 1988: 308.';

TEXT TAXON $=49$ CHARACTER $=121$ TEXT $=$ 'Changed Brachydectes from 1 to 2. See Wellstead, 1991: 
fig. 2.^n';

TEXT TAXON $=50$ CHARACTER $=121$ TEXT $=$ 'Changed Eocaecilia from 1 to 2. See Jenkins et al, 2007, fig. 1, and text (that region is supposedly hidden). That is true, to a small extent, but the drawings and pictures show plainly that there could not be one. The quote of Nussbaum and Wilkinson (1989) cannot be substantiated; personal observations by one of us (ML) in Marvalee Wake?s collection have failed to reveal a single gymnophionan ectopterygoid, and no more recent investigation has substantiated the presence of this bone. -- Changed to 1 or 2 because a very small one (as found in several extant caecilians) could have been present; Jenkins et al. 2007: 304.';

TEXT TAXON = 52 CHARACTER $=121 \mathrm{TEXT}=$ 'Changed salamanders from 1 to 2. See Carroll \& Holmes, 1980.^n';

TEXT TAXON = 53 CHARACTER $=121$ TEXT $=$ 'Changed Triadobatrachus from 1 to 2. See Rage \& Rocek, 1989.^n';

TEXT TAXON $=54$ CHARACTER $=121$ TEXT $=$ 'Changed frogs from 1 to 2 . See Duellman \& Trueb, 1986: figs $13-17$ and $13-18 .^{\wedge}$ ';

TEXT CHARACTER = 131 TEXT = 'at_least_one_zygo"s_width_again_from_centrum';

TEXT TAXON $=50$ CHARACTER $=138$ TEXT $=$

'is_second_row_of_equal_teeth,_but_pseudentary,_no_coronoid';

TEXT CHARACTER $=146$ TEXT $=$ 'When this is coded as simultaneous, this probably just reflects a lack of temporal resolution. There is widespread agreement about this among developmental biologists (e.g., BinindaEmonds et al., 2003: 341). This character should be deleted; it is scored for very few taxa anyway. $\wedge^{n B i n i n d a-}$ Emonds O. R. P., J. E. Jeffrey, \& M. K. Richardson. 2003. Is sequence heterochrony an important evolutionary mechanism in mammals? Journal of Mammalian Evolution 10: 335-361.^n';

TEXT TAXON = 35 CHARACTER = 146 TEXT = 'Changed Utaherpeton from ? to 0. See Carroll \& Chorn, 1995: fig. 4b. ^n';

TEXT CHARACTER = 153 TEXT = 'triangular=non_parallel-sided__rect=parallel-sided';

TEXT CHARACTER = 165 TEXT = 'at_least_one_zygo"s_width_again_from_centrum';

TEXT TAXON = 37 CHARACTER = 168 TEXT = 'Perhaps initially based on Bossy \& Milner, 1998: fig. 59C, that is a bit ambiguous. Bossy, 1976: fig. 25B suggests an expanded anterior surface. Confirmed by text, p. 102: "the lateral facets for the exoccipitals are only slightly expanded, so that the anteroir face of the atlas is not much broader than the more posterior centra." Thus, there is some expansion. Changed to 1.';

TEXT TAXON = 38 CHARACTER = 168 TEXT = 'Ptyonius. Changed from 0 to 1. See Bossy, 1976: fig. 51a. Again, the expansion is very modest, but it is there. ${ }^{\wedge} n '$;

TEXT TAXON = 39 CHARACTER = 168 TEXT = 'Urocordylus. Changed from 0 to 1. See Bossy, 1976: 215: ?Its anterior face is slightly concave and broadened laterally, probably for articulation with the exoccipital?.';

TEXT TAXON $=40$ CHARACTER $=168$ TEXT $=$ 'Keraterpeton. Changed from 0 to ?. Does not seem to be known, although a specimen certainly has a preserved atlas (but in dorsal view, which hides the centrum). See Huxley \& Wright, 1867: plate XIX, and Jaekel, 1903. ^nJaekel O. 1903. Ueber Ceraterpeton, Diceratosaurus und Diplocaulus. Neues Jahrbuch für Mineralogie, Geologie und Paläontologie 109-134. $\wedge^{\wedge} \mathrm{n}^{\wedge} \mathrm{n}^{\wedge} \mathrm{n}^{\prime}$;

TEXT TAXON $=42$ CHARACTER $=168$ TEXT $=$ Changed_from_0_to_?._Seems_unknown.;

TEXT TAXON $=45$ CHARACTER $=168$ TEXT $=$ Changed_from_0_to_?._Seems_unknown.;

TEXT TAXON = 46 CHARACTER $=168$ TEXT = 'Correct. See Andrews \& Carroll, 1991: fig. 6.';

TEXT TAXON $=49$ CHARACTER $=168 \mathrm{TEXT}=$ 'Brachydectes changed from 0 to 1. See Wellstead, 1991: figs 11C, 18.';

TEXT TAXON = 6 CHARACTER = 179 TEXT = 'See our Cont. Zool. paper (2008).';

TEXT TAXON = 7 CHARACTER = 179 TEXT = 'See our Cont. Zool. paper (2008).';

TEXT TAXON $=12$ CHARACTER $=179$ TEXT = 'All preserved ribs are long and "moderately curved"

(Berman et al. 1985).';

TEXT TAXON = 13 CHARACTER = 179 TEXT = 'See our Cont. Zool. paper (2008).';

TEXT TAXON = 27 CHARACTER = 179 TEXT = 'See our Cont. Zool. paper (2008).';

TEXT TAXON = 28 CHARACTER = 179 TEXT = 'See our Cont. Zool. paper (2008) and the text.';

TEXT TAXON = 32 CHARACTER = 179 TEXT = 'See our Cont. Zool. paper (2008).'; 
TEXT TAXON $=36$ CHARACTER $=179$ TEXT $=$ 'Unknown and more or less unknowable (Berman et al. 1988: 312).';

TEXT TAXON = 46 CHARACTER = 179 TEXT = Andrews_\&_Carroll_1991_fig._6.;

TEXT TAXON $=47$ CHARACTER $=179$ TEXT $=$ Baird_1964_fig._1.;

TEXT TAXON $=48$ CHARACTER $=179$ TEXT $=$ Baird_1964_fig._1.;

TEXT TAXON = 50 CHARACTER = 179 TEXT = 'The ribs are tiny, tiny, tiny! (Jenkins et al., 2007)';

TEXT TAXON = 21 CHARACTER = 181 TEXT = 'Completely impossible to tell (Carroll \& Baird 1968, figures 4 to 7).';

TEXT TAXON $=27$ CHARACTER $=181 \mathrm{TEXT}=$ 'The fossil ends in the middle of the second sacral (Carroll \& Gaskill 1986: 57, fig. 31).';

TEXT TAXON = 30 CHARACTER = 181 TEXT = 'Completely unknown (Carroll \& Gaskill 1978: 85 and fig. 58A).';

TEXT TAXON = 32 CHARACTER = 181 TEXT = 'Impossible to tell (Carroll \& Gaskill 1978 fig. 70).';

TEXT TAXON = 35 CHARACTER $=181$ TEXT = 'Carroll et al. 1991:318 actually_say_ "It is uncertain whether it was a second sacral or a first caudal" (and then go on to point out that "The ilium is so narrow that it is unlikely to have accommodated more than a single sacral rib", but let"s be generous).';

TEXT TAXON = 53 CHARACTER = 183 TEXT = 'Can"t see a reason to exclude states 1 and 2 (Rage \& Rocek 1989: 11).';

TEXT TAXON $=37$ CHARACTER $=191$ TEXT $=$ 'Changed Sauropleura scalaris from 0 to 1 . See Bossy, 1976: fig. 33.';

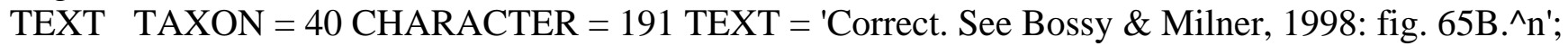

TEXT TAXON = 49 CHARACTER = 191 TEXT = 'See Wellstead, 1991: fig. 19D.';

TEXT TAXON = 15 CHARACTER = 192 TEXT = 'May be correct. See plate II from Broili \& Schrödre 1937. Better, see Schoch \& Rubidge, 2005: fig. 6D.^nBroili F. \& J. Schröder. 1937. Beobachtungen an Wirbeltieren der Karrooformation. XXV. Über Micropholis Huxley. Sitzungsberichte der Bayerischen Akademie der Wissenschaften 19-38.^nSchoch R. R. \& B. S. Rubidge. 2005. The amphibamid Micropholis from the Lystrosaurus Assemblage Zone of South Africa. Journal of Vertebrate Paleontology 25: 502-522.';

TEXT TAXON = 37 CHARACTER $=192$ TEXT $=$ 'Changed Sauropleura scalaris from 0 to 1 . See Bossy, 1976: fig. 33.';

TEXT TAXON $=38$ CHARACTER $=192$ TEXT $=$ 'Changed Ptyonius from 0 to 1. See Bossy, 1976: fig. 57a. $\wedge^{\prime}$;

TEXT TAXON = 39 CHARACTER = 192 TEXT = 'Borderline, but correct. See Bossy, 1976: fig. 77a.';

TEXT TAXON = 49 CHARACTER = 192 TEXT = Changed_from_0_to_1.;

TEXT TAXON = 1 CHARACTER = 201 TEXT = 'Changed from 0 to 2. See Coates 1996: fig. 16.';

TEXT TAXON $=2$ CHARACTER $=201$ TEXT $=$ 'Changed Proterogyrinus from 0 to 2. See Holmes, 1984: fig. 26.';

TEXT TAXON = 3 CHARACTER = 201 TEXT = 'Changed Greererpeton from 1 to 2. See Godfrey, 1989: fig. 18.';

TEXT TAXON = 49 CHARACTER = 201 TEXT = 'Correct. See Wellstead, 1991: fig. 21A-D.';

TEXT TAXON = 50 CHARACTER = 201 TEXT = 'Changed Eocaecilia from 2 to 0. See Jenkins et al., 2007: fig. 41.';

TEXT TAXON = 52 CHARACTER = 201 TEXT = 'Salamanders: Weak in Chunerpeton (Cryptobranchidae; Gao \& Shubin, 2003: figs 1, 2), Ranodon (Hynobiidae; Averianov, 1995: fig. 4), Palaeoamphiuma (Amphiumidae; Rieppel \& Grande, 1998: fig. 5), Necturus (Proteidae; Wischnitzer, 1979: fig. 2-8). Moderate in Parahynobius betfianus (Veanczel, fig. 2E). The primitive condition is clearly for a weak crest. Changed from 2 to $0 . \wedge n^{\prime}$;

TEXT TAXON = 54 CHARACTER = 201 TEXT = 'Frogs: Prominent in Latonia (Discoglossidae; Rocek, 1994: fig. 17); intermediate in Beleaphryne (Discoglossidae; Sanchiz \& Alcover, 1982: figs 1-3); weak in Eoxenopoides reuningi (Pipidae; Estes, 1977: fig. 8), Thoraciliacus (Trueb, 1999: fig. 2), Pipa pipa (Trueb et al., 2000: fig. 7), Xenopus arabiensis (Henrici \& Báez, 2001: figs 2-4). Intermediate seems a reasonable guess about the primitive condition. $\wedge^{\wedge}$;

TEXT TAXON = 51 CHARACTER = 203 TEXT = 'Changed Albanerpetontidae from 0 to 1. See McGowan 
2002: fig. 3 for Celtedens.';

TEXT TAXON = 38 CHARACTER = 206 TEXT = ' Correct. See Bossy 1976: 168.';

TEXT TAXON = 39 CHARACTER = 206 TEXT = ' Probably correct. See Bossy 1976: 226.';

TEXT TAXON = 49 CHARACTER = 206 TEXT = 'Correct. See Wellstead, 1991: 32';

TEXT TAXON $=20$ CHARACTER $=207$ TEXT $=$ 'Changed Gerobatrachus from 1 to ? See Marjanovic \& Laurin 2008.^ $\mathrm{n}^{\wedge} \mathrm{n}^{\prime}$;

TEXT TAXON = 3 CHARACTER = 208 TEXT = 'Changed (Coates 1996:415). See text.';

TEXT TAXON = 7 CHARACTER = 208 TEXT = 'Changed (Holmes et al. 1998); see text.';

TEXT TAXON = 13 CHARACTER = 208 TEXT = 'State 2 can be excluded (Olson 1941).';

TEXT TAXON = 15 CHARACTER = 208 TEXT = 'Changed (Schoch \& Rubidge 2005: 512).';

TEXT TAXON = 17 CHARACTER = 208 TEXT = 'State 2 can be excluded (Sumida et al. 1998).';

TEXT TAXON = 24 CHARACTER $=208$ TEXT = 'Nothing can be ruled out (C\&G 38).';

TEXT TAXON = 32 CHARACTER $=208$ TEXT $=$ ' 4 are preserved, but a higher number cannot be excluded based on the preservation (C\&G: 111)';

TEXT TAXON $=39$ CHARACTER $=208$ TEXT $=$ Bossy_\&_Milner_1998.;

TEXT TAXON $=40$ CHARACTER $=208$ TEXT $=$ Contradictions_in_the_literature._See_text.;

TEXT TAXON $=42$ CHARACTER $=208$ TEXT = Contradictions_in_the_literature._See_text.;

TEXT CHARACTER = 217 TEXT $=$ 'The three cases of 6 are obviously not homologous: in Acanthostega it"s the fibulare, in Tuditanus the postminimus or a sesamoid or who knows what, and in salamanders the prehallux. Therefore excluded from all analyses.';

TEXT TAXON = 49 CHARACTER = 219 TEXT = 'Correct. See Wellstead, 1991: 25.';

Version 4.0 87;

LastModified -1017388859;

FileSettings editor '0' '0' '92' '1';

Singles 010;

Editor 00011001111111100100010010 '0' '24'

Geneva '9' '100' '1'

all;

EditorPosition '44' '5' '643' '987';

TreeWindowPosition '46' '6' '719' '974';

ListWindow Characters closed Geneva '9' '50' '10' '273' '644'

ListWindow Taxa open Geneva '9' '479' '360' '273' '295'

000;

ListWindow Trees closed Geneva '9' '564' '39' '129' '393';

ListWindow TypeSets closed Geneva '9' '50' '10' '276' '490';

ListWindow WtSets closed Geneva '9' '50' '10' '276' '490';

ListWindow ExSets closed Geneva '9' '50' '10' '276' '490';

ListWindow CharSets closed Geneva '9' '50' '10' '276' '490';

ListWindow TaxSets closed Geneva '9' '50' '10' '276' '490';

ListWindow CharPartitions closed Geneva '9' '50' '10' '276' '490';

ListWindow CharPartNames closed Geneva '9' '50' '10' '276' '490';

ListWindow WtSets closed Geneva '9' '50' '10' '276' '490';

ChartWindowPosition '52' '30' '686' '964';

StateNamesSymbols open Geneva '9' '10' '540' '754' '192' '220';

WindowOrder Data States List Taxa;

OtherSymbols \& / 00 ? -;

Correlation '0' '0' '1000' '0' '0'

10011010;

Salmo 00000001;

EditorFile '2';

ExportHTML_ MOSS '100' 110000;

PrettyPrint 10;

EditorToolsPosition '492' '136' '115' '165';

TreeToolsPosition '583' '25' '126' '138';

TreeWindowProgram 10; 
TreeWindow 0000;

Continuous '0' '3'

1

Calculations 0000001;

SummaryMode '0' '0'

Charts Geneva '9' (

NexusOptions '0' '0' '50'

TipLabel '1';

TreeFont Geneva '9' (

TreeShape 1.01 .0 1110;

TraceLabels 0101;

ChartColors '0' '0' '65535' '9' '0'

ChartBiggestSpot 1;

ChartPercent 10;

ChartBarWidth '10'

0;
normal )
001011011;

normal );

ChartVerticalAxis 10101;

ChartMinMax '0';

TraceAllChangesDisplay '1'

1

BarsOnBranchesDisplay '0' '0' '60000' '10000' '10000' '10000' '10000' '60000' '65000' '65000' '65000' '6' '1' 0000101;

ContinuousBranchLabels 0;

AllStatesBranchLabels 1;

IndexNotation '2' 1 ;

PrintTree 10.00 '2' '2' '2' '2' '2' '2' '2' '2' '2' '2' '2'

Geneva '10' (

normal )

Geneva '9' ( normal )

Geneva '9' (

Geneva '9' (

bold )

Geneva '9' (

normal )

Geneva '9' (

normal )

Geneva '9' ( normal )

'0' '0' '-15492' '456' '636' '35' '678' '35' '678' '288' '24' '35' '1' '1' '1' '1' '29440' '-17792' '-39' '4' '-40' '0' '1' '2' '4' '8' '8' '8' '0' '2'

MatchChar 00 .; 0100110000000000010100000111000 ;

EntryInterpretation 00;

ColorOptions 00;

TreeTools '0' '5' '4' '0' '10' '4' '0'

EditorTools '0' '0' '0' '1000' '0' '0' '6' '3' '1'

PairAlign '2' '2' '3' '2' '1' '1' '2' '1' '3'

00100111111101110; 100010101110011;

BothTools '1'; 1010 ;

END;

BEGIN MESQUITECHARMODELS;

ProbModelSet * UNTITLED = 'Mk1 (est.)': 1 - 219;

END;

Begin MESQUITE;

MESQUITESCRIPTVERSION 2;

TITLE AUTO;

tell ProjectCoordinator;

getEmployee \#mesquite.minimal.ManageTaxa.ManageTaxa;

tell It;

setID 0 5128558849605471043;

tell It;

setDefaultOrder 013435362342373839404143474849525351456789101112

131415171819202122232425262728293132333016464450 45;

attachments ;

endTell;

endTell;

getEmployee \#mesquite.charMatrices.ManageCharacters.ManageCharacters;

tell It; 
setID 0 8479452511181763361;

tell It;

setDefaultOrder 012345678910111213141516171819202122232425262728 29303132333435363738394041424344454647484950515253545556575859606162636465 666768697071727374757677787980818283848586878889909122193949596979899100101 102103104105106107108109110111112113114115116117118119120121122123124125126127 128129130131132133134135136137138139140141142143144145146147148149150151152153 154155156157158159160161162163164165166167168169170171172173174175176177178179 180181182183184185186187188189190191192193194195196197198199200201202203204205 206207208209210211212213214215216217 218;

endTell; attachments ;

checksumv 02262862292 null;

endTell;

getWindow;

tell It;

suppress;

setResourcesState false false 100;

setPopoutState 400;

setExplanationSize 0;

setAnnotationSize 0;

setFontIncAnnot 0;

setFontIncExp 0;

setSize 1920 1079;

setLocation 0 22;

setFont SanSerif;

setFontSize 10;

getToolPalette;

tell It;

endTell;

desuppress;

endTell;

getEmployee \#mesquite.trees.ManageTrees.ManageTrees;

tell It;

showTrees 0 \#mesquite.lists.TreesList.TreesList;

tell It;

setTreeBlock 1;

getWindow;

tell It;

newAssistant \#mesquite.lists.NumForTreeList.NumForTreeList;

tell It;

suppress;

setValueTask \#mesquite.trees.NumberOfTaxa.NumberOfTaxa;

desuppress;

endTell;

newAssistant \#mesquite.lists.TreeListRooted.TreeListRooted;

newAssistant \#mesquite.lists.TreeListPolys.TreeListPolys;

newAssistant \#mesquite.lists.TreeListPolyAssumption.TreeListPolyAssumption;

getTable;

tell It;

rowNamesWidth 327;

endTell;

setExplanationSize 30;

setAnnotationSize 20;

setFontIncAnnot 0;

setFontIncExp 0;

setSize 1820 1012; 
setLocation 0 22;

setFont SanSerif;

setFontSize 10;

getToolPalette;

tell It;

setTool mesquite.lists.TreesList.TreesListWindow.ibeam;

endTell;

endTell;

showWindow;

endTell;

showTreeBlocks \#mesquite.lists.TreeblockList.TreeblockList;

tell It;

getWindow;

tell It;

newAssistant \#mesquite.lists.TreeblocksListNumber.TreeblocksListNumber;

newAssistant \#mesquite.lists.TreeblocksListTaxa.TreeblocksListTaxa;

setExplanationSize 30;

setAnnotationSize 20;

setFontIncAnnot 0;

setFontIncExp 0;

setSize 1820 1012;

setLocation 0 22;

setFont SanSerif;

setFontSize 10;

getToolPalette;

tell It;

setTool mesquite.lists.lib.ListableVectorWindow.ibeam;

endTell;

endTell;

setActive;

showWindow;

endTell;

getEmployee \#mesquite.trees.BasicTreeWindowCoord.BasicTreeWindowCoord;

tell It;

makeTreeWindow \#5128558849605471043

\#mesquite.trees.BasicTreeWindowMaker.BasicTreeWindowMaker;

tell It;

suppressEPCResponse;

setTreeSource \#mesquite.trees.StoredTrees.StoredTrees;

tell It;

setTreeBlock 1;

toggleUseWeights off;

endTell;

setAssignedID 1293.1239345682121.8984554425152804462;

getTreeWindow;

tell It;

popAsTile false;

popOut;

setExplanationSize 30;

setAnnotationSize 20;

setFontIncAnnot 0;

setFontIncExp 0;

setSize 1121 708;

setLocation 3 34;

setFont SanSerif;

setFontSize 10; 
getToolPalette;

tell It;

setTool mesquite.trees.NodeNamer.NodeNamerExtra.nodeNamer;

endTell;

getTreeDrawCoordinator

\#mesquite.trees.BasicTreeDrawCoordinator.BasicTreeDrawCoordinator;

tell It;

suppress;

setTreeDrawer \#mesquite.trees.SquareTree.SquareTree;

tell It;

setNodeLocs \#mesquite.trees.NodeLocsStandard.NodeLocsStandard;

tell It;

branchLengthsToggle off;

toggleScale on;

toggleBroadScale off;

toggleCenter on;

toggleEven on;

endTell;

setEdgeWidth 6;

orientUp;

toggleCorners off;

endTell;

setBackground White;

setBranchColor Black;

showNodeNumbers off;

showBranchColors on;

labelBranchLengths off;

centerBrLenLabels on;

showBrLensUnspecified on;

showBrLenLabelsOnTerminals on;

setBrLenLabelColor 00 255;

setNumBrLenDecimals 6;

desuppress;

getEmployee \#mesquite.trees.BasicDrawTaxonNames.BasicDrawTaxonNames; tell It;

setColor Black;

toggleColorPartition on;

toggleShadePartition off;

toggleShowFootnotes on;

toggleNodeLabels on;

toggleCenterNodeNames off;

toggleShowNames on;

namesAngle ?;

endTell;

endTell;

setTreeNumber 1 ;

setDrawingSizeMode 0;

toggleLegendFloat on;

scale 0 ;

toggleTextOnTree off;

showWindow;

newAssistant \#mesquite.trees.TreeLegendMaker.TreeLegendMaker; tell It;

setOffsetsX 4;

setOffsetsY 4;

getLegendsVector;

tell It; 
distributeCommands;

setBounds 44217 39;

setOffsetX 4;

setOffsetY 4;

endDistributeCommands;

endTell;

newLegendItemNoCalc \#mesquite.trees.TreeValueUsingMatrix.TreeValueUsingMatrix; tell It;

getEmployee \#mesquite.parsimony.TreelengthForMatrix.TreelengthForMatrix; tell It;

getEmployee \#mesquite.parsimony.ParsCharSteps.ParsCharSteps; tell It;

setModelSource

\#mesquite.parsimony.CurrentParsModels.CurrentParsModels; endTell;

endTell;

getEmployee \#mesquite.charMatrices.CharMatrixCoordIndep.CharMatrixCoordIndep; tell It;

setCharacterSource \#mesquite.charMatrices.StoredMatrices.StoredMatrices; tell It;

setDataSet \#8479452511181763361;

endTell;

endTell;

endTell;

calculate;

endTell;

endTell;

desuppressEPCResponse;

getEmployee \#mesquite.trees.ColorBranches.ColorBranches;

tell It;

setColor Red;

removeColor off;

endTell;

getEmployee \#mesquite.ornamental.BranchNotes.BranchNotes;

tell It;

setAlwaysOn off;

endTell;

getEmployee \#mesquite.ornamental.ColorTreeByPartition.ColorTreeByPartition;

tell It;

endTell;

colorByPartition off;

getEmployee \#mesquite.ornamental.DrawTreeAssocDoubles.DrawTreeAssocDoubles;

tell It;

setOn on;

toggleShow consensusFrequency;

setDigits 4;

writeAsPercentage off;

toggleCentred on;

toggleHorizontal on;

setFontSize 10;

setOffset 0 ;

endTell;

getEmployee \#mesquite.trees.TreeInfoValues.TreeInfoValues;

tell It;

panelOpen false;

endTell;

endTell; 
endTell;

getEmployee \#mesquite.charMatrices.BasicDataWindowCoord.BasicDataWindowCoord; tell It;

showDataWindow \#8479452511181763361

\#mesquite.charMatrices.BasicDataWindowMaker.BasicDataWindowMaker;

tell It;

getWindow;

tell It;

getTable;

tell It;

rowNamesWidth 110;

endTell;

setExplanationSize 30;

setAnnotationSize 120;

setFontIncAnnot 0;

setFontIncExp 0;

setSize 1820 912;

setLocation 0 22;

setFont SanSerif;

setFontSize 10;

getToolPalette;

tell It;

setTool mesquite.charMatrices.BasicDataWindowMaker.BasicDataWindow.ibeam; endTell;

setTool mesquite.charMatrices.BasicDataWindowMaker.BasicDataWindow.ibeam;

colorCells \#mesquite.charMatrices.NoColor.NoColor;

colorRowNames \#mesquite.charMatrices.TaxonGroupColor.TaxonGroupColor;

colorColumnNames \#mesquite.charMatrices.CharGroupColor.CharGroupColor;

colorText \#mesquite.charMatrices.NoColor.NoColor;

setBackground White;

toggleShowNames on;

toggleShowTaxonNames on;

toggleTight off;

toggleThinRows off;

toggleShowChanges on;

toggleSeparateLines off;

toggleShowStates on;

toggleAutoWCharNames on;

toggleShowDefaultCharNames off;

toggleConstrainCW on;

toggleBirdsEye off;

toggleAllowAutosize on;

toggleColorsPanel off;

toggleDiagonal on;

setDiagonalHeight 80;

toggleLinkedScrolling on;

toggleScrollLinkedTables off;

endTell;

showWindow;

getWindow;

tell It;

forceAutosize;

endTell;

getEmployee \#mesquite.charMatrices.ColorCells.ColorCells;

tell It;

setColor Red;

removeColor off; 
endTell;

getEmployee \#mesquite.categ.StateNamesStrip.StateNamesStrip;

tell It;

endTell;

showStrip off;

getEmployee \#mesquite.charMatrices.AnnotPanel.AnnotPanel;

tell It;

togglePanel off;

endTell;

getEmployee \#mesquite.charMatrices.CharReferenceStrip.CharReferenceStrip; tell It;

showStrip off;

endTell;

getEmployee \#mesquite.charMatrices.QuickKeySelector.QuickKeySelector;

tell It;

autotabOff;

endTell;

getEmployee \#mesquite.stratigraphictools.ColorScaleCells.ColorScaleCells;

tell It;

setColor Red;

removeColor off;

endTell;

getEmployee \#mesquite.categ.SmallStateNamesEditor.SmallStateNamesEditor; tell It;

endTell;

panelOpen true;

endTell;

endTell;

getEmployee \#mesquite.charMatrices.ManageCharacters.ManageCharacters;

tell It;

showCharacters \#8479452511181763361 \#mesquite.lists.CharacterList.CharacterList;

tell It;

setData 0;

getWindow;

tell It;

newAssistant \#mesquite.lists.DefaultCharOrder.DefaultCharOrder;

newAssistant \#mesquite.lists.CharListInclusion.CharListInclusion;

newAssistant \#mesquite.lists.CharListPartition.CharListPartition;

newAssistant \#mesquite.lists.CharacterStats.CharacterStats;

tell It;

toggleSelectedOnly off;

endTell;

newAssistant \#mesquite.parsimony.CharListParsModels.CharListParsModels;

newAssistant \#mesquite.lists.CharListWeights.CharListWeights;

setExplanationSize 30;

setAnnotationSize 20;

setFontIncAnnot 0;

setFontIncExp 0;

setSize 1820 1012;

setLocation 0 22;

setFont SanSerif;

setFontSize 10;

getToolPalette;

tell It;

setTool mesquite.lists.CharacterList.CharacterListWindow.ibeam; endTell;

endTell; 
showWindow;

getEmployee \#mesquite.lists.CharListAnnotPanel.CharListAnnotPanel; tell It;

togglePanel off; endTell;

endTell;

endTell;

end;

endTell; 
\#NEXUS

[written Tue Apr 21 15:12:16 CEST 2009 by Mesquite version 2.6+ (build 487) at G5-de-David-

Marjanovic.local/10.8.64.236]

BEGIN TAXA;

TITLE Taxa;

DIMENSIONS NTAX=6;

TAXLABELS

Notobatrachus Yizhoubatrachus Vieraella Mesophryne Ascaphus rest

END;

BEGIN CHARACTERS;

TITLE Character_Matrix;

DIMENSIONS NCHAR=2;

FORMAT DATATYPE = STANDARD GAP = - MISSING = ? SYMBOLS = " 0 1";

CHARSTATELABELS

1 'Pterygoid constricts subtemporal fenestra; generous interpretation of Ascaphus', 2 'Pterygoid constricts subtemporal fenestra; strict interpretation of Ascaphus' ;

MATRIX

Notobatrachus 11

Yizhoubatrachus 00

Vieraella 00

Mesophryne 11

Ascaphus 10

rest $\quad 00$

END;

BEGIN TREES;

Title Trees;

LINK Taxa = Taxa;

TRANSLATE

1 Notobatrachus,

2 Yizhoubatrachus,

3 Vieraella,

4 Mesophryne,

5 Ascaphus,

6 rest;

TREE tree $=((1,2),(3,(4,(5,6))))$;

END;

BEGIN ASSUMPTIONS;

TYPESET * UNTITLED = unord: 1 - 2;

END;

BEGIN MESQUITECHARMODELS;

ProbModelSet * UNTITLED = 'Mk1 (est.)': 1 - 2;

END;

Begin MESQUITE; 
MESQUITESCRIPTVERSION 2;

TITLE AUTO;

tell ProjectCoordinator;

getEmployee \#mesquite.minimal.ManageTaxa.ManageTaxa;

tell It;

endTell;

setID 0 3366549656872469409;

getEmployee \#mesquite.charMatrices.ManageCharacters.ManageCharacters;

tell It;

setID 0 9176248464225086950;

checksumv 02888337455 null;

endTell;

getWindow;

tell It;

suppress;

setResourcesState false false 100;

setPopoutState 400;

setExplanationSize 0;

setAnnotationSize 0;

setFontIncAnnot 0;

setFontIncExp 0;

setSize 761 521;

setLocation 8 22;

setFont SanSerif;

setFontSize 10;

getToolPalette;

tell It;

endTell;

desuppress;

endTell;

getEmployee \#mesquite.trees.ManageTrees.ManageTrees;

tell It;

showTreeBlocks \#mesquite.lists.TreeblockList.TreeblockList;

tell It;

getWindow;

tell It;

newAssistant \#mesquite.lists.TreeblocksListNumber.TreeblocksListNumber; newAssistant \#mesquite.lists.TreeblocksListTaxa.TreeblocksListTaxa;

setExplanationSize 30;

setAnnotationSize 20;

setFontIncAnnot 0;

setFontIncExp 0;

setSize 661 454;

setLocation 8 22;

setFont SanSerif;

setFontSize 10;

getToolPalette;

tell It;

endTell;

endTell;

showWindow;

endTell;

endTell;

getEmployee \#mesquite.trees.BasicTreeWindowCoord.BasicTreeWindowCoord;

tell It;

makeTreeWindow \#3366549656872469409

\#mesquite.trees.BasicTreeWindowMaker.BasicTreeWindowMaker; 
tell It;

suppressEPCResponse;

setTreeSource \#mesquite.trees.StoredTrees.StoredTrees;

tell It;

setTreeBlock 1;

endTell;

toggleUseWeights off;

setAssignedID 984.1239909960369.4011266357751987828;

getTreeWindow;

tell It;

setExplanationSize 30;

setAnnotationSize 20;

setFontIncAnnot 0;

setFontIncExp 0;

setSize 661 454;

setLocation 8 22;

setFont SanSerif;

setFontSize 10;

getToolPalette;

tell It;

endTell;

setActive;

getTreeDrawCoordinator

\#mesquite.trees.BasicTreeDrawCoordinator.BasicTreeDrawCoordinator;

tell It;

suppress;

setTreeDrawer \#mesquite.trees.SquareTree.SquareTree;

tell It;

setNodeLocs \#mesquite.trees.NodeLocsStandard.NodeLocsStandard;

tell It;

branchLengthsToggle off;

toggleScale on;

toggleBroadScale off;

toggleCenter on;

toggleEven on;

endTell;

setEdgeWidth 6;

orientUp;

toggleCorners off;

endTell;

setBackground White;

setBranchColor Black;

showNodeNumbers off;

showBranchColors on;

labelBranchLengths off;

centerBrLenLabels on;

showBrLensUnspecified on;

showBrLenLabelsOnTerminals on;

setBrLenLabelColor 00 255;

setNumBrLenDecimals 6;

desuppress;

getEmployee \#mesquite.trees.BasicDrawTaxonNames.BasicDrawTaxonNames; tell It;

setColor Black;

toggleColorPartition on;

toggleShadePartition off;

toggleNodeLabels on; 
toggleCenterNodeNames off;

toggleShowNames on;

namesAngle ?;

endTell;

endTell;

setTreeNumber 1 ;

setDrawingSizeMode 0;

toggleLegendFloat on;

scale 0 ;

toggleTextOnTree off;

showWindow;

newAssistant \#mesquite.ancstates.TraceCharacterHistory.TraceCharacterHistory; tell It;

suspend ;

setDisplayMode \#mesquite.ancstates.ShadeStatesOnTree.ShadeStatesOnTree; tell It;

toggleLabels off;

toggleGray off;

endTell;

setHistorySource \#mesquite.ancstates.RecAncestralStates.RecAncestralStates; tell It;

getCharacterSource \#mesquite.charMatrices.CharSrcCoordObed.CharSrcCoordObed; tell It;

setCharacterSource \#mesquite.charMatrices.StoredCharacters.StoredCharacters; tell It;

setDataSet \#9176248464225086950;

endTell;

endTell;

setMethod \#mesquite.parsimony.ParsAncestralStates.ParsAncestralStates;

tell It;

setModelSource \#mesquite.parsimony.CurrentParsModels.CurrentParsModels; toggleMPRsMode off; endTell;

endTell;

setCharacter 2;

setMapping 1;

toggleShowLegend on;

toggleGray off;

toggleWeights on;

setInitialOffsetX -162;

setInitialOffsetY -183;

setLegendWidth 142;

setLegendHeight 170;

resume ;

endTell;

endTell;

desuppressEPCResponse;

getEmployee \#mesquite.trees.ColorBranches.ColorBranches;

tell It;

setColor Red;

removeColor off;

endTell;

getEmployee \#mesquite.ornamental.BranchNotes.BranchNotes;

tell It;

setAlwaysOn off;

endTell;

getEmployee \#mesquite.ornamental.ColorTreeByPartition.ColorTreeByPartition; 
tell It;

endTell;

colorByPartition off;

getEmployee \#mesquite.ornamental.DrawTreeAssocDoubles.DrawTreeAssocDoubles; tell It;

setOn on;

toggleShow consensusFrequency;

setDigits 4;

writeAsPercentage off;

toggleCentred on;

toggleHorizontal on;

setFontSize 10;

setOffset $0 \quad 0$;

endTell;

getEmployee \#mesquite.trees.TreeInfoValues.TreeInfoValues;

tell It;

endTell;

panelOpen false;

endTell;

endTell;

getEmployee \#mesquite.charMatrices.BasicDataWindowCoord.BasicDataWindowCoord;

tell It;

showDataWindow \#9176248464225086950

\#mesquite.charMatrices.BasicDataWindowMaker.BasicDataWindowMaker;

tell It;

getWindow;

tell It;

setExplanationSize 30;

setAnnotationSize 20;

setFontIncAnnot 0;

setFontIncExp 0;

setSize 661 454;

setLocation 8 22;

setFont SanSerif;

setFontSize 10;

getToolPalette;

tell It;

setTool mesquite.charMatrices.BasicDataWindowMaker.BasicDataWindow.ibeam; endTell;

setTool mesquite.charMatrices.BasicDataWindowMaker.BasicDataWindow.ibeam; colorCells \#mesquite.charMatrices.NoColor.NoColor;

colorRowNames \#mesquite.charMatrices.TaxonGroupColor.TaxonGroupColor;

colorColumnNames \#mesquite.charMatrices.CharGroupColor.CharGroupColor;

colorText \#mesquite.charMatrices.NoColor.NoColor;

setBackground White;

toggleShowNames on;

toggleShowTaxonNames on;

toggleTight off;

toggleThinRows off;

toggleShowChanges on;

toggleSeparateLines off;

toggleShowStates on;

toggleAutoWCharNames on;

toggleShowDefaultCharNames off;

toggleConstrainCW on;

toggleBirdsEye off;

toggleAllowAutosize on; 
toggleColorsPanel off;

toggleDiagonal on;

setDiagonalHeight 80;

toggleLinkedScrolling on;

endTell;

toggleScrollLinkedTables off;

showWindow;

getWindow;

tell It;

forceAutosize;

endTell;

getEmployee \#mesquite.charMatrices.ColorCells.ColorCells;

tell It;

setColor Red;

removeColor off;

endTell;

getEmployee \#mesquite.categ.StateNamesStrip.StateNamesStrip;

tell It;

showStrip off;

endTell;

getEmployee \#mesquite.charMatrices.AnnotPanel.AnnotPanel;

tell It;

togglePanel off;

endTell;

getEmployee \#mesquite.charMatrices.CharReferenceStrip.CharReferenceStrip; tell It;

showStrip off;

endTell;

getEmployee \#mesquite.charMatrices.QuickKeySelector.QuickKeySelector;

tell It;

autotabOff;

endTell;

getEmployee \#mesquite.stratigraphictools.ColorScaleCells.ColorScaleCells;

tell It;

setColor Red;

removeColor off;

endTell;

getEmployee \#mesquite.categ.SmallStateNamesEditor.SmallStateNamesEditor; tell It;

endTell;

panelOpen true;

endTell;

endTell;

end;

endTell; 
\#NEXUS

[written Tue Apr 21 15:34:46 CEST 2009 by Mesquite version 2.6+ (build 487) at G5-de-David-

Marjanovic.local/10.8.64.236]

BEGIN TAXA;

TITLE Urodeles;

DIMENSIONS NTAX=9;

TAXLABELS

Karaurus Hynobiidae Cryptobranchidae Ambystomatidae Plethodontidae Salamandridae Proteidae Amphiumidae Sirenidae

END;

\section{BEGIN CHARACTERS;}

TITLE Character_Matrix;

DIMENSIONS NCHAR=3;

FORMAT DATATYPE = STANDARD GAP = - MISSING = ? SYMBOLS = " 012 3";

CHARSTATELABELS

1 Dorsal_processes_of_premax / 'broad, low, indistinct dorsal process' 'alary process (broad, vaguely triangular process)' 'moderately high, vaguely rectangular process, or acutely triangular linked directly to base' 'narrow, long dorsal process, along the midline or parasagittal', 2 Number_of_premax_teeth / '>=10' '5-9' '<5', 3 Number_of_max_teeth / '>=30' '20-29' '<20' ;

\section{MATRIX}

Karaurus $\quad 100$

Hynobiidae $\quad\{13\} 1\{12\}$

Cryptobranchidae 200

Ambystomatidae 200

Plethodontidae 310

Salamandridae $\quad 3\left(\begin{array}{ll}0 & 1\end{array}\right)\left(\begin{array}{ll}0 & 1\end{array}\right)$

Proteidae 30?

Amphiumidae 312

Sirenidae $\quad 312$

END;

BEGIN TREES;

Title Trees;

LINK Taxa = Urodeles;

TRANSLATE

1 Karaurus,

2 Hynobiidae,

3 Cryptobranchidae,

4 Ambystomatidae,

5 Plethodontidae,

6 Salamandridae,

7 Proteidae,

8 Amphiumidae,

9 Sirenidae;

TREE Alary_process_optimization $=(1,((2,3),(9,((5,8),(7,(4,6))))))$;

END; 
TYPESET * UNTITLED = unord: 1 - 2, ord: 3;

END;

BEGIN MESQUITECHARMODELS;

ProbModelSet * UNTITLED = 'Mk1 (est.)': 1 - 3;

END;

Begin MESQUITE;

MESQUITESCRIPTVERSION 2;

TITLE AUTO;

tell ProjectCoordinator;

getEmployee \#mesquite.minimal.ManageTaxa.ManageTaxa;

tell It;

setID 0 1289524600427350746;

endTell;

getEmployee \#mesquite.charMatrices.ManageCharacters.ManageCharacters;

tell It;

setID 0 437647273697402900;

checksumv 022499153713 null;

endTell;

getWindow;

tell It;

suppress;

setResourcesState false false 100;

setPopoutState 400;

setExplanationSize 0;

setAnnotationSize 0;

setFontIncAnnot 0;

setFontIncExp 0;

setSize 1168 464;

setLocation 207 87;

setFont SanSerif;

setFontSize 10;

getToolPalette;

tell It;

endTell;

endTell;

desuppress;

getEmployee \#mesquite.trees.BasicTreeWindowCoord.BasicTreeWindowCoord; tell It;

makeTreeWindow \#1289524600427350746

\#mesquite.trees.BasicTreeWindowMaker.BasicTreeWindowMaker;

tell It;

suppressEPCResponse;

setTreeSource \#mesquite.trees.StoredTrees.StoredTrees;

tell It;

setTreeBlock 1;

toggleUseWeights off;

endTell;

setAssignedID 1841.1239624217592.7879340418447371515;

getTreeWindow;

tell It;

setExplanationSize 30;

setAnnotationSize 20;

setFontIncAnnot 0;

setFontIncExp 0; 
setSize 1068 397;

setLocation 207 87;

setFont SanSerif;

setFontSize 10;

getToolPalette;

tell It;

setTool mesquite.trees.BasicTreeWindowMaker.BasicTreeWindow.arrow; endTell;

setActive;

getTreeDrawCoordinator

\#mesquite.trees.BasicTreeDrawCoordinator.BasicTreeDrawCoordinator;

tell It;

suppress;

setTreeDrawer \#mesquite.trees.SquareTree.SquareTree;

tell It;

setNodeLocs \#mesquite.trees.NodeLocsStandard.NodeLocsStandard;

tell It;

branchLengthsToggle off;

toggleScale on;

toggleBroadScale off;

toggleCenter on;

toggleEven on;

endTell;

setEdgeWidth 6;

orientUp;

toggleCorners off;

endTell;

setBackground White;

setBranchColor Black;

showNodeNumbers off;

showBranchColors on;

labelBranchLengths off;

centerBrLenLabels on;

showBrLensUnspecified on;

showBrLenLabelsOnTerminals on;

setBrLenLabelColor 00 255;

setNumBrLenDecimals 6;

desuppress;

getEmployee \#mesquite.trees.BasicDrawTaxonNames.BasicDrawTaxonNames; tell It;

setColor Black;

toggleColorPartition on;

toggleShadePartition off;

toggleNodeLabels on;

toggleCenterNodeNames off;

toggleShowNames on;

namesAngle ?;

endTell;

endTell;

setTreeNumber 1;

setDrawingSizeMode 0;

toggleLegendFloat on;

scale 0 ;

toggleTextOnTree off;

showWindow;

newAssistant \#mesquite.ancstates.TraceCharacterHistory.TraceCharacterHistory; tell It; 
suspend ;

setDisplayMode \#mesquite.ancstates.ShadeStatesOnTree.ShadeStatesOnTree;

tell It;

toggleLabels off;

endTell;

toggleGray off;

setHistorySource \#mesquite.ancstates.RecAncestralStates.RecAncestralStates;

tell It;

getCharacterSource \#mesquite.charMatrices.CharSrcCoordObed.CharSrcCoordObed; tell It;

setCharacterSource \#mesquite.charMatrices.StoredCharacters.StoredCharacters; tell It;

setDataSet \#437647273697402900; endTell;

endTell;

setMethod \#mesquite.parsimony.ParsAncestralStates.ParsAncestralStates; tell It;

setModelSource \#mesquite.parsimony.CurrentParsModels.CurrentParsModels; toggleMPRsMode off;

endTell; endTell;

setCharacter 1;

setMapping 1;

toggleShowLegend on;

toggleGray off;

toggleWeights on;

setInitialOffsetX -142;

setInitialOffsetY -199;

setLegendWidth 142;

setLegendHeight 186;

resume ;

endTell;

endTell;

desuppressEPCResponse;

getEmployee \#mesquite.trees.ColorBranches.ColorBranches;

tell It;

setColor Red;

removeColor off;

endTell;

getEmployee \#mesquite.ornamental.BranchNotes.BranchNotes;

tell It;

endTell;

setAlwaysOn off;

getEmployee \#mesquite.ornamental.ColorTreeByPartition.ColorTreeByPartition; tell It;

colorByPartition off;

endTell;

getEmployee \#mesquite.ornamental.DrawTreeAssocDoubles.DrawTreeAssocDoubles;

tell It;

setOn on;

toggleShow consensusFrequency;

setDigits 4;

writeAsPercentage off;

toggleCentred on;

toggleHorizontal on;

setFontSize 10;

setOffset 0 ; 
endTell;

getEmployee \#mesquite.trees.TreeInfoValues.TreeInfoValues;

tell It;

endTell;

panelOpen false;

endTell;

endTell;

getEmployee \#mesquite.charMatrices.BasicDataWindowCoord.BasicDataWindowCoord;

tell It;

showDataWindow \#437647273697402900

\#mesquite.charMatrices.BasicDataWindowMaker.BasicDataWindowMaker;

tell It;

getWindow;

tell It;

setExplanationSize 30;

setAnnotationSize 20;

setFontIncAnnot 0;

setFontIncExp 0;

setSize 1068 397;

setLocation 207 87;

setFont SanSerif;

setFontSize 10;

getToolPalette;

tell It;

setTool mesquite.charMatrices.BasicDataWindowMaker.BasicDataWindow.ibeam; endTell;

setTool mesquite.charMatrices.BasicDataWindowMaker.BasicDataWindow.ibeam;

colorCells \#mesquite.charMatrices.NoColor.NoColor;

colorRowNames \#mesquite.charMatrices.TaxonGroupColor.TaxonGroupColor;

colorColumnNames \#mesquite.charMatrices.CharGroupColor.CharGroupColor;

colorText \#mesquite.charMatrices.NoColor.NoColor;

setBackground White;

toggleShowNames on;

toggleShowTaxonNames on;

toggleTight off;

toggleThinRows off;

toggleShowChanges on;

toggleSeparateLines off;

toggleShowStates on;

toggleAutoWCharNames on;

toggleShowDefaultCharNames off;

toggleConstrainCW on;

toggleBirdsEye off;

toggleAllowAutosize on;

toggleColorsPanel off;

toggleDiagonal on;

setDiagonalHeight 80;

toggleLinkedScrolling on;

toggleScrollLinkedTables off;

endTell;

showWindow;

getWindow;

tell It;

forceAutosize;

endTell;

getEmployee \#mesquite.charMatrices.ColorCells.ColorCells;

tell It; 
setColor Red;

removeColor off;

endTell;

getEmployee \#mesquite.categ.StateNamesEditor.StateNamesEditor;

tell It;

makeWindow;

tell It;

setExplanationSize 30;

setAnnotationSize 20;

setFontIncAnnot 0;

setFontIncExp 0;

setSize 1068 397;

setLocation 207 87;

setFont SanSerif;

setFontSize 10;

getToolPalette;

tell It;

setTool mesquite.categ.StateNamesEditor.StateNamesWindow.ibeam; endTell;

rowsAreCharacters on;

toggleConstrainChar on;

toggleConstrainCharNum 3;

togglePanel off;

toggleSummaryPanel off;

endTell;

showWindow;

endTell;

getEmployee \#mesquite.categ.StateNamesStrip.StateNamesStrip;

tell It;

showStrip off;

endTell;

getEmployee \#mesquite.charMatrices.AnnotPanel.AnnotPanel;

tell It;

togglePanel off;

endTell;

getEmployee \#mesquite.charMatrices.CharReferenceStrip.CharReferenceStrip; tell It;

showStrip off;

endTell;

getEmployee \#mesquite.charMatrices.QuickKeySelector.QuickKeySelector;

tell It;

autotabOff;

endTell;

getEmployee \#mesquite.stratigraphictools.ColorScaleCells.ColorScaleCells;

tell It;

setColor Red;

removeColor off;

endTell;

getEmployee \#mesquite.categ.SmallStateNamesEditor.SmallStateNamesEditor; tell It;

panelOpen true;

endTell;

endTell;

endTell;

getEmployee \#mesquite.charMatrices.ManageCharacters.ManageCharacters;

tell It;

showCharacters \#437647273697402900 \#mesquite.lists.CharacterList.CharacterList; 
tell It;

setData 0 ;

getWindow;

tell It;

newAssistant \#mesquite.lists.DefaultCharOrder.DefaultCharOrder;

newAssistant \#mesquite.lists.CharListInclusion.CharListInclusion;

newAssistant \#mesquite.lists.CharListPartition.CharListPartition;

newAssistant \#mesquite.stochchar.CharListProbModels.CharListProbModels;

newAssistant \#mesquite.parsimony.CharListParsModels.CharListParsModels;

setExplanationSize 30;

setAnnotationSize 20;

setFontIncAnnot 0;

setFontIncExp 0;

setSize 1068 397;

setLocation 207 87;

setFont SanSerif;

setFontSize 10;

getToolPalette;

tell It;

endTell;

endTell;

showWindow;

getEmployee \#mesquite.lists.CharListAnnotPanel.CharListAnnotPanel;

tell It;

togglePanel off;

endTell;

endTell;

endTell;

end;

endTell; 